\title{
WestVirginiaUniversity
}

THE RESEARCH REPOSITORY @ WVU

Graduate Theses, Dissertations, and Problem Reports

2012

\section{Pharmacological Characterization of an Optimized Sigma Receptor Ligand}

\author{
Michael Seminerio \\ West Virginia University
}

Follow this and additional works at: https://researchrepository.wvu.edu/etd

\section{Recommended Citation}

Seminerio, Michael, "Pharmacological Characterization of an Optimized Sigma Receptor Ligand" (2012). Graduate Theses, Dissertations, and Problem Reports. 3561.

https://researchrepository.wvu.edu/etd/3561

This Dissertation is protected by copyright and/or related rights. It has been brought to you by the The Research Repository @ WVU with permission from the rights-holder(s). You are free to use this Dissertation in any way that is permitted by the copyright and related rights legislation that applies to your use. For other uses you must obtain permission from the rights-holder(s) directly, unless additional rights are indicated by a Creative Commons license in the record and/ or on the work itself. This Dissertation has been accepted for inclusion in WVU Graduate Theses, Dissertations, and Problem Reports collection by an authorized administrator of The Research Repository @ WVU.

For more information, please contact researchrepository@mail.wvu.edu. 


\section{Pharmacological Characterization of an Optimized Sigma Receptor Ligand}

\section{Michael Seminerio}

A dissertation submitted to the School of Pharmacy at

West Virginia University in partial fulfillment of the requirements for the degree of

Doctor of Philosophy in Pharmaceutical and Pharmacological Sciences

Rae R. Matsumoto, Ph.D., Chair Robert Griffith, Ph.D. Jason D. Huber, Ph.D. James O'Donnell, Ph.D. William Petros, Pharm.D.

Department of Basic Pharmaceutical Sciences

Morgantown, West Virginia 2012

Keywords: Methamphetamine, Sigma receptors, Hyperthermia, Neurotoxicity, Dopamine, Serotonin, Cognition 


\section{$\underline{\text { Abstract }}$ \\ Pharmacological Characterization of an Optimized Sigma Receptor Ligand

\author{
Michael Seminerio
}

Methamphetamine is an addictive psychostimulant drug with an increasing prevalence of abuse worldwide. Recent evidence has linked methamphetamine exposure to a wide array of neurological complications some of which lead to neurodegenerative changes in the brain and hyperthermia. Currently, there are no FDA approved pharmacologic agents to treat the effects of methamphetamine. Recent evidence has suggested methamphetamine may, in part, produce some of its effects through sigma receptors making them a potential target for pharmacological intervention. While our lab has shown a number of selective sigma receptor ligands can provide neuroprotection against the neurotoxic and behavioral effects of methamphetamine, limitations such as metabolic instability have prevented the advancement of any lead compound to ladder drug development studies. To address this issue and pursue a lead therapeutic compound to aid against methamphetamine-induced complications, CM156, a previously studied selective sigma receptor ligand, was optimized for metabolic stability. Following the synthesis and evaluation of thirty CM156 analogs, a lead compound was identified. Radioligand binding studies demonstrated the lead analog, AZ66, displayed high nanomolar affinity for both sigma-1 and sigma-2 receptors ( $2.4 \pm 0.63$ and $0.51 \pm 0.15$, respectively). In addition, AZ66 had preferential affinity for sigma receptors compared to sixty-four other sites and a significantly longer half life than its predecessor, CM156, in vitro and in vivo. To further characterize AZ66 as a potential lead compound, we evaluated AZ66 against the neurotoxic, behavioral, and cognitive effects produced by methamphetamine. Pretreatment of male, Swiss Webster mice with intraperitoneal $(10-20 \mathrm{mg} / \mathrm{kg})$ or oral $(20-30 \mathrm{mg} / \mathrm{kg})$ dosing of AZ66significantly attenuated the acute locomotor stimulatory effects of methamphetamine in addition to reducing the expression and development of behavioral sensitization induced by repeated methamphetamine administration. Furthermore, AZ66 significantly attenuated methamphetamine-induced striatal dopamine depletions, striatal dopamine transporter reductions, and hyperthermia. Additionally, neurotoxic dosing with methamphetamine caused significant memory impairment in the object recognition test which was attenuated when animals were pretreated with AZ66; similar trends were observed in the step-through passive avoidance test. The studies presented herein demonstrate that targeting sigma receptors can provide neuroprotective effects against methamphetamine and AZ66 may represent a promising lead compound for developing future therapeutics. 
Dedicated to

The loving memory of my late Grandmother

\section{Beatrice Beer}

The greatest parents a son could ask for

Fran and John Seminerio

The most influential siblings

Jennifer and Frankie

And the greatest dog ever

Bella Mia Seminerio 


\section{ACKNOWLEDGMENTS}

My gratitude extends to my mentor and advisor Dr. Rae Matsumoto. She provided me with the opportunity to succeed and I am grateful for her support during these past several years.

I would also like to acknowledge my committee members, Dr. James O'Donnell, Dr. Jason Huber, Dr. William Petros, and Dr. Robert Griffith, for their guidance and insight.

Special thanks to Dr. Christopher McCurdy at the University of Mississippi and Dr. Andrew Coop at University of Maryland for synthesizing and providing the compounds for my studies.

I would also like to acknowledge the support I received from current and previous members of the Matsumoto lab. Specifically, I would like to thank Bahar Noorbakhsh for all of her support. 


\section{TABLE OF CONTENTS}

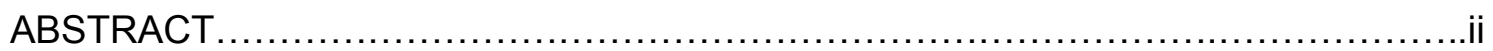

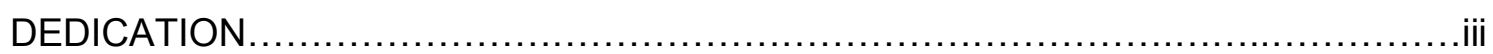

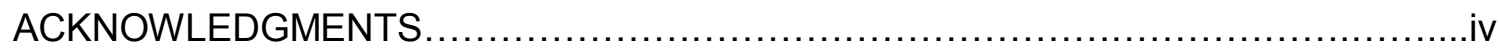

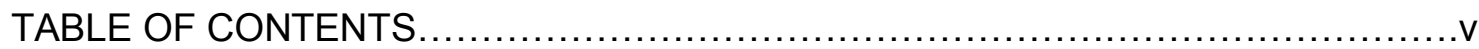

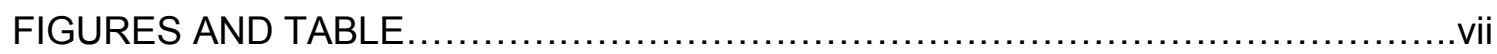

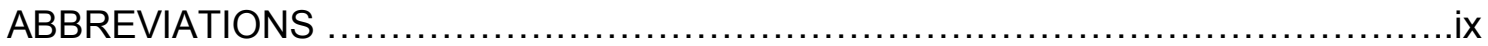

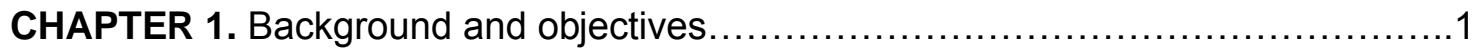

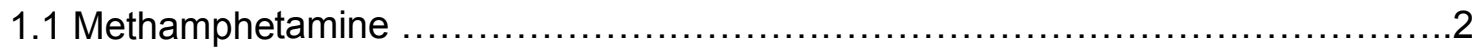

1.2 Methamphetamine mechanism of action..........................................

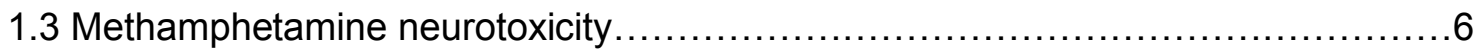

1.4 Interactions between methamphetamine and sigma receptors......................11

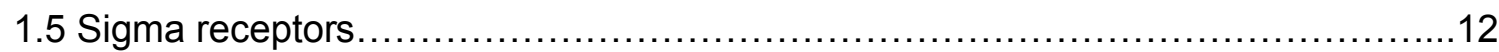

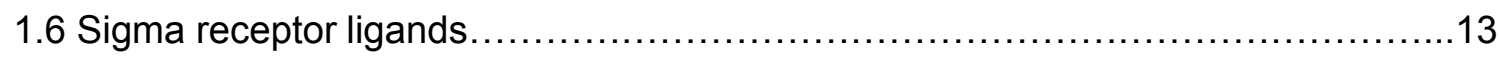

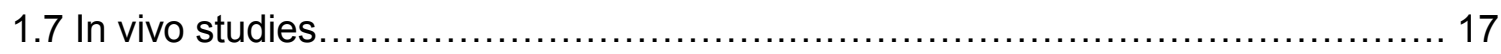

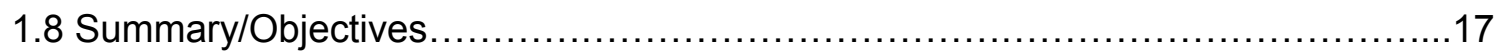

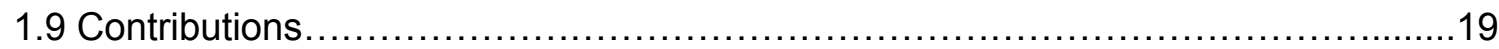

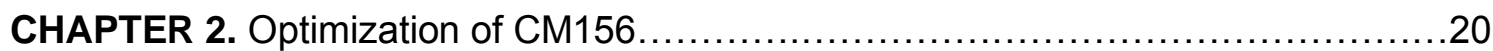

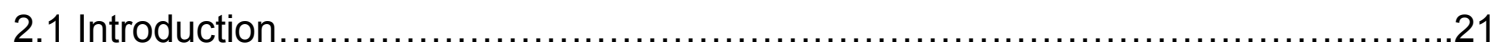

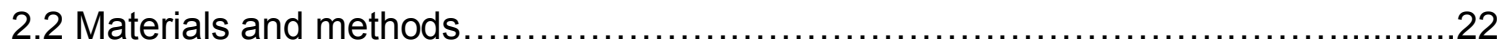

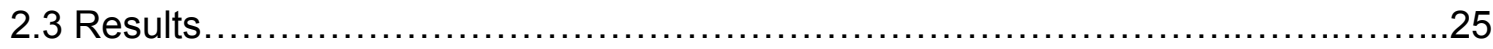

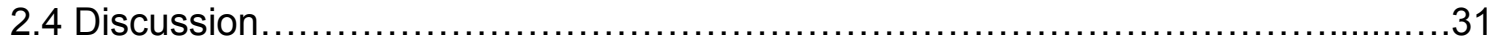

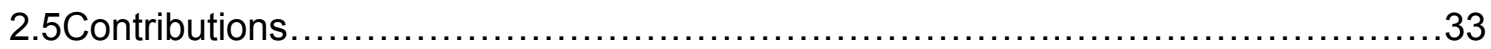


CHAPTER 3. Evaluation of AZ66 against the behavioral effects of

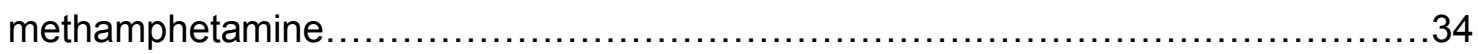

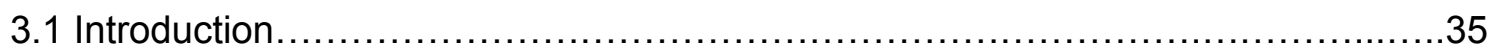

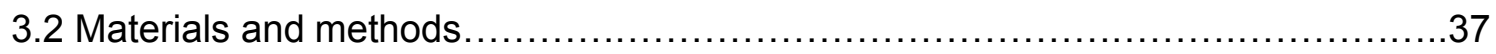

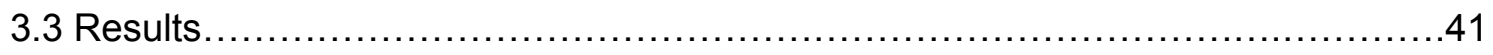

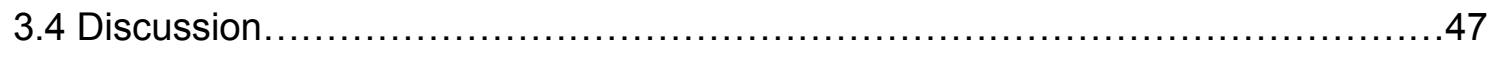

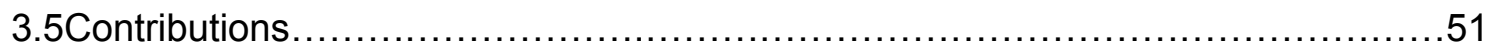

CHAPTER 4.Evaluation of AZ66 against methamphetamine-induced

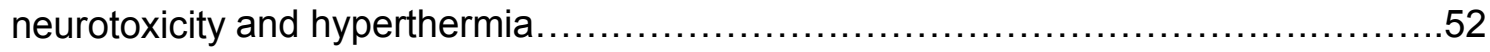

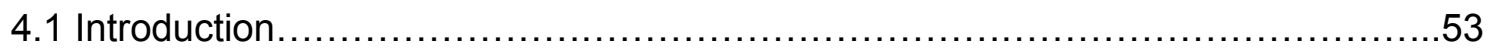

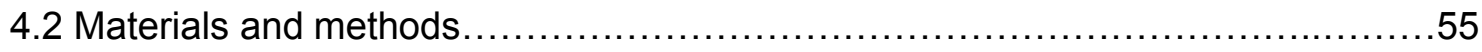

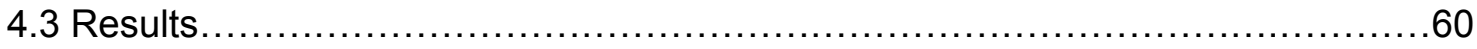

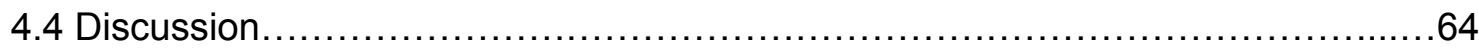

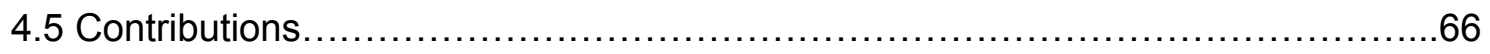

CHAPTER 5. Evaluation of AZ66 against methamphetamine-induced

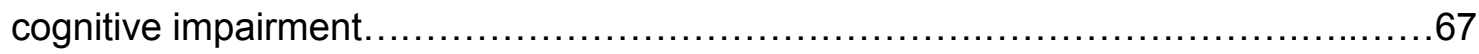

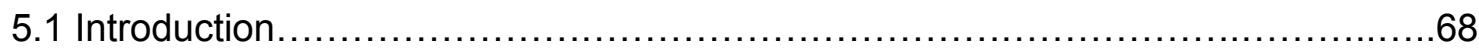

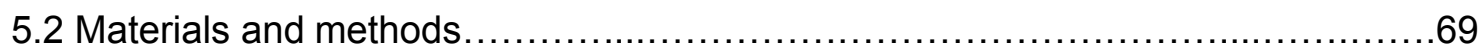

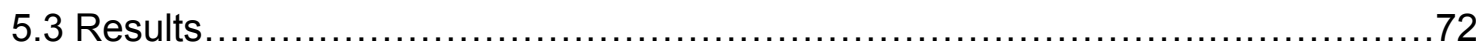

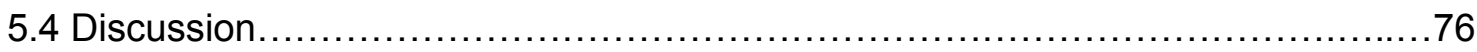

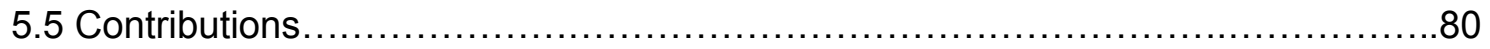

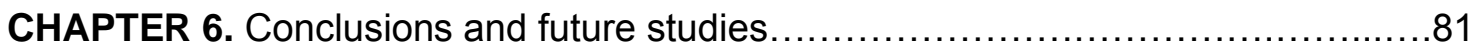

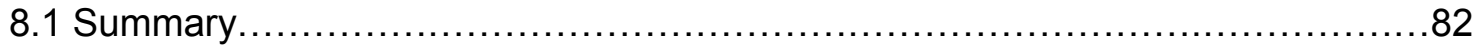




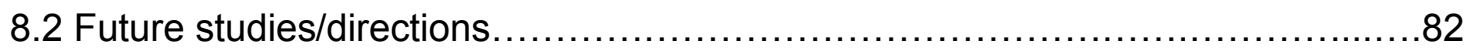

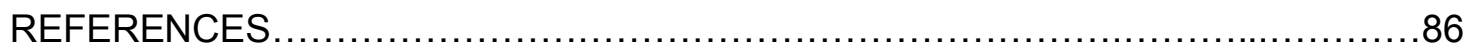

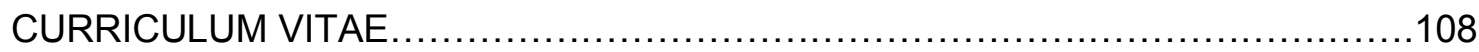




\section{LIST OF FIGURES}

Figure 1.1. Pharmacologic effects of methamphetamine on the dopaminergic

system $\ldots \ldots \ldots \ldots \ldots \ldots \ldots \ldots \ldots \ldots \ldots \ldots \ldots \ldots \ldots \ldots \ldots \ldots \ldots \ldots \ldots \ldots \ldots \ldots \ldots \ldots \ldots \ldots \ldots .5$

Figure 1.2. Neurotoxic effects of methamphetamine....................................

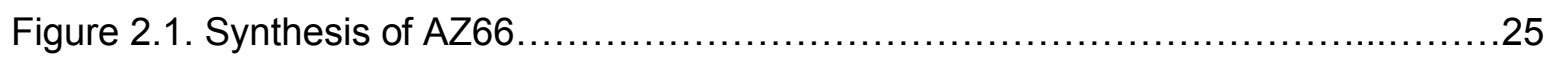

Figure 3.1. The effects of methamphetamine and AZ66 on locomotor activity............43

Figure 3.2. Dose dependent effects of methamphetamine on behavioral sensitization......44

Figure 3.3. Effects of AZ66 on the development of behavioral sensitization to

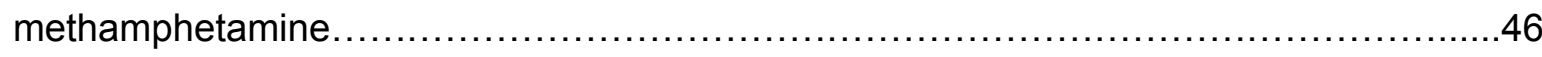

Figure 3.4. Effects of AZ66 on the expression of behavioral sensitization to

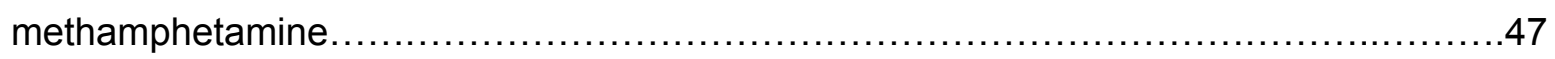

Figure 4.1. Repeated dosing paradigm of methamphetamine $\ldots \ldots \ldots \ldots \ldots \ldots \ldots \ldots \ldots \ldots$

Figure 4.2. Dose response effects of methamphetamine on dopamine (DA) levels in the

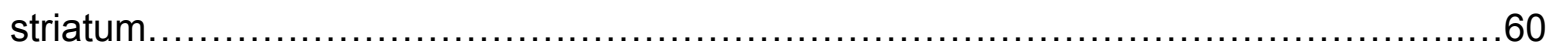

Figure 4.3. Effects of methamphetamine and AZ66 on dopamine levels in

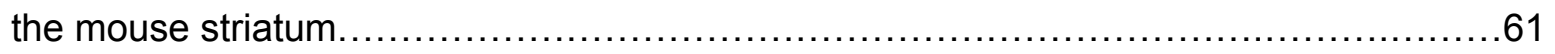

Figure 4.4. Effects of methamphetamine and AZ66 on 5-HT levels in the

mouse striatum.

Figure 4.5. Effects of methamphetamine and AZ66 on dopamine

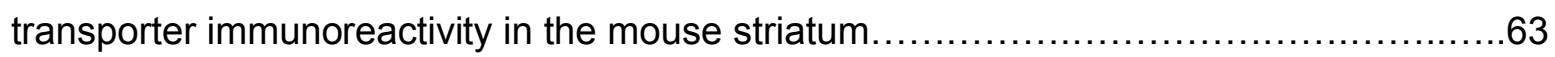

Figure 4.6. Effects of AZ66 on methamphetamine-induced hyperthermia................64 
Figure 5.1. Effects of AZ66 on methamphetamine-induced memory

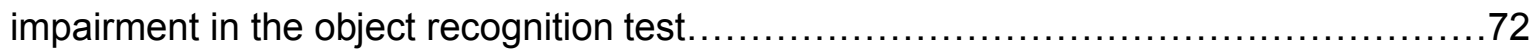

Figure 5.2. Effects of AZ66 on methamphetamine-induced cognitive

impairment in the step-through passive avoidance test..............................

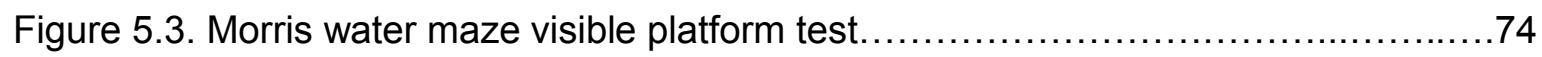

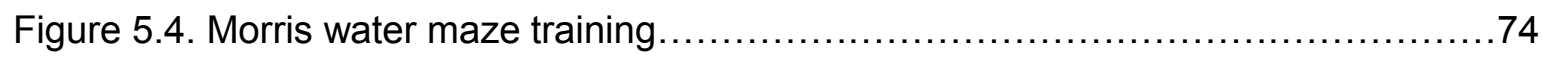

Figure 5.5. Effects of AZ66 and methamphetamine in the Morris water maze probe test...75 


\section{LIST OF TABLES}

Table 1.1.Sigma binding affinity of methamphetamine

Table 1.2.Binding affinity of CM156 and AZ66 for sigma receptors and

non-sigma receptor sites.

Table 2.1. Chemical structure and binding affinities of CM156 and its analogs.

Table 2.2. In vitro half-life (in $\mathrm{min}$ ) of redesigned analogs compared with CM156....

Table 2.3. In vivo half-life (in $\mathrm{min}$ ) of CM156 (5 mg/kg, i.v.) and

AZ66 (2.5 mg/kg, i.v.)

Table 2.4. Pharmacokinetic profile of AZ66 (20 mg/kg, p.o.).

Table 3.1. Treatment schedule for sensitization experiments.

Table 3.2. Binding affinities of AZ66 for sigma receptors,

monoamine transporters, and non-sigma sites. 
CHAPTER 1 BACKGROUND AND OBJECTIVES 


\subsection{Methamphetamine}

Methamphetamine, also referred to as methylamphetamine, $\mathrm{N}$-methylamphetamine, desoxyephedrine, phenylisopropylmethylamine, and street names speed, meth, ice, crank, crystal and chalk, is a methylated analogue of amphetamine thought to act primarily on the central nervous system (Schep et al., 2010). Originally used therapeutically to treat obesity and attention deficit disorder, methamphetamine is now a schedule II drug rarely used in the clinic. Methamphetamine abuse has become a worldwide public health issue and is the second most commonly used illegal drug in the world(Cruickshank and Dyer, 2009; Krasnova and Cadet, 2009). Because of its ease of synthesis from over-the-counter drugs, long duration of action, and relatively low cost, methamphetamine is widely available and easily accessible. This is evident by the estimated 290 tons of methamphetamine synthesized in 2005 worldwide, an amount equivalent to 2.9 billion 100-mg doses(Cruickshank and Dyer, 2009). Use and public awareness appears to be increasing worldwide as amphetamine-type stimulant (ATS) seizures have reached a record high globally, much of this attributed to a rise in methamphetamine seizures, particularly in North America, Asia, and Oceania(Crime, 2011). Over 12 million Americans have used methamphetamine at least once in their life and there are roughly 16 million users worldwide, a number which exceeds that of combined heroin and cocaine users(United Nations, 2007). In 2005, an estimated 20-40 billion dollars was spent on methamphetamine-related complications stemming from addiction, premature death, and psychological treatment (Dobkin and Nicosia, 2009). However, due to a large gap in our understanding of the mechanisms behind methamphetamine, the field is currently lacking a proven pharmacologic agent to treat methamphetamine-induced complications. With a steady and annual increase of treatment admissions for methamphetamine (Roehr, 2005), the development of an effective therapeutic agent would result in significant health and economic benefits. 


\subsubsection{Pharmacokinetics of Methamphetamine. The pharmacokinetics of}

methamphetamine are important to consider as varying routes can display increased or decreased effects. Methamphetamine is used through four primary routes - intravenous, inhalation (smoking), oral, and intra-nasal. Route of use dictates bioavailability with studies demonstrating oral administration resulting in the lowest bioavailability (67\%) and intravenous administration resulting in the greatest bioavailability (100\%) (Schep et al., 2010). Intranasal (79\%) and smoking (67-90\%), depending on technique utilized, fall in between(Cruickshank and Dyer, 2009). Similarly, as would be expected, route of administration determines time to peak effect as well. Intravenous and intranasal dosing results in peak effects within the first 15 minutes while smoking demonstrates a slightly longer time-to-peak of 18 minutes and lastly, oral uptake results in a significant delay of approximately 3 hours(Cruickshank and Dyer, 2009). Alternative routes of administration, for which little to no pharmacokinetic data exist, have emerged in recent years and require further investigation to elucidate drug uptake. These include body stuffing in which poorly packaged drugs are ingested, usually in an attempt to avoid prosecution by the police; 'parachuting' in which the drug is placed into a plastic bag with the seal removed, rolled tightly, and swallowed, theoretically releasing the drug over a prolonged period; and 'shelving', also known as intra vaginal stuffing (Hendrickson et al., 2006; Kashani and Ruha, 2004; West et al., 2010). Notably, method of administration likely influences the development of methamphetamine-induced neurotoxicity based on preclinical studies in rhesus macaques that demonstrated a similar peak temperature but delayed onset when the drug is administered orally compared to peritoneal injections (Crean et al., 2007; Crean et al., 2006).

Methamphetamine metabolism occurs primarily in the liver through three main processes. These include $N$-demethylation via cytochrome P450 2D6, aromatic hydroxylation through cytochrome P450 2D6, and ß-hydroxylation, producing amphetamine, 4hydroxymethamphetamine, and norephedrine, respectively (Schep et al., 2010). It seems 
unlikely that metabolites are responsible for clinical effects of the ingested drug due to the fact that peak metabolite levels occur after approximately 12 hours, producing minimal effects(Cruickshank and Dyer, 2009). Within one day of dosing, nearly $70 \%$ of methamphetamine is excreted in the urine. Analysis reveals $30-50 \%$ is in the form of methamphetamine, up to $15 \%$ as 4 -hydroxymethamphetamine, and $10 \%$ as amphetamine(Cruickshank and Dyer, 2009).

Methamphetamine is metabolized by CYP2D6 at the first step of hydroxylation and demethylation (Dougan et al., 1987). Variants of CYP2D6 can alter responses and effects to methamphetamine in humans. Ramamoorty et al (2001) demonstrated intrinsic clearance of methamphetamine in 4-hydroxylation in CYPD2D6 mutant mice were 30-67 fold slower compared to wild type. Other studies have found distributions of CYD2D6 allele and phenotype frequency were significantly associated with susceptibility to methamphetamine dependence (Otani et al., 2008). Reduced CYD2D6 activity is believed to be a negative risk factor for methamphetamine dependence as well (Otani et al., 2008).

\subsubsection{Clinical Implications of Methamphetamine. Methamphetamine use is responsible} for an estimated 94,000 emergency department admissions yearly with presenting symptoms largely dependent on the dose taken(NIDA, 2011).Symptoms commonly observed by medical personnel, particularly in high-dose patients, include hypertension, tachycardia, dyspnea, hyperthermia, and chest pain with other presenting symptoms involving increased agitation, altered mental status, pupil dilation, shivering, and possible seizure activity(Albertson et al., 1999).While clinical experiments and reporting of emergency department presentations have resulted in an improved understanding of the behavioral and medical implications of methamphetamine-induced effects, relatively little is understood concerning long-term health implications of acute and/or chronic methamphetamine-induced complications. These systemic events, particularly those associated with an increased metabolic rate and cardiovascular 
changes leading to tachycardia and hypertension, can contribute to neurotoxicity and hyperthermia.

\subsubsection{Methamphetamine and Other Non-toxic Drugs of Abuse}

The neurotoxic effects of methamphetamine stem from its ability to enter the cell (highly lipophilic structure). Other psychostimulants, such as cocaine, may produce the same euphoric feeling (from an acute increase in dopamine), however lack the neurotoxic component because of its inability to cross the cell membrane and induce neurotoxic consequences. In addition, methamphetamine is believed to interact directly with sigma receptors as it binds to both subtypes at physiologically relevant concentrations (Matsumoto, 2009). Ethanol and nicotine, two other non-toxic drug of abuse, do not interact with sigma receptors and its effects are likely downstream (Robson et al., 2012). Other drugs of abuse act at different systems than that of methamphetamine. PCP, a strong hallucinogen believed to produce severe cognitive impairments, acts primarily through NMDA receptors (Morris et al., 2005). Opioids also act via a completely different series of cascades and receptors compared to methamphetamine (Kasai and Ikeda, 2011).

\subsection{Methamphetamine mechanism of action}

The immediate effects of methamphetamine are similar to other amphetamines in which the user experiences an increase in energy with a lessened sense of anxiety, increased productivity and overall strong feeling of euphoria (Cadet and Krasnova, 2009; Davidson et al., 2001). Chronic methamphetamine use results in increased anxiety, depression, aggressiveness, psychomotor dysfunction, and as recent reports indicate, Parkinson's like symptoms(Cadet and Krasnova, 2009; Krasnova and Cadet, 2009).

Methamphetamine is an indirect agonist that can cause the release of newly synthesized monoamine neurotransmitters, particularly dopamine and serotonin, and inhibit their reuptake 
from the synapse by the dopamine transporter (DAT) and serotonin transporter (SERT) (Sulzer et al., 2005). While the exact mechanism is unknown, it appears as though methamphetamine causes a redistribution of dopamine and serotonin from the synaptic vesicles, through the vesicular monoamine transporter (VMAT2), into the neuronal cytoplasm (Kish, 2008; Sulzer et al., 2005). The acute euphoric effects of methamphetamine are a result of this immediate increase in dopamine and serotonin. However, excess dopamine and serotonin in the cytoplasm and synaptic cleft are believed to undergo auto-oxidation resulting in the creation of reactive particle formation (Cadet et al., 2007; Tata et al., 2007). The free radicals formed are thought to be a primary cause of nerve ending damage associated with methamphetamine abuse (Tata et al., 2007). Figure 1.1 displays the molecular effects of methamphetamine on dopminergic transmission in regions of the brain thought to be affected following methamphetamine exposure (Kish et al. 2009).

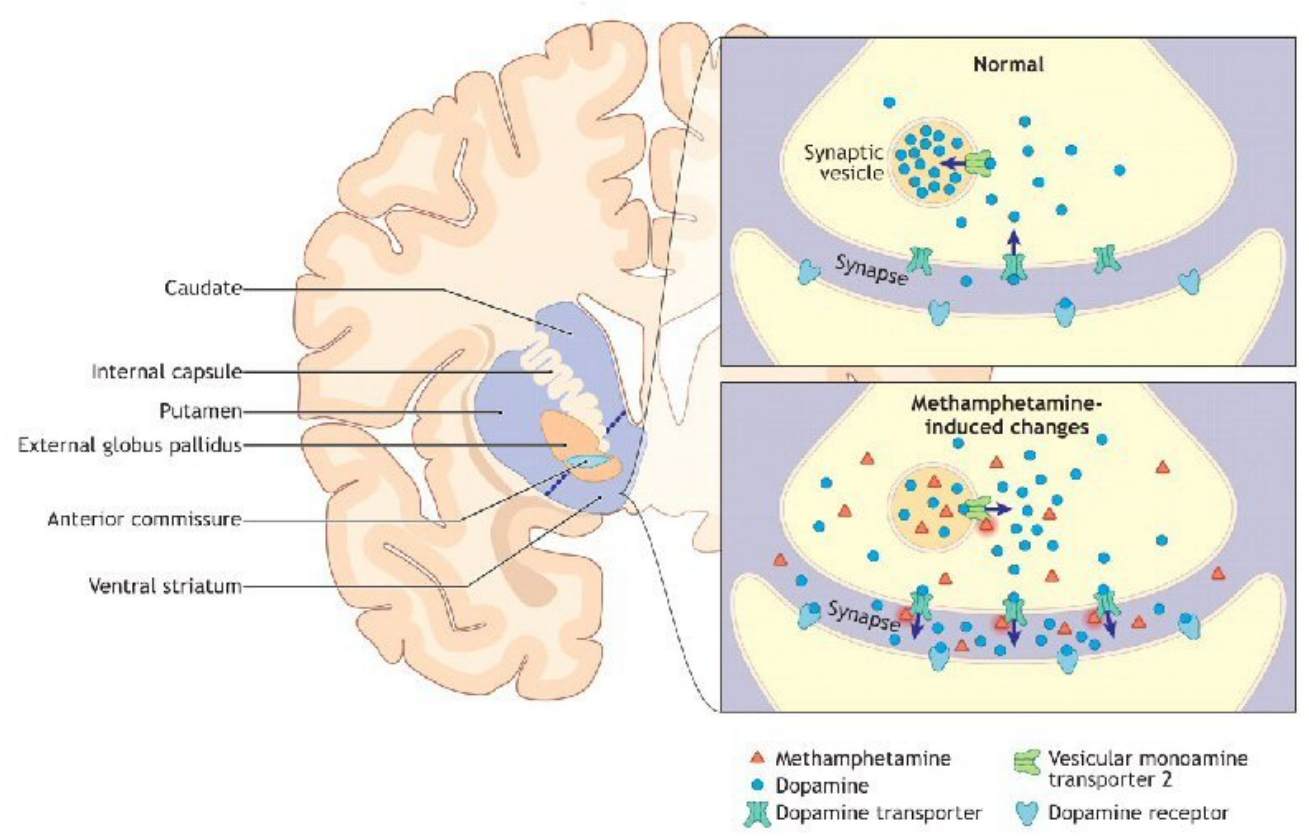

Figure 1.1. Pharmacologic effects of methamphetamine on the dopaminergic system. Schematic diagram of the human dopamine-rich striatum, which is made up of the caudate nucleus, putamen and ventral striatum (left), and a striatal dopamine nerve ending (right). Methamphetamine causes dopamine release from the nerve endings. Normally, dopamine released into the synapse is taken back up into the nerve ending by the dopamine transporter and is transported into the synaptic vesicle by the vesicular monoamine transporter 2 . Methamphetamine causes the release of striatal dopamine from the nerve ending into the synapse. This likely involves the translocation of dopamine from the synaptic vesicle to the neuronal cytoplasm via the vesicular monoamine transporter 2 and the reverse transport of dopamine from the cytoplasm into the synapse via the dopamine transporter. Figure and legend from Kish et al., 2009 and image by Lianne Friesen and Nicholas Woolridge. 


\subsection{Methamphetamine neurotoxicity}

The neurotoxic effects of methamphetamine have been well characterized and a number of hypotheses have been reported for understanding the mechanisms involved in methamphetamine-induced neurotoxicity. Some of these, seen in figure 1.2 include: reactive oxygen species (involved in a variety of effects), hyperthermia, excitotoxicity (glutamate release), blood brain barrier disruption, mitochondrial dysfunction, microglial activation, and death cascades (autophagy).

1.3.1 Reactive Oxygen Species (ROS). ROS has become one of the key components thought to lead to methamphetamine-induced neurotoxicity. Following entry into the cell via quick diffusion or transport by the DAT/SERT, methamphetamine causes a release of neurotransmitters from the synaptic vesicle via VMAT2(Cadet and Krasnova, 2009; Krasnova and Cadet, 2009). Furthermore, methamphetamine causes a reduction in DAT/SERT decreasing the reuptake of excess dopamine and serotonin from the synaptic cleft and damages VMAT2, thereby preventing neurotransmitter storage within the cytoplasm (Krasnova and Cadet, 2009). Subsequently, excess dopamine and serotonin undergoes auto-oxidation to form toxic quinones with generation of superoxide radicals and hydrogen peroxide via quinone cycling (Kita et al., 2003; Krasnova and Cadet, 2009). Formation of hydroxyl radicals through interactions of superoxides radicals and hydrogen peroxide with transition metals lead to the creation of oxidative stress(Kita et al., 2003). This increase in oxidative stress disrupts lipids, proteins, mitochondrial and nuclear DNA which may play a role in methamphetamine-induced nerve-degeneration and neuronal apoptosis(Cadet et al., 1997; Davidson et al., 2001).

1.3.2 Hyperthermia. Methamphetamine-induced hyperthermia has been shown to be an important component of neurotoxicity. Temperature alterations can drastically change the 
effects of methamphetamine-induced neurotoxicity. When temperature is increased, neurotoxicity is exacerbated while a certain degree of neuroprotection can be seen when temperature is decreased(Bowyer et al., 1994). Animal and clinical reports have indicated a tight correlation between the lethality of methamphetamine and hyperthermia(Bowyer et al., 1994; Davidson et al., 2001). Overall, methamphetamine-induced hyperthermia has been shown to be correlated with nerve terminal degeneration, however is not sufficient by itself (Davidson et al., 2001). The relationship between neurotoxicity and hyperthermia still remains ambiguous; however dopamine and serotonin appear to play a vital role.

Methamphetamine has been reported to cause an increase in the release of dopamine and serotonin in various regions of the brain potentially involved in temperature regulation (Phelps et al., 2010). Dopamine and serotonin are thought to be directly involved in temperature regulation within the CNS(Cannon and Nedergaard, 2004; Salmi, 1998; Salmi and Ahlenius, 1998; Salmi et al., 1993) and may play roles in the hyperthermic effects of methamphetamine (Bowyer et al., 1994; Rusyniak et al., 2008). Since thermoregulation within the hypothalamus is thought to be primarily controlled by dopamine and serotonin (Mallick et al., 2002), the effects of methamphetamine on these neurotransmitter systems are of significant importance.

1.3.2.1 Dopamine: The dopaminergic system is believed to be the primary site for methamphetamine and subsequent research dedicated to understanding methamphetamineinduced hyperthermia have focused largely on dopamine. Following administration, methamphetamine can readily enter the cell and facilitate the increased release of dopamine while preventing the reuptake (Cadet and Krasnova, 2009; Davidson et al., 2001). Studies have shown dopamine receptor activation is a necessary component for methamphetamine-induced hyperthermia (Funahashi et al., 1990; Albers and Sonsalla et al., 1995; He et al., 2004; Broening et al., 2005). LaVoie and Hastings showed that maintaining a low ambient temperature, thus preventing hyperthermia, can prevent increases in dopamine oxidation 
products(LaVoie and Hastings, 1999). One of the most significant findings in this area was from Bowyer et al., which demonstrated the degree of hyperthermia following methamphetamine administration correlated with subsequent depletions in striatal dopamine and lethality and was potentiated by increasing environmental temperatures. In addition, this study demonstrated cold environments that reduce core body temperature can significantly decrease striatal extracellular dopamine concentrations following methamphetamine administration (Bowyer et al., 1994).

\subsubsection{Serotonin: Similar to dopamine, serotonin has a distinctive role in} thermoregulation and subsequent neurotoxicity. Serotonergic pathways have been directly implicated in the central control of most forms of thermogenesis (Rothwell, 1994). Previous data have shown that changes in neuronal serotonin levels correlate with changes in brain and core body temperatures (Salmi and Ahlenius, 1998; Schwartz et al., 1995). In addition, serotonin regulates skin blood flow, which is a major mechanism in thermoregulation (Maurer-Spurej, 2005).Methamphetamine facilitates serotonin release in the nerve terminal (Ago et al., 2006; Kuczenski et al., 1995)which can lead to increases in body temperature (Fukumura et al., 1998; Numachi et al., 2007). Numachi et al. demonstrated that while methamphetamine is likely to exert its hyperthermic effects primarily through the DAT, the SERT may have a compensatory role in the absence of the DAT. Other reports have suggested directly or indirectly blocking the actions of released serotonin on the central neuronal pathways involved in the temperature regulation can prevent temperature elevation in addition to serotonergeric neurotoxicity (Azzaro and Rutledge, 1973; Ginawi et al., 2005).

\subsubsection{Excitotoxicity (glutamate release). Methamphetamine administration can lead to} increased release of glutamate (Nash and Yamamoto, 1992).Known as excitotoxicity, NMDA receptors become activated leading to another source of reactive species(Nash and Yamamoto, 1992). The underlying effects seen as a result of glutamate release stems from nitric oxide and 
nitric oxide synthase. Increases in glutamate leads to a subsequent increase in intracellular calcium levels which activates various kinases, lipases, and proteases ultimately ending in free radical generation and DNA damage (Quinton and Yamamoto, 2006). The calcium influx induced via NMDA activation has been reported to be correlated with an increase in nitric oxide synthase activation, which further leads to reactive particle formation (Schmidt et al., 1996). It is also important to point out excess intracellular calcium release may be in and of itself sufficient to increase reactive particle formation (Kahlert et al., 2005).

1.3.4 Mitochondrial Dysfunction. Due to the lipophilicity of methamphetamine, it can readily diffuse into the mitochondria and subsequently be retained (Davidson et al., 2001). It has now become apparent that methamphetamine affects the electrochemical gradient formed from the electron transport chain (ETC) resulting in decreased ATP synthesis, ultimately ending in a decreased energy state (Krasnova and Cadet, 2009; Quinton and Yamamoto, 2006). In addition to the decreased energy output, the effects methamphetamine has on the mitochondria can be detrimental when it comes to the increased ROS production(effects on lipids and DNA) seen following administration (Krasnova and Cadet, 2009). The disruptive effects on the mitochondria can further alter calcium storage. Methamphetamine leads to a release of stored calcium through the permeability transition pore (PTP) which can in turn result in activation of programmed cell death proteases and caspases (Davidson et al., 2001). The mitochondria, which has been linked to the necrotic and apoptotic cell death pathways seen with several of the known neurodegenerative diseases (Davidson et al., 2001), can trigger a series of cellular events ending with neuronal death. Methamphetamine has been reported to increase proapoptotic proteins (Bax, Bad, and Bid) while decreasing anti-apoptotic proteins (Bcl-2 and Bcl$\mathrm{XI}$ ) resulting in the release of cytochrome $\mathrm{c}$ and apoptosis inducing factor (AIF) into the cytosol (Krasnova and Cadet, 2009). 
1.3.5 Microglial Reactions. Under normal physiologically conditions, microglial cells act as the macrophages within the brain and spinal cord. A dose-dependent microglial activation was reported following methamphetamine administration (Thomas et al., 2004) indicating the systems response following exposure. Methamphetamine-induced neurotoxicity was shown to be attenuated following the treatment with a non-steroidal anti-inflammatory drug (Asanuma et al., 2003). A variety of evidence suggests that once activated, microglial cells release an abundance of cytokines, reactive oxygen and nitrogen particles, and prostaglandins believed to be involved in nerve terminal damage (Krasnova and Cadet, 2009). Specifically, methamphetamine was shown to initiate a microglial response in regions of the brain that undergo neuronal degeneration (Krasnova and Cadet, 2009). While protection from excess microglial activation is not sufficient to prevent against methamphetamine-induced neurotoxicity, it appears that activated microglial cells exacerbate methamphetamine-induced neurotoxicity similarly to hyperthermia (Krasnova and Cadet, 2009). Sustained increases in intracellular calcium levels have also been shown to be important to the induction of the inflammatory response, specifically microglia activation (Hoffmann et al., 2003).

1.3.7 Death Cascades (autophagy). As previous reports have indicated, neurotoxic doses of methamphetamine can induce autophagy both in vivo and in vitro (Krasnova and Cadet, 2009). Cytoplasmic vacuoles which resemble autophagic molecules have been shown in striatal dopaminergic neurons and gabanergic neurons following methamphetamine exposure (Krasnova and Cadet, 2009).Based on evidence of dopamine's role in methamphetamineinduced dysfunction of the ubiquitin-proteasome system as well as formation of cytoplasmic vacuoles, it appears as though dopamine is the primary factor in which methamphetamine can induce autophagy. 


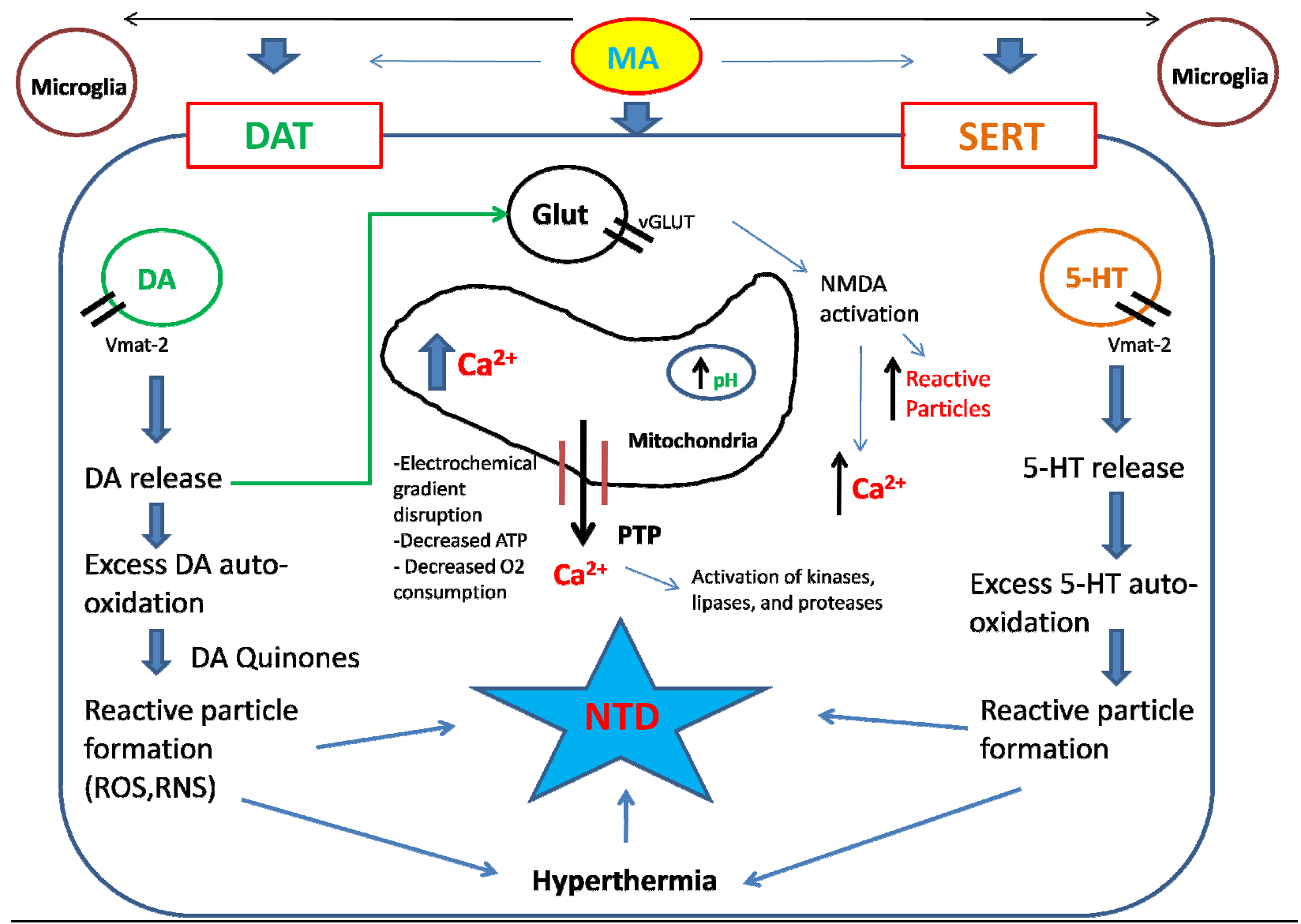

Figure 1.2 Neurotoxic effects of methamphetamine. Methamphetamine (MA) is believed to enter the cell through the dopamine and serotonin transporter. Once into the cell, methamphetamine can cause a series of cellular events including: dopamine and serotonin release and subsequent auto-oxidation resulting in reactive particle formation, activation of microglia cells, mitrochondrial dysfunction and release of calcium through the post transmembrane pore, NMDA activation from glutamate release, increase in body temperature, and ultimately nerve terminal degeneration. MA=methamphetamine, DAT=dopamine transporter, SERT=serotonin transporter, $\mathrm{DA}=$ dopamine, $5-\mathrm{HT}=$ serotonin, Glut=glutamate, NTD=nerve terminal degeneration.

\subsection{Interactions between methamphetamine and sigma receptors}

In addition to interacting with various neurotransmitter systems(Fleckenstein et al., 2000), methamphetamine is thought to interact with sigma receptors (Itzhak, 1993; Nguyen et al., 2005) (Table 1.1).

Table 1.1.Sigma binding affinity of methamphetamine.

\begin{tabular}{|l|l|l|}
\hline & Sigma-1 $\mathrm{K}_{\mathrm{i}}(\mu \mathrm{M})$ & Sigma-2 $_{\mathrm{i}}(\mu \mathrm{M})$ \\
\hline
\end{tabular}




\begin{tabular}{|l|c|c|}
\hline Methamphetamine & $2 \pm 0.2$ & $47 \pm 10$ \\
\hline
\end{tabular}

Recent evidence has shown that methamphetamine produces some of its physiological and behavioral effects through sigma receptors (Nguyen et al., 2005), suggesting a potential site for pharmacological intervention. Specifically, sigma receptors are thought to have a role in the behavioral and neurotoxic effects of methamphetamine (Matsumoto et al., 2008). Sigma receptors are found on monoaminergic neurons (Bastianetto et al., 1995; Booth and Baldessarini, 1991; Gundlach et al., 1986) and modulate the release of neurotransmitters such as dopamine and serotonin(Matsumoto et al., 2008; Salmi and Ahlenius, 1998; Schwartz et al., 1995). In addition, sigma receptor ligands can modulate thermoregulation (Rawls et al., 2002), likely through an interaction with thermosensitive neurons in the hypothalamus (Bouchard and Quirion, 1997; Mei and Pasternak, 2001).

\subsubsection{Gender Differences and Implications for Methamphetamine and Sigma Receptors}

Previous reports have suggested woman maybe more likely to use methamphetamine than males and methamphetamine has the highest rate of females currently being treated for addiction (Dluzen et al., 2007). No significant differences in direct pharmacokinetic comparisons have been reported between males and females however gastrointestinal transit time is greater in the luteal phase which would suggest greater absorption in females (Lynch et al., 2002). Other studies have shown amphetamine-stimulated dopamine release was higher in men than woman (Munro et al., 2006). Additionally, and as other reports have shown, woman may have less neurotoxicity compared to men due to the neuroprotective effects of estrogen (Dluzen et al., 2007). Protective effects against amphetamines have been directly correlated with estrogen levels (Justice et al., 1999) and treatment with an estradiol patch provided protection against the effects of amphetamine (Justice et al., 2000). Lastly females appear more likely than males to receive treatment and acknowledge dependence (Dluzen et al., 2007). 
The irony of gender differences in methamphetamine abuse lies in the fact that despite woman are more dependent on and vulnerable to methamphetamine use, they appear more protected against the toxic effects of methamphetamine (Dluzen et al., 2007).

Previous studies have demonstrated neuroactive steroids such as progesterone may be an endogenous ligand for the sigma receptor (Matsumoto et al., 2009). Additionally, a more recent report suggested the sigma-2 receptor binding site as progesterone receptor membrane component 1 (PGMRC1) and overexpression and knockdown of the PGRMC1 protein resulted in an increase (overexpression) and a decrease (knockdown) in binding of a sigma-2 selective radioligand (Xu et al., 2011). Due to the interactions of progesterone with the sigma receptor, the majority of sigma studies utilize male mice. While the effects have not been directly compared with both male and female animals, it is likely that different results would be observed based on gender.

\subsection{Sigma receptors}

Sigma receptors are unique proteins which are distinct from other known receptors and consist of at least two subtypes, sigma-1 and sigma-2(Guitart et al., 2004; Matsumoto et al., 2003; Su and Hayashi, 2003). They are distributed in the brain and peripheral organs(Itzhak, 1993; Walker et al., 1992). Of the two subtypes, sigma-1 receptors are localized intercellularly (Hayashi et al., 2000; Hayashi and Su, 2003) and have been cloned in several species (Mei and Pasternak, 2001; Prasad et al., 1998). Sigma-1 receptors have important roles in the modulation of several neurotransmitters by affecting intracellular second messenger systems, particularly calcium mobilization (Hayashi et al., 2000; Hayashi and Su, 2003). In addition, because of the chaperone like characteristics of sigma-1 receptors, they are believed to partake in proteinprotein interactions and undergo translocation between various cellular compartments (Hayashi and Su, 2007). Sigma-2 receptors, on the other hand, have not been cloned and at 18-22 kDa, are smaller than sigma-1 receptors (Hellewell et al., 1994). They are believed to regulate 
calcium release from stores within the endoplasmic reticulum (Bowen et al., 1995; Vilner and Bowen, 2000) and are implicated in the regulation of cell proliferation and cell viability (Vilner and Bowen, 1993; Vilner et al., 1995b). As with the sigma-1 receptor, sigma-2 receptors are widely distributed throughout the cell including the mitochondria, endoplasmic reticulum, lysosome, and plasma membrane (Zeng et al., 2007).

\subsubsection{Sigma Receptors in Post Mortem Brains}

Previous studies have shown $\left[{ }^{3} \mathrm{H}\right]$-haloperidol, a high affinity sigma receptor compound, in the presence of $50 \mathrm{nM}$ spiperone binds to a single and saturable class of receptors in the human brain (Weissman et al., 1988). In addition to haloperidol ,d-3-PPP was found to have high affinity for the sigma receptor binding site in post-mortem studies, whereas other potent dopaminergic drugs (apomorphine, $d$-butaclamol) are relatively less potent at sigma receptors. The cerebellum was also found to have a high density of sigma receptors in the human brain as haloperidol and DTG were found to bind to sigma receptors in this region (Su et al., 1982; Tam, 1983, Gundlach et al. 1986). In post mortem schizophrenic brains, nemonapride-labeled sigma receptor binding was decreased compared to normal controls (Helmeste et al., 1996). Other studies evaluated memantine and amantadine for their ability to compete with (+)-pentazocine in homogenates of post-mortem human frontal cortex. Memantine likely does not interact with sigma receptors; however Amantadine, at therapeutic concentrations, probably binds both to the sigma site and to the phencyclidine (PCP) binding site of the N-methyl-D-aspartate (NMDA) receptor (Kornhuber et al., 1993).

\subsubsection{Sigma Receptor Knockout/Knockdown Studies}

Several sigma receptor knockout studies have been done since the cloning and sequencing of the sigma-1 receptor. Despite the broad expression pattern found for the sigma-1 gene, homozygous mutant mice are viable, fertile and did not display any obvious phenotype, 
when compared to control litter mates (Langa et al., 2003). However, a significant decrease in the hypermotility response was found in knockout mice upon challenge with (+)SKF-10 047, in agreement with the involvement of sigma 1-receptors in the induction of psychostimulant actions (Langa et al., 2003). Furthermore, sigma-2 receptors activity does not appear to be affected from the knockout of the sigma-1 receptor. Other studies concluded sigma-1 knockout mutants displayed an increase in immobility time using the forced swimming test, but demonstrated normal anxiety-like behavior in the elevated plus-maze and light/dark box tests and normal locomotor activity (Sabino et al., 2009). Formalin-induced pain was also shown to be reduced by approximately $55 \%$ in sigma- 1 receptor knockout mice in comparison to wild-type animals (Cendan et al., 2005). Lastly, studies looking at the effects of methamphetamine in sigma-1 knockout mice indicated methamphetamine still produces its effects, potential indicating a compensatory role for the sigma-2 receptor (Fontanilla et al., 2009).

A couple of studies have explored knockdown studies to further evaluate the effects of sigma-1 receptors. Studies that have used sequence-specific antisense oligonucleotides have demonstrated a role for sigma-1 receptors in the actions of drugs of abuse such as cocaine and methamphetamine (Matsumoto et al., 2002; Nguyen et al., 2005). Specifically, antisense oligodeoxynucleotide against sigma-1 receptors were found to attenuate the convulsive and locomotor stimulant effects of cocaine (Matsumoto et al., 2002). In addition, mice that were administered an antisense oligodeoxynucleotide to down-regulate the sigma-1 receptor were found to display reduced locomotor stimulatory response to methamphetamine when compared to control mice receiving mismatch oligonucleotides (Nguyen et al., 2005).

\subsection{Sigma receptor ligands}




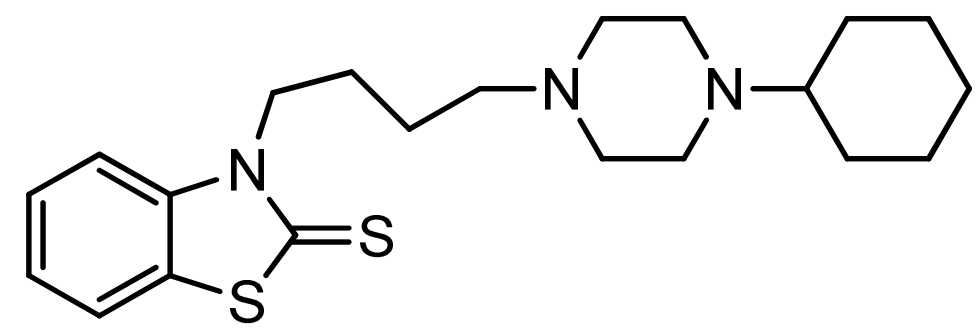

CM156-(3-(4-(4-cyclohexylpiperazin-1-yl)butyl)benzo[d] thiazole-2(3H)-thione)

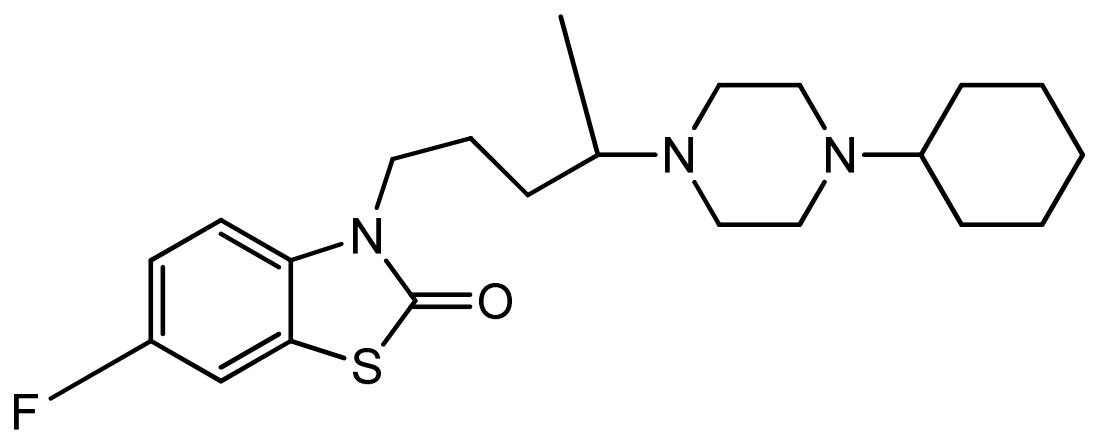

AZ66- (3-(4-(4-cyclohexylpiperazin-1-yl)pentyl)-6-flourobenzo[d]thiazol-2(3H)-one)

Two compounds were used throughout the studies presented herein, CM156(3-(4-(4cyclohexylpiperazin-1- yl)butyl)benzo[d] thiazole-2(3H)-thione) and AZ66(3-(4-(4cyclohexylpiperazin-1-yl)pentyl)-6-flourobenzo[d]thiazol-2(3H)-one). CM156 and AZ66were synthesized to have high affinity and selectivity for sigma receptors over other non-sigma sites (Maeda et al., 2002; Seminerio et al., 2011b; Xu et al., 2010). CM156 is a previously studied compound (Kaushal et al., 2009; Kaushal et al., 2011; Xu et al., 2010; Xu et al., 2012) that was optimized for metabolic stability and led to the development of our lead analog, AZ66. The affinities of CM156 and AZ66 for sigma-1 and sigma-2 receptors, as well as other receptors, transporters, ion channels and binding sites are listed in Table 1.2.

1.7.1 Receptor Binding Assays: The radioligand binding assays were preformed in rat brain homogenates using methods previously described in detail (Matsumoto et al., 1995; Matsumoto et al., 2008). Briefly, sigma-1 receptors were labeled with $\left.5 \mathrm{nM} \mathrm{[}{ }^{3} \mathrm{H}\right](+)$-pentazocine 
and sigma-2 receptors were labeled with $3 \mathrm{nM}\left[{ }^{3} \mathrm{H}\right]$ di-o-tolylguanidine (DTG)in the presence of $300 \mathrm{nM}(+)$-pentazocine to block sigma-1 receptors. Nonspecific binding was determined in the presence of $10 \mu \mathrm{M}$ haloperidol. All of the assays were terminated with the addition of ice-cold buffer and rapid vacuum filtration over glass fiber filters. To further evaluate CM156 and AZ66 binding profile, the compounds was subject to NOVAScreen (Caliper Life Sciences, Hanover, MD) at targets not previously tested in our lab. Further details of each assay condition can be accessed through their website at www.caliperls.com.

Table 1.2. Binding affinity of CM 156 and AZ66 for sigma receptors and non-sigma receptor sites

\begin{tabular}{|c|c|c|c|c|c|}
\hline \multicolumn{2}{|l|}{ Binding Site } & \multirow{2}{*}{\multicolumn{2}{|c|}{ Nonspecific binding }} & \multicolumn{2}{|c|}{$\mathbf{K}_{\mathbf{i}}$} \\
\hline \multicolumn{2}{|l|}{ Sigma Receptors: } & & & CM156 & AZ66 \\
\hline Sigma-1 & $5 \mathrm{nM}[3 \mathrm{H}](+)$-pentazocine & $10 \mu \mathrm{M}$ haloperidol & Rat brain & $1.3 \pm 0.4$ & $1.20 \pm 0.2$ \\
\hline Sigma-2 & $3 \mathrm{nM}[3 \mathrm{H}] \mathrm{di}$-o-tolylguanidine & $10 \mu \mathrm{M}$ haloperidol & Rat brain & $0.6 \pm 0.1$ & $0.31 \pm 0.1$ \\
\hline \multicolumn{6}{|c|}{ Monoamine Transporters: } \\
\hline Dopamine & $0.5 \mathrm{nM}[3 \mathrm{H}] \mathrm{WIN} 35,428$ & $50 \mu \mathrm{M}$ cocaine & Rat striatum & $1175 \pm 100$ & $872 \pm 122$ \\
\hline Serotonin & $0.2 \mathrm{nM}[3 \mathrm{H}]$ paroxetine & $1.5 \mu \mathrm{M}$ imipramine & Rat brainstem & $1402 \pm 152$ & $612 \pm 44$ \\
\hline Norepinephrine & $0.5 \mathrm{nM}[3 \mathrm{H}]$ nisoxetine & $4 \mu \mathrm{M}$ desipramine & Rat cerebral cortex & $>10,000$ & $>10,000$ \\
\hline \multicolumn{6}{|c|}{ Neurotransmitter Related: } \\
\hline Adenosine & $4.0 \mathrm{nM}\left[{ }^{3} \mathrm{H}\right] \mathrm{NECA}$ & $1 \mu \mathrm{M} \mathrm{NECA}$ & Bovine striatum & $>10,000$ & $>10,000$ \\
\hline $\begin{array}{l}\text { Adrenergic, } \\
\text { alpha1 }\end{array}$ & $\begin{array}{l}\left.0.3 \mathrm{nM} \mathrm{[}{ }^{3} \mathrm{H}\right] 7-\mathrm{MeO} \mathrm{xy}- \\
\text { Prazosin }\end{array}$ & $\begin{array}{l}1 \mu \mathrm{M} \text { Phentolamine } \\
\text { mesylate }\end{array}$ & Rat forebrain & $>100$ & $>100$ \\
\hline $\begin{array}{l}\text { Adrenergic, } \\
\text { alpha2 }\end{array}$ & $1 \mathrm{Nm}[3 \mathrm{H}] \mathrm{RX} 821002$ & $\begin{array}{l}1 \mu \mathrm{M} \text { Phentolamine } \\
\text { mesylate }\end{array}$ & Rat cortex & $>100$ & $>100$ \\
\hline Adrenergic, beta1 & $\begin{array}{l}0.04 \mathrm{nM}\left[{ }^{125} \mathrm{I}\right](- \\
\text { )iodocyanopindolol }\end{array}$ & $3 \mu \mathrm{M}$ alprenolol & $\begin{array}{l}\text { Human } \\
\text { Neuroepithelioma }\end{array}$ & $>10,000$ & $>10,000$ \\
\hline Cannabinoid, CB1 & $0.5 \mathrm{nM}\left[{ }^{3} \mathrm{H}\right] \mathrm{CP} 55940$ & $1 \mu \mathrm{M} \mathrm{HU}-210$ & $\begin{array}{l}\text { Human recombinant } \\
\text { HEK293 cells }\end{array}$ & $>10,000$ & $>10,000$ \\
\hline Cannabinoid, CB2 & $0.5 \mathrm{nM}\left[{ }^{3} \mathrm{H}\right] \mathrm{CP} 55940$ & $1 \mu \mathrm{M} \mathrm{HU}-210$ & $\begin{array}{l}\text { Human recombinant } \\
\mathrm{CHO} \text { cells }\end{array}$ & $>10,000$ & $>10,000$ \\
\hline Dopamine $\mathrm{D}_{4.2}$ & $5 \mathrm{nM}\left[{ }^{3} \mathrm{H}\right](-)$-sulpiride & $1 \mu \mathrm{M}$ haloperidol & Rat brain & $>100$ & $>100$ \\
\hline $\begin{array}{l}\text { GABA A, agonist } \\
\text { site }\end{array}$ & $5 \mathrm{nM}\left[{ }^{3} \mathrm{H}\right] \mathrm{GABA}$ & $1 \mu \mathrm{M}$ GABA & Bovine cerebellum & $>10,000$ & $>10,000$ \\
\hline $\begin{array}{l}\text { GABA A, BDZ } \\
\text { alpha } 1\end{array}$ & $1 \mathrm{nM}\left[{ }^{3} \mathrm{H}\right]$ flunitrazepam & $0.5 \mu \mathrm{M}$ flumazenil & Bovine cortex & $>10,000$ & $>10,000$ \\
\hline GABA-B & $1 \mathrm{nM}\left[^{3} \mathrm{H}\right] \mathrm{CGP} 54626 \mathrm{~A}$ & $100 \mu \mathrm{M}$ baclofen & Rat cerebral cortex & $>10,000$ & $>10,000$ \\
\hline Glutamate, AMPA & $5 \mathrm{nM}\left[{ }^{3} \mathrm{H}\right] \mathrm{AMPA}$ & $100 \mu \mathrm{M}$ AMPA & Rat forebrain & $>10,000$ & $>10,000$ \\
\hline Glutamate, kainite & $10 \mathrm{nM}\left[{ }^{3} \mathrm{H}\right]$ kainic acid & $10 \mu \mathrm{M}$ kainic acid & Rat forebrain & $>10,000$ & $>10,000$ \\
\hline $\begin{array}{l}\text { Glutamate, NMDA } \\
\text { agonist }\end{array}$ & $2 \mathrm{nM}\left[^{3} \mathrm{H}\right] \mathrm{CGP} 39653$ & $300 \mu \mathrm{MNMDA}$ & Rat forebrain & $>10,000$ & $>10,000$ \\
\hline $\begin{array}{l}\text { Glutamate, NMDA } \\
\text { glycine }\end{array}$ & $4 \mathrm{nM}\left[{ }^{3} \mathrm{H}\right] \mathrm{MDL}-105,519$ & $3 \mu \mathrm{MMDL}-105,519$ & Rat cortex/hippoc & $>10,000$ & $>10,000$ \\
\hline $\begin{array}{l}\text { Glutamate, } \\
\text { NMDA/PCP }\end{array}$ & $\begin{array}{l}10 \mathrm{nM}\left[^{3} \mathrm{H}\right] \mathrm{TCP} \\
5 \mathrm{nM}\left[{ }^{3} \mathrm{H}\right] \mathrm{TCP}\end{array}$ & $\begin{array}{l}100 \mu \mathrm{M}(+)-M K 801 \\
10 \mu \mathrm{M} \text { cyclazocine }\end{array}$ & $\begin{array}{l}\text { Rat forebrain } \\
\text { Rat brain }\end{array}$ & $\begin{array}{l}>10,000>10 \\
, 000\end{array}$ & $\begin{array}{l}>10,000> \\
10,000\end{array}$ \\
\hline $\begin{array}{l}\text { Glutamate, } \\
\text { mGluR1 }\end{array}$ & $20 \mathrm{nM}\left[{ }^{3} \mathrm{H}\right]$ quisqualic acid & $1 \mathrm{mM}$ L-glutamate & Rat cerebellum & $>10,000$ & $>10,000$ \\
\hline $\begin{array}{l}\text { Glutamate, } \\
\text { mGluR5 }\end{array}$ & $10 \mathrm{nM}\left[{ }^{3} \mathrm{H}\right] \mathrm{MPEP}$ & $10 \mu \mathrm{M}$ MPEP & Rat brain & $>10,000$ & $>10,000$ \\
\hline Glycine,strychnine & $16 \mathrm{nM}\left[{ }^{3} \mathrm{H}\right]$ strychnine & $\begin{array}{l}100 \mu \mathrm{M} \text { strychnine } \\
\text { nitrate }\end{array}$ & Rat spinal cord & $>10,000$ & $>10,000$ \\
\hline
\end{tabular}




\begin{tabular}{|c|c|c|c|c|c|}
\hline Histamine $\mathrm{H}_{1}$ & $2 \mathrm{nM}\left[{ }^{3} \mathrm{H}\right]$ Pyrilamine & $10 \mu \mathrm{M}$ Triprolidine & $\begin{array}{l}\text { Bovine cerebellar } \\
\text { membranes }\end{array}$ & $>100$ & $>100$ \\
\hline Histamine $\mathrm{H}_{2}$ & $0.1 \mathrm{nM}\left[{ }^{125} \mathrm{I}\right]$ aminopotentidine & $3 \mu \mathrm{M}$ tiotidine & Guinea pig striatum & $>100$ & $>100$ \\
\hline Histamine $\mathrm{H}_{3}$ & $0.2 \mathrm{nM}\left[{ }^{3} \mathrm{H}\right] \mathrm{N}-\mathrm{a}-\mathrm{MeH}$ istamine & $\begin{array}{l}100 \mathrm{nM} \mathrm{R}(-) \mathrm{a}- \\
\text { Methylhistamine }\end{array}$ & Rat forebrain & $>100$ & $>100$ \\
\hline $\begin{array}{l}\text { Muscarinic, } \\
\text { central }\end{array}$ & $0.15 \mathrm{nM}\left[{ }^{3} \mathrm{H}\right] \mathrm{QNB}$ & $0.1 \mu \mathrm{M}$ atropine & Rat cerebral cortex & $>100$ & $>100$ \\
\hline $\begin{array}{l}\text { Muscarinic, } \\
\text { peripheral }\end{array}$ & $0.3 \mathrm{nM}\left[{ }^{3} \mathrm{H}\right] \mathrm{QNB}$ & $0.1 \mu \mathrm{M}$ atropine & Guinea pig bladder & $>100$ & $>100$ \\
\hline Muscarinic $\mathrm{M}_{1}$ & $\begin{array}{l}0.5 \mathrm{nM}\left[{ }^{3} \mathrm{H}\right] \mathrm{N} \text {-methyl } \\
\text { scopolamine }\end{array}$ & $1 \mu \mathrm{M}(-)$ scopolamine & $\begin{array}{l}\text { Human recombinant } \\
\mathrm{CHO} \text { cells }\end{array}$ & $>100$ & $>100$ \\
\hline Muscarinic $\mathrm{M}_{2}$ & $\begin{array}{l}0.5 \mathrm{nM}\left[{ }^{3} \mathrm{H}\right] \mathrm{N} \text {-methyl } \\
\text { scopolamine }\end{array}$ & $\begin{array}{l}1 \mu \mathrm{M} \\
\text { methylscopolamine }\end{array}$ & $\begin{array}{l}\text { Human recombinant } \\
\mathrm{CHO} \text { cells }\end{array}$ & $>100$ & $>100$ \\
\hline Nicotinic, muscle & $1 \mathrm{nM}\left[{ }^{125} \mathrm{l}\right] \mathrm{a}$-bungarotoxin & $10 \mu$ Mnicotine & Human TE671 cells & $>10,000$ & $>10,000$ \\
\hline $\begin{array}{l}\text { Nicotinic, } \\
\text { neuronal }\end{array}$ & $0.05 \mathrm{nM} \mathrm{[}{ }^{3} \mathrm{H}$ ]epibatidine & $20 \mathrm{nM}$ epibatidine & Human SK-N-F1 cells & $>10,000$ & $>10,000$ \\
\hline Opioid, Kappa 1 & $0.75 \mathrm{nM}\left[{ }^{3} \mathrm{H}\right] \mathrm{U}-69593$ & $1 \mu \mathrm{M} \mathrm{U69593}$ & $\begin{array}{l}\text { Guinea pig } \\
\text { cerebellum }\end{array}$ & $>10,000$ & $>10,000$ \\
\hline Opioid, Mu & $1 \mathrm{nM}\left[{ }^{3} \mathrm{H}\right] \mathrm{DAMGO}$ & $1 \mu \mathrm{M}$ Naloxone & Rat forebrain & $>10,000$ & $>10,000$ \\
\hline \multicolumn{6}{|c|}{ Hormone, peptide, steroid receptors: } \\
\hline $\begin{array}{l}\text { Angiotensin II, } \\
\mathrm{AT}_{1}\end{array}$ & $\begin{array}{l}0.06 \mathrm{nM}\left[{ }^{125} \mid\right]\left(\mathrm{Sar}^{1}-\right. \\
\left.\mathrm{lle}^{8}\right) \text { angiotensin }\end{array}$ & $1 \mu \mathrm{M}$ angiotensin II & Human KAN-TS cells & $>10,000$ & $>10,000$ \\
\hline $\begin{array}{l}\text { Angiotensin II, } \\
\mathrm{AT}_{2}\end{array}$ & $\begin{array}{l}0.1 \mathrm{nM}\left[{ }^{125} \mathrm{I}\right] \mathrm{Tyr}^{4} \text {-angiotensin } \\
\text { II }\end{array}$ & $0.05 \mu \mathrm{M}$ angiotensin II & Bovine cerebellum & $>10,000$ & $>10,000$ \\
\hline Bradykinin, $\mathrm{BK}_{2}$ & $0.2 \mathrm{nM}\left[{ }^{3} \mathrm{H}\right]$ bradykinin & $100 \mathrm{nM}$ bradykinin TFA & Guinea pig ileum & $>10,000$ & $>10,000$ \\
\hline $\begin{array}{l}\text { Cholecystokinin, } \\
\text { CCK }_{\mathrm{A}}\end{array}$ & $0.02 \mathrm{nM}\left[{ }^{125} \mathrm{I}\right] \mathrm{CCK}-8$ & $1 \mu \mathrm{M} \mathrm{CCK}-8$ & Mouse pancreas & $>10,000$ & $>10,000$ \\
\hline $\begin{array}{l}\text { Cholecystokinin, } \\
\mathrm{CCK}_{\mathrm{B}}\end{array}$ & $0.02 \mathrm{nM}\left[{ }^{125} \mathrm{I}\right] \mathrm{CCK}-8$ & $1 \mu \mathrm{M}$ CCK-8 & Mouse forebrain & $>10,000$ & $>10,000$ \\
\hline $\begin{array}{l}\text { CRF, non- } \\
\text { selective }\end{array}$ & $0.1 \mathrm{nM}\left[{ }^{125} I\right] \mathrm{Tyr}^{0}-\mathrm{oCRF}$ & $1 \mu \mathrm{M} \mathrm{Tyr}{ }^{0}-\mathrm{oCRF}$ & Rat cerebral cortex & $>10,000$ & $>10,000$ \\
\hline Endothelin, $\mathrm{ET}_{\mathrm{A}}$ & $0.033 \mathrm{nM}\left[{ }^{125} \mathrm{I}\right]$ endothelin-1 & $0.1 \mu \mathrm{M}$ endothelin-1 & Human neuroblastoma & $>10,000$ & $>10,000$ \\
\hline Endothelin, $\mathrm{ET}_{\mathrm{B}}$ & $0.025 \mathrm{nM}\left[{ }^{125} \mathrm{I}\right]$ endothelin-1 & $0.1 \mu \mathrm{M}$ endothelin-1 & Human astrocytoma & $>10,000$ & $>10,000$ \\
\hline Estrogen & $0.1 \mathrm{nM}\left[{ }^{125} \mid\right] 3,7 \square$-estradiol & $10 \mathrm{nM} \mathrm{17 \square -estadiol}$ & Human breast cancer & $>10,000$ & $>10,000$ \\
\hline $\begin{array}{l}\text { Galanin, non- } \\
\text { selective }\end{array}$ & $0.07 \mathrm{nM}\left[{ }^{125} \mathrm{l}\right]$ galanin & $\begin{array}{l}100 \mathrm{nM} \text { galanin } \\
\text { (porcine) }\end{array}$ & Rat brain & $>10,000$ & $>10,000$ \\
\hline Glucocorticoid & $1 \mathrm{nM}\left[{ }^{3} \mathrm{H}\right]$ dexamethasone & $10 \mu \mathrm{M}$ triamcinolone & Human recombinant & $>10,000$ & $>10,000$ \\
\hline Neurokinin, $\mathrm{NK}_{1}$ & $1.4 \mathrm{nM}\left[{ }^{3} \mathrm{H}\right]$ substance $\mathrm{P}$ & $1 \mu \mathrm{M}$ substance $\mathrm{P}$ & Rat submaxillary gland & $>10,000$ & $>10,000$ \\
\hline Neurokinin, $\mathrm{NK}_{2}$ & $\left.0.1 \mathrm{nM}\left[{ }^{125}\right]\right]$ neurokinin $\mathrm{A}$ & $1 \mu \mathrm{M}$ neurokinin $\mathrm{A}$ & $\begin{array}{l}\text { Human recombinant } \\
\mathrm{CHO} \text { cells }\end{array}$ & $>10,000$ & $>10,000$ \\
\hline $\begin{array}{l}\text { Neurokinin, } \mathrm{NK}_{3} \\
\text { (NKB) }\end{array}$ & $0.1 \mathrm{nM}\left[{ }^{125} \mathrm{I}\right]$ eledoisin & $1 \mu \mathrm{M}$ eledoisin & Rat cerebral cortex & $>10,000$ & $>10,000$ \\
\hline Oxytocin & $1 \mathrm{nM}\left[{ }^{3} \mathrm{H}\right]$ oxytocin & $1 \mu \mathrm{M}$ oxytocin & Rat uterus & $>10,000$ & $>10,000$ \\
\hline $\begin{array}{l}\text { Testosterone, } \\
\text { cytosolic }\end{array}$ & $\left.0.5 \mathrm{nM} \mathrm{[}{ }^{3} \mathrm{H}\right]$ methyltrienolone & $0.7 \mu \mathrm{M}$ methyltrienolone & Human LnCAP cells & $>10,000$ & $>10,000$ \\
\hline $\mathrm{TRH}$ & $2 \mathrm{nM}\left[{ }^{3} \mathrm{H}\right]\left(3 \mathrm{MeHis^{2 }}\right) \mathrm{TRH}$ & $10 \mu \mathrm{M} \mathrm{TRH}$ & Rat forebrain & $>10,000$ & $>10,000$ \\
\hline VIP, non-selective & $0.05 \mathrm{nM}\left[{ }^{125} \mathrm{I}\right] \mathrm{VIP}$ & $1 \mu \mathrm{M}$ VIP & Rat forebrain & $>10,000$ & $>10,000$ \\
\hline Vasopressin 1 & $\begin{array}{l}0.5 \mathrm{nM}\left[{ }^{3} \mathrm{H}\right] \text { phenylalanyl- } \\
3,4,5-\mathrm{V}\end{array}$ & $1 \mu \mathrm{M} \mathrm{Arg}^{8}$-vasopressin & Rat liver & $>10,000$ & $>10,000$ \\
\hline \multicolumn{6}{|l|}{ Ion channels: } \\
\hline $\begin{array}{l}\text { Calcium, type L } \\
\text { (Benzothiazepine } \\
\text { Site) }\end{array}$ & $5 \mathrm{nM}\left[{ }^{3} \mathrm{H}\right]$ Diltiazem, $\operatorname{cis}(+)$ & $10 \mu \mathrm{M}$ Diltiazem & Rat cerebral cortex & $>100$ & $>100$ \\
\hline $\begin{array}{l}\text { Calcium, type L } \\
\text { (Dihydropyridine } \\
\text { Site) }\end{array}$ & $0.2 \mathrm{nM}\left[{ }^{3} \mathrm{H}\right]$ Nitrendipine & $1 \mu \mathrm{M}$ Nifedipine & Rat cerebral cortex & $>10,000$ & $>10,000$ \\
\hline Calcium, type $\mathrm{N}$ & $\begin{array}{l}0.01 \mathrm{nM}\left[{ }^{125} \mathrm{I}\right] \omega \text {-conotoxin } \\
\text { GVIA }\end{array}$ & $\begin{array}{l}0.1 \mu \mathrm{M} \omega \text {-conotoxin } \\
\text { GVIA }\end{array}$ & Rat cerebral cortex & $>10,000$ & $>10,000$ \\
\hline $\begin{array}{l}\text { Potassium, ATP- } \\
\text { sensitive }\end{array}$ & $0.2 \mathrm{nM}\left[{ }^{3} \mathrm{H}\right]$ glibenclamide & $0.1 \mu \mathrm{M}$ glibenclamide & Rat cerebral cortex & $>10,000$ & $>10,000$ \\
\hline $\begin{array}{l}\text { Potassium, } \mathrm{Ca}^{2+} \\
\text { act } \mathrm{VI}\end{array}$ & $0.05 \mathrm{nM}\left[{ }^{125} \mathrm{I}\right]$ apamin & $100 \mathrm{nM}$ apamin & Rat forebrain & $>10,000$ & $>10,000$ \\
\hline Sodium, Site 2 & $2 \mathrm{nM}\left[{ }^{3} \mathrm{H}\right]$ Batrachotoxin & $1 \mathrm{mM}$ Aconitine & Rat forbrain & $>100$ & $>100$ \\
\hline
\end{tabular}




\begin{tabular}{|c|c|c|c|c|c|}
\hline \multicolumn{5}{|c|}{ Enzymes and other miscellaneous: } & \multirow[b]{2}{*}{$>100$} \\
\hline $\begin{array}{l}\text { Acetylcholine } \\
\text { esterase }\end{array}$ & $\begin{array}{l}0.3 \mathrm{mM} \\
{\left[{ }^{3} \mathrm{H}\right] \text { acethylthiocholine }}\end{array}$ & $100 \mu$ Mphysostigmine & Human recombinant & $>100$ & \\
\hline $\begin{array}{l}\text { Choline } \\
\text { acetyltransferase }\end{array}$ & $0.2 \mathrm{nM}\left[{ }^{14} \mathrm{C}\right]$ acetyl coenzyme & $0.1 \mu \mathrm{M}$ Ro 41-1049 & Rat cerebral cortex & $>10,000$ & $>10,000$ \\
\hline $\begin{array}{l}\text { Glutamic acid } \\
\text { decarboxylase }\end{array}$ & $4 \mu \mathrm{M}\left[{ }^{14} \mathrm{C}\right] \mathrm{L}$-glutamic acid & $\begin{array}{l}100 \mu \text { Maminooxy acetic } \\
\text { acid }\end{array}$ & Rat striatum & $>10,000$ & $>10,000$ \\
\hline $\begin{array}{l}\text { Leukotriene, } \mathrm{LTB}_{4} \\
\text { (BLT) }\end{array}$ & $0.48 \mathrm{nM}\left[{ }^{3} \mathrm{H}\right]$ leukotriene $\mathrm{B}_{4}$ & $500 \mathrm{nM}$ leukotriene $\mathrm{B}_{4}$ & Guinea pig spleen & $>10,000$ & $>10,000$ \\
\hline $\begin{array}{l}\text { Leukotriene, } \mathrm{LTD}_{4} \\
\text { (CysLT1) }\end{array}$ & $0.2 \mathrm{nM}\left[{ }^{3} \mathrm{H}\right]$ leukotriene $\mathrm{D}_{4}$ & $1 \mu \mathrm{M}$ leukotriene $\mathrm{D}_{4}$ & Guinea pig lung & $>10,000$ & $>10,000$ \\
\hline $\begin{array}{l}\text { MAO-A oxidase, } \\
\text { peripheral }\end{array}$ & $50 \mu \mathrm{M}\left[{ }^{14} \mathrm{C}\right] 5-\mathrm{HT}$ & $1 \mu \mathrm{MRo} 41-1049$ & Rat liver mitochondria & $>10,000$ & $>10,000$ \\
\hline $\begin{array}{l}\text { MAO-B oxidase, } \\
\text { peripheral }\end{array}$ & $10 \mu \mathrm{M}\left[{ }^{14} \mathrm{C}\right]$ phenylethylamine & $10 \mu$ MRo 16-6491 & Rat liver mitochondria & $>10,000$ & $>10,000$ \\
\hline Nitric oxide, NOS & $5 \mathrm{nM}\left[{ }^{3} \mathrm{H}\right] \mathrm{NOARG}$ & $100 \mu \mathrm{M}$ NOARG & Rat brain & $>10,000$ & $>10,000$ \\
\hline $\begin{array}{l}\text { Platelet activating } \\
\text { factor }\end{array}$ & $\begin{array}{l}1.7 \mathrm{nM}\left[{ }^{3} \mathrm{H}\right] \text { hexadecyl-acetyl- } \\
\text { PAF }\end{array}$ & $1 \mu \mathrm{M} \mathrm{C}_{16}-\mathrm{PAF}$ & Rabbit platelets & $>10,000$ & $>10,000$ \\
\hline $\begin{array}{l}\text { Thromboxane, } \\
\text { TXA }_{2}\end{array}$ & $\left.2 \mathrm{nM} \mathrm{[}{ }^{3} \mathrm{H}\right] \mathrm{SQ} 29,548$ & $\begin{array}{l}10 \mu \mathrm{M} \text { pinane- } \\
\text { thromboxane }\end{array}$ & Human platelets & $>10,000$ & $>10,000$ \\
\hline
\end{tabular}

Affinities ( $\mathrm{Ki}$ in $\mathrm{nM}$ ) were determined in tissue or cell homogenates. The values in this table represent the mean + S.E.M. from replicate assays. Values of $>10,000$ signify that there was less than $30 \%$ displacement of the radioligand at that concentration. AMPA=alpha-amino-3-hydroxy-5-methyl-4- isoxazole-propionic acid; CCK=cholecystokinin; CGP 39653=2-amino-4-propyl-5-phosphono-3-pentenoic acid; CGP 54626A=cyclohexylmethyl-[(2S)-3-[[(1S)-1-(3,4dichlorophenyl)ethyl]amino]-2-hydroxypropyl]phosphinic acid; CP 55,940=2-[(1R,2R,5R)-5-hydroxy-2-(3hydroxypropyl) cyclohexyl]-5-(2-methyloctan-2-yl)phenol; CRF=corticotrophin releasing factor; DAMGO=(2S)-2-[[2[[(2R)-2-[[(2S)-2-amino-3-(4-hydroxyphenyl)propanoyl]amino]propanoyl]amino]acetyl]-methylamino]-N-(2hydroxyethyl)-3-phenylpropanamide; GABA= $=$-aminobutyric acid; GVIA=(3-[125I]lodotyrosyl22)omega-conotoxic; 5$\mathrm{HT}=$ serotonin; HU-210=(6aR,10aR)- 9-(hydroxymethyl)- 6,6-dimethyl- 3-(2-methyloctan-2-yl)- 6a,7,10,10atetrahydrobenzo [c]chromen- 1-ol; MAO=monoamine oxidase; MDL-105,519=(E)-4,6-dichloro-3-(2-phenyl-2carboxyethenyl)indole-2-carboxylic acid; MK801=(5R,10S)-(+)-5-methyl-10,11-dihydro-5H-dibenzo[a,d]cyclohepten5,10-imine hydrogen maleate dizocilpine hydrogen maleate; MPEP=2-methyl-6-(phenylethynyl)pyridine; NECA=5'-Nethylcarboxamidoadenosine; NMDA $=(2 R)-2-($ methylamino $)$ butanedioic acid; NOARG $=\mathrm{L}_{-} \mathrm{N}^{\mathrm{G}}$-nitro-arginine; $\mathrm{PAF}=$ platelet activating factor; $\mathrm{PCP}=$ phencyclidine; $\mathrm{QNB}=$ quinuclidinyl benzilate; Ro 16-6491=N-(2-aminoethyl)-4chlorobenzamide; Ro 41,1049=N-(2-aminoethyl)-5-(3-fluorophenyl)-4-thiazolecarboxamide; Rx 821002=2-(2,3dihydro-2-methoxy-1,4-benzodioxin-2-yl)-4,5-dihydro-1 H-imidazole; SQ 29,548=[1S-[1 $\alpha, 2 \alpha(Z), 3 \alpha, 4 \alpha]]-7-[3-[[2-$ [(phenylamino)carbonyl]hydrazino]methyl]-7-oxabicyclo[2.2.1]hept-2- yl]-5-heptenoic acid; TCP=1-(1-(2Thienyl)cyclohexyl)piperidine; TFA=trifluoroacetic acid; TRH=thyrotropin releasing hormone; $U-69593=(+)-(5 \alpha, 7 \alpha, 8 \beta)-$ $\mathrm{N}$-methyl-N-[7-(1-pyrrolidinyl)-1-oxaspiro[4.5]dec-8-yl]-benzeneacetamide; VIP=vasoactive intestinal peptide.

\subsection{In vivo studies}

All of the in vivo studies performed were done so using male Swiss Webster mice. The mice were housed in groups of 4-6 with a 12:12-h light/dark cycle and ad libitum food and water. Each cage was made from polysulfone and provided $542 \mathrm{~cm}^{2}$ of floor space (Tecniplast, Philadelphia, PA), which was covered with corn cob bedding and packing material (ULINE, Waukegan, IL). The mice were acclimated for one week before being used in any experiment and they were randomly assigned to their treatment group according to the study. 
Previous studies have demonstrated the usefulness of Swiss Webster mice in studying the effects of methamphetamine and sigma receptors (Ali and Itzhak, 1998; Callahan et al., 1998; Itzhak and Ali, 1996; Matsumoto et al., 2008; Nguyen et al., 2005). The choice to use male mice rather than female is based on the varying hormones in female mice and its potential to cause effects (either positive or negative) in our studies (Kosaka et al., 1988).

\subsection{Summary/Objectives}

Methamphetamine has detrimental effects on a wide array of neurological functions and has quickly become an international public health concern. With the absence of a proven pharmacological agent to counteract methamphetamine-induced complications, the development of a therapeutic treatment is essential. Methamphetamine has been shown to bind to sigma receptors at physiologically relevant concentrations, and sigma receptors have emerged as viable therapeutic targets. In particular, CM156, a selective sigma receptor ligand, displayed high nanomolar affinity at both sigma-1 and sigma-2 receptors while providing in-vivo protective effects against methamphetamine-induced neurotoxicity and locomotor hyperactivity. However, an exceedingly short half-life due to poor metabolic stability has deemed the compound inadequate for pursuing future drug studies in humans. The hypothesis of this work is that CM156 can be structurally optimized to a more metabolically stable compound while demonstrating neuroprotective properties against the neurotoxic, behavioral, and cognitive effects of methamphetamine. Accordingly, CM156 analogs have been synthesized by our collaborators at the University of Mississippi, under the supervision of Dr. Christopher McCurdy. To test our hypothesis, the project has three specific aims:

\section{To confirm high affinity and relative selectivity of novel CM156 analogs for sigma receptors in addition to increased metabolic stability (Chapter 2).Structural modifications were made with the notion that there will be no significant change in binding affinity but display increased metabolic stability. Affinities will be determined at both sigma-1 and sigma-2}


receptors using radioligand binding assays. Furthermore, following the identification of a lead compound, a comprehensive binding profile, via Novascreen, will be completed and metabolic stability studies will be performed to determine the lead compound's half life compared to CM156.

\section{To demonstrate protective effects of novel CM156 analogs in-vivo againstthe} behavioral and neurotoxic effects of methamphetamine (Chapter $3 \& 4$ ). Mice will be pretreated with the lead analog and its ability to attenuate methamphetamine-induced stimulant (locomotor and behavioral sensitization) and neurotoxic (dopaminergic and serotonergic neurotoxicity and hyperthermia) effects will be evaluated.

\section{To demonstrate protective effects of novel CM156 analogs in-vivo againstthe cognitive} effects of methamphetamine (Chapter 5). Mice will be pretreated with the lead analog and its ability to attenuate methamphetamine-induced cognitive impairments will be evaluated.

The overall goal of this study is to develop a lead sigma receptor ligand that can be pursued as a first- line treatment for methamphetamine-induced complications. It is anticipated that if the specific structural enhancements made to CM156 yield similar pharmacological profiles with increased metabolic stability, future pharmacotherapies are likely to be developed.

\subsection{Contributions}

Compounds CM156 and AZ66 were synthesized by Dr. Christophe Mésangeau and Ahmed Abdelazeem in Dr. Christopher R. McCurdy's lab at University of Mississippi.

The radioligand binding studies for CM156 and AZ66 were performed by Dr. Jamaluddin Shaikh and Michael Seminerio at the University of Mississippi and West Virginia University. The NOVAScreen for both compounds were performed by Calipers Life Sciences (Hanover, MD). The National Institute on Drug Abuse (NIDA) very generously supported the Novascreen costs in their medications development program. 
CHAPTER 2

OPTIMIZATION OF CM156 


\subsection{Introduction}

There are no effective pharmacological agents to aid in the treatment of methamphetamine-induced complications. This is problematic because over 12 million Americans have used methamphetamine at least once in their life (Services, 2007) and methamphetamine ranks second worldwide only to cannabis as the most extensively abused drug (Krasanova and Cadet, 2009). In 2005, an estimated 20-40 billion dollars was spent on methamphetamine-related complications stemming from addiction, premature death, and psychological treatment (Nicosia et al., 2008). The development of a novel pharmacological agent to treat the effects of methamphetamine would results in substantial health and economic benefits.

Previous work has suggested methamphetamine may produce some of its physiological and behavioral effects through sigma receptors (Nguyen et al., 2005). Sigma receptors are found on monoaminergic neurons (Bastianetto et al., 1995; Booth et al., 1991) and methamphetamine binds to these receptorsat physiologically relevant concentrations (Itzhak et al., 2005).Two subtypes of sigma receptors have been characterized, designated sigma-1 and sigma-2. The subtypes differ in their cellular and anatomical distribution in addition to their function (Guitart et al., 2004). Sigma-1 receptors have been cloned with high homology and identity in different species (Guitart et al., 2004) and are through to have a role in calcium regulation at the endoplasmic reticulum (ER)-mitochondrion interface (Hayashi et al., 2007). Sigma-2 receptors have yet to be cloned but have been linked to cell cycle function and apoptosis (Crawford and Bowen, 2002; Matsumoto et al., 2007).

The overall objective of this study is to optimize a novel sigma receptor ligand with protective effects against methamphetamine by enhancing its metabolic stability. Through the administration of a selective sigma receptor ligand, we hope to mitigate neurologic complications induced by methamphetamine. In an earlier study, we reported that a high affinity 
and selective sigma receptor ligand, CM156 (3-(4-(4-cyclohexylpiperazin-1yl)butyl)benzo[d]thiazole-2(3H)-thione), provided protective effects following methamphetamine exposure (Kaushal et al., 2011). However, due to poor metabolic stability, CM156 was deemed inadequate for future drug development studies in humans. In an effort to increase metabolic stability while maintaining protective effects through sigma receptors, a series of CM156 analogs were synthesized. Two primary structural moieties, cyclohexylpiperazine and benzo[d]thiazole, have been reported to be important for sigma receptor selectivity (Berardi et al., 2004). Additionally, a four methylene spacer between the piperazine and heterocyclic system increases sigma-2 affinity (Mesangeau et al., 2008). Therefore, analogs were designed to maintain these vital components. Methyl groups were added to prevent $\mathrm{N}$-dealkylation while a fluoride group, previously shown to enhance sigma selectivity, was included to increase the electronegativity of the structure. Overall, 30 compounds were designed and synthesized toincorporate modifications that provide steric hindrance, bulkiness, and stability which may prevent early metabolic breakdown. In addition, in vitro and in vivo metabolism studies were conducted to determine the half life of compounds that demonstrated high sigma receptor binding affinity.

\subsection{Materials and Methods}

2.2.1 Competition Binding Assays. To determine the binding affinity for each of the CM156 analogs, radioligand binding studies were performed. The radioligand binding assays were preformed in rat brain homogenates using methods previously described in detail (Matsumoto et al., 1995; Matsumoto et al., 2008). Briefly, sigma-1 receptors were labeled with 5 $\mathrm{nM}\left[{ }^{3} \mathrm{H}\right](+)$-pentazocine and sigma-2 receptors were labeled with $3 \mathrm{nM}\left[{ }^{3} \mathrm{H}\right]$ di-o-tolylguanidine (DTG)in the presence of $300 \mathrm{nM}(+)$-pentazocine to block sigma-1 receptors. Nonspecific binding was determined in the presence of $10 \mu \mathrm{M}$ haloperidol. All of the assays were terminated with the addition of ice-cold buffer and rapid vacuum filtration over glass fiber filters. 
2.2.2 In Vitro Metabolism Studies. In order to confirm structural modifications to CM156 resulted in increased metabolic stability, in vitro metabolism studies were conducted. Analogs were evaluated in liver microsomes prepared from rat using standard procedures. Analogs (5 $\mu \mathrm{M})$ were incubated at $37^{\circ} \mathrm{C}$ in $50 \mathrm{mM}$ potassium phosphate buffer $(\mathrm{pH} 7.4), 3 \mathrm{mM} \mathrm{MgCl}_{2}$, and 1 mM EDTA ( $\mathrm{pH} 7.4)$, in the presence and absence of cofactor, NADPH-generating system [1 mM NADP (pH 7.4), 5 mM glucose 6-phosphate ( $\mathrm{pH} 7.4$ ), and 1 unit/ml glucose-6-phosphate dehydrogenase]. Reactions were initiated by adding the cofactor mix and terminated at designated time points $(0,15,30$, and $60 \mathrm{~min})$ with the addition of stop reagent (adding equal volume of ice cold acetonitrile). The samples were centrifuged $10,000 \mathrm{rpm}$ for $10 \mathrm{~min}$ at $4^{\circ} \mathrm{C}$. The supernatants were collected and analyzed using ultra performance liquid chromatography (UPLC)/mass spectrometry/mass spectrometry.

The UPLC system consisted of a Waters Acquity UPLC (Milford, MA) equipped with a binary solvent manager, vacuum degasser and an auto sampler. Chromatographic separations were performed on an Atlantis dC18 column $(2.1 \times 50 \mathrm{~mm})$. The mobile phase consisted of 10 $\mathrm{mM}$ ammonium acetate containing $0.1 \%$ acetic acid and methanol $(25: 75, \mathrm{v} / \mathrm{v})$ and pumped at a flow rate of $0.18 \mathrm{ml} / \mathrm{min}$. The injection volume was $10 \mu \mathrm{l}$. A Micromass Quattro Micro ${ }^{\mathrm{TM}}$ system (Waters Corp., Manchester, UK) equipped with electrospray ionization source was used for the mass spectrophotometric detection. The electrospray ionization source was operated in positive ionization mode. The acquisitions were performed using multiple reaction monitoring. The mass transitions chosen for quantitation were $\mathrm{m} / \mathrm{z} 405 \rightarrow \mathrm{m} / \mathrm{z} 181$ for AZ66 and m/z $448 \rightarrow \mathrm{m} / \mathrm{z} 285$ for aripiprazole (internal standard). The mass spectrophotometer parameters were optimized for maximum analyte detection: capillary voltage $4.88 \mathrm{kV}$, cone voltage $44 \mathrm{~V}$, and argon was used as the collision gas at $3.5 \times 10^{-3}$ Pirani. Collision energies were set at 30 and $21 \mathrm{eV}$ for AZ66 and aripiprazole, respectively. 
2.2.3 In Vivo Metabolism Studies. To further evaluate the metabolic stability of AZ66, pharmacokinetic studies were performed in vivo. Briefly,blood samples from male, Sprague Dawley rats $(n=5)$ outfitted with indwelling catheters in the jugular vein were collected. An initial blood volume of $0.1 \mathrm{ml}$ was withdrawn to clear the line. A fresh syringe was used to withdraw a $0.15 \mathrm{ml}$ blood sample. This and all subsequent blood samples were placed in heparinized microfuge tubes at $0^{\circ} \mathrm{C}$. The rats were administered $20 \mathrm{mg} / \mathrm{kg} \mathrm{AZ66}$ orally (p.o.). Timed blood samples were then collected for up to $36 \mathrm{~h}$. For each blood sample, plasma was separated by centrifugation at $10,000 \mathrm{rpm}$ for $10 \mathrm{~min}$ at $4^{\circ} \mathrm{C}$. AZ66 was quantified using ultra performance liquid chromatography/ mass spectrometry/mass spectrometry as described above.

2.2.4 Synthesis of AZ66. The synthetic scheme for AZ66 is shown in Fig. 2.1. Commercially available 4-fluoroaniline (1), hydrochloric acid was refluxed in water with $\mathrm{NH}_{4} \mathrm{SCN}$ for $4 \mathrm{~h}$ to afford compound 2 after recrystallization from ethanol. A solution of bromine in chloroform was added to compound 2 at $0^{\circ} \mathrm{C}$ and subsequently refluxed for $2 \mathrm{~h}$ to afford compound 3. Compound $\mathbf{3}$ was stirred with $\mathrm{KOH}$ to afford compound $\mathbf{4}$. Compound $\mathbf{4}$ was treated with carbonyl-1,1'-diimidazole under reflux for $3 \mathrm{~h}$ to provide the fluorinated benzothiazolone 5. Benzothiazolone 5 was alkylated with 1,4 -dibromopentane in DMF at $60^{\circ} \mathrm{C}$ over $3 \mathrm{~h}$ to afford compound $\mathbf{6}$. Compound $\mathbf{6}$ was reacted with commercially available cyclohexyl piperazine to afford AZ66. AZ66 was subsequently converted to the hydrochloride salt for biological studies. Elemental analysis $(\mathrm{C}, \mathrm{H}, \mathrm{N})$ of $\mathbf{A Z 6 6}$ was determined using a PerkinElmer CHN/SO Series II Analyzer. Obtained results were within $0.4 \%$ of the theoretical values. 

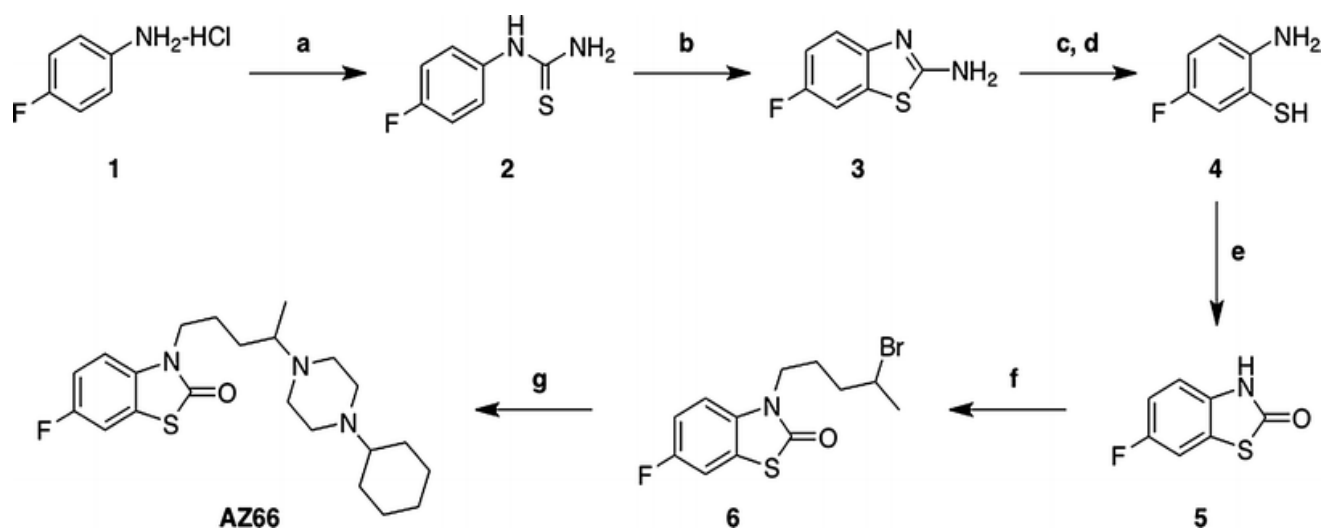

Figure2.1.Synthesis of AZ66.Reagents and conditions: (a) $\mathrm{NH}_{4} \mathrm{SCN}, \mathrm{H}_{2} \mathrm{O}$, reflux, $4 \mathrm{~h}$; (b) $\mathrm{Br}_{2}, \mathrm{CHCl}_{3}, 1 \mathrm{~h}$ at $0^{\circ} \mathrm{C}$, reflux, $2 \mathrm{~h}$ (c) $\mathrm{KOH}$ (d) $\mathrm{Gl}$. acetic acid (e) Carbonyl 1,1' diimidazole, THF, reflux, $3 \mathrm{~h}$; (f) 1,4-dibromopentane , $\mathrm{K}_{2} \mathrm{CO}_{3}$, $\mathrm{DMF}, 60^{\circ} \mathrm{C}, 3 \mathrm{~h}$; (g) cyclohexyl piperazine, $\mathrm{K}_{2} \mathrm{CO}_{3}$, TBAI, $\mathrm{ACN}$, reflux, $6 \mathrm{~h}$.

\subsection{Results}

2.3.1 Competition Binding Assays. The average binding affinities for CM156 and its analogs at both sigma-1 and sigma-2 receptors are shown in Table 2.1.Specifically, the addition of a methyl group to prevent $\mathrm{N}$-dealkylation displayed no significant differences on either sigma1 or sigma-2 receptor binding affinity. Furthermore, in an attempt to make the structure more electronegative, fluoride and oxygen groups were added and also demonstrated no significant change in sigma receptor binding affinity. However, compounds that were adjusted for bulkiness and steric hindrance were found to show significantly lower sigma-1 binding affinity.

Table 2.1 Chemical structure and binding affinities of CM156 and its analogs

\begin{tabular}{|l|l|l|l|}
\hline Structure & Compound name & Sigma-1 $\mathbf{K}_{\mathbf{i}}$ & Sigma-2 $\mathbf{K}_{\mathbf{i}}$ \\
\hline
\end{tabular}




\begin{tabular}{|l|l|l|}
\hline & & \\
\hline
\end{tabular}




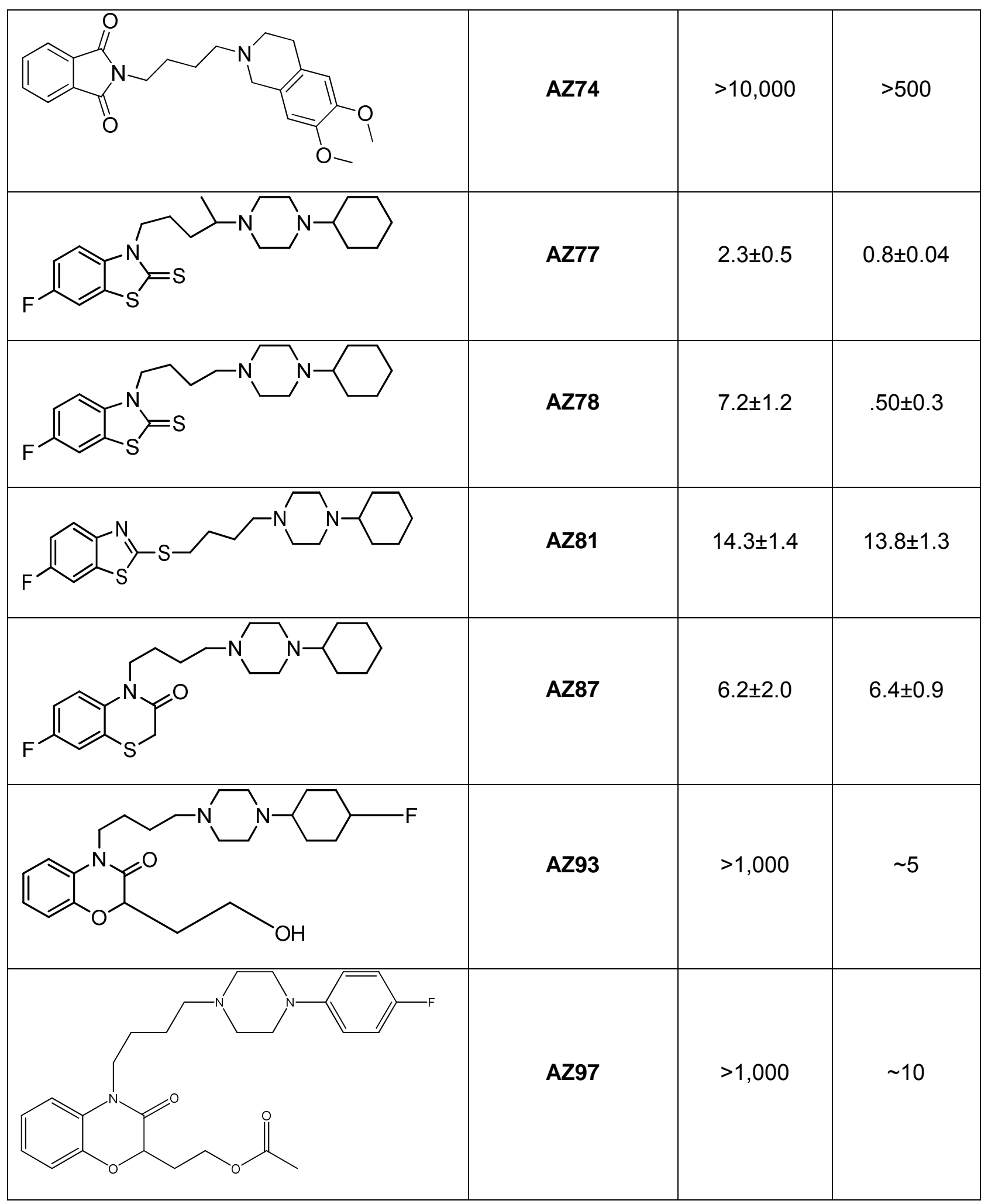




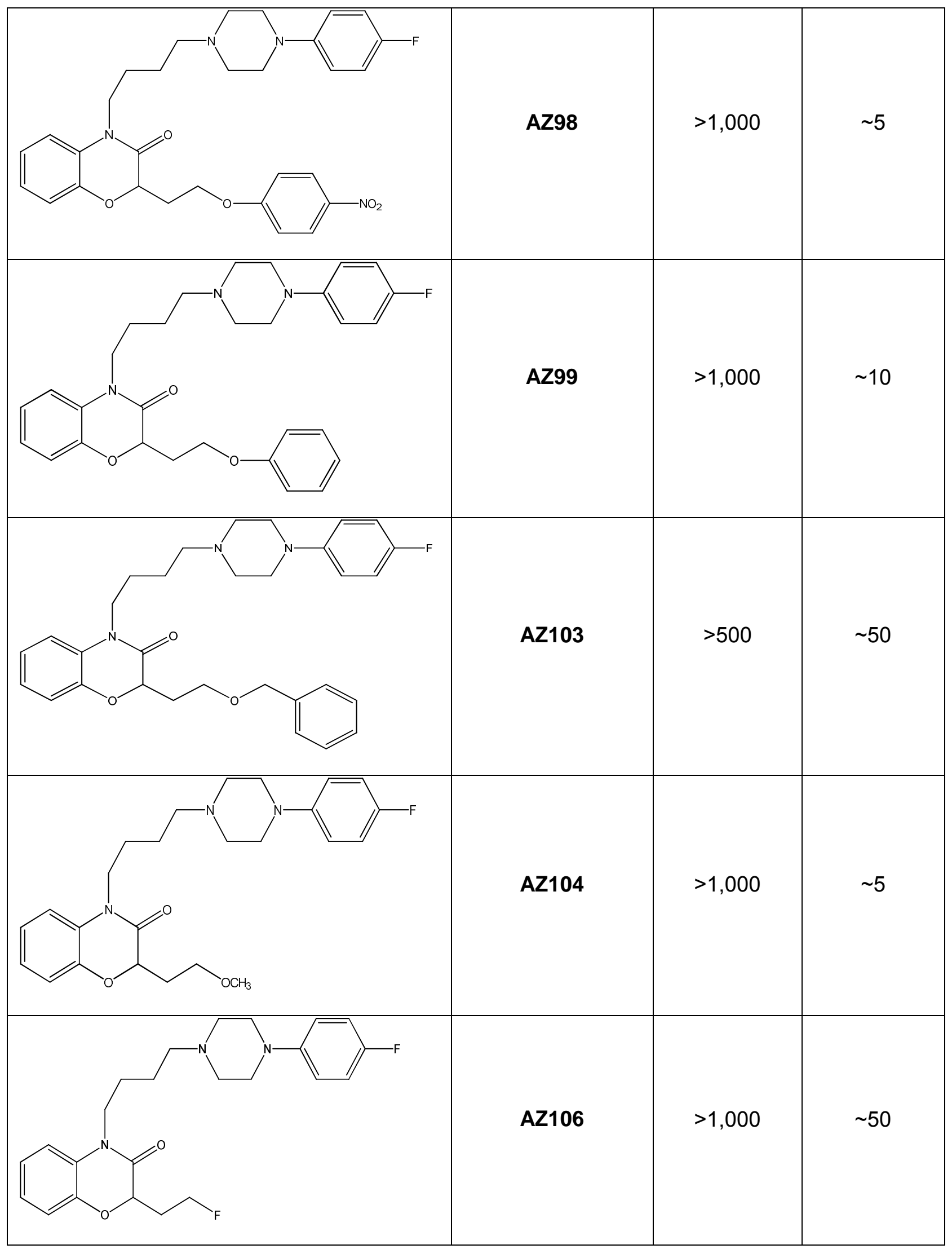




\begin{tabular}{|c|c|c|c|c|}
\hline & $>10$ \\
\hline
\end{tabular}




\begin{tabular}{|l|l|l|l|}
\hline & MES71.2 & $26.7 \pm 1.4$ & $3.0 \pm 0.1$ \\
\hline
\end{tabular}

Affinities $\left(\mathrm{K}_{\mathrm{i}}\right.$ in $\left.\mathrm{nM}\right)$ were determined in tissue or cell homogenates. The values in this table represent the mean + S.E.M. from replicate assays. Values of $>10,000$ signify that there was less than $30 \%$ displacement of the radioligand at that concentration.

3.3.2 In Vitro Metabolism Studies. The in vitro half-life of CM156 and four other CM156 analogs that demonstrated high sigma receptor binding affinity with desirable structural modifications were evaluated in rat liver microsomes. AZ66 displayed the longest half life (115.6 min), significantly longer than its parent compound CM156 (4.6 min).

Table 2.2. In vitro half-life ( $\mathrm{min}$ ) in liver microsomes, prepared from rat, of CM156 and redesigned analogs

\begin{tabular}{|c|c|}
\hline Compound & Half-life \\
\hline CM156 & 4.6 \\
\hline AZ57 & 68.0 \\
\hline AZ66 & 115.6 \\
\hline AZ68 & 47.1 \\
\hline AZ77 & 14.8 \\
\hline
\end{tabular}


3.3.3 In Vivo Metabolism Studies. Based on the in vitro metabolism results, coupled with the binding affinity and chemical structure, AZ66 was evaluated in vivo. Similar to the in vitro results, AZ66 was found to have a significantly longer half-life in vivo when compared with CM156 (Table 3). Additionally, the pharmacokinetic parameters associated with oral dosing of AZ66 (20 mg/kg) was shown to have a drugable-like profile (Table 4).

Table 2.3. In vivo half-life ( $\mathrm{min}$ ) of CM156 (5 mg/kg, i.v.) and AZ66 (2.5 mg/kg, i.v.) evaluated in blood samples from male, Sprague Dawley rats

\begin{tabular}{|c|c|}
\hline Compound & Half-life \\
\hline CM156 & $65.2 \pm 4.1$ \\
\hline AZ66 & 129.2 \\
\hline
\end{tabular}

Table 2.4. Pharmacokinetic profile of AZ66 (20 mg/kg, p.o.)evaluated in blood samples from male, Sprague Dawley rats

\begin{tabular}{|c|c|}
\hline Parameter & Value \\
\hline Area under the curve (AUC) & $158.22 \pm 2.79 \mu \mathrm{g}-\mathrm{h} / \mathrm{ml}$ \\
\hline Half life, $\mathrm{T}_{1 / 2}$ & $8.79 \pm 0.10 \mathrm{~h}$ \\
\hline Maximum concentration, $\mathrm{C}_{\max }$ & $0.30 \pm 0.02 \mu \mathrm{gg} / \mathrm{ml}$ \\
\hline Mean residence time & $8.82 \pm 0.24 \mathrm{~h}$ \\
\hline Volume of distribution, $\mathrm{V}_{\mathrm{d}}$ & $78.06 \pm 0.85 \mathrm{l} / \mathrm{kg}$ \\
\hline $\begin{array}{c}\text { Apparent oral clearance at } \\
\text { steady state, } \mathrm{Cl}_{\mathrm{ss}} / \mathrm{F}\end{array}$ & $6.15 \pm 0.11 \mathrm{l} / \mathrm{h} / \mathrm{kg}$ \\
\hline $\begin{array}{c}\text { Time to reach maximum } \\
\text { concentration, } \mathrm{T}_{\max }\end{array}$ & $2.00 \pm 0.22 \mathrm{~h}$ \\
\hline Oral bioavailability & $58.17 \%$ \\
\hline
\end{tabular}

\subsection{Discussion}

CM156 was previously shown to have significant neuroprotective effects against methamphetamine. However, due to a poor metabolic profile, further studies using CM156 were halted. In an effort to maintain CM156's protective profile while increasing its metabolic stability, a series of compounds were designed, synthesized, and tested for their binding affinity at sigma-1 and sigma-2 receptors in addition to their in vitro and in vivo half life. The results presented herein demonstrate several modifications made to enhance metabolic stability have 
no effect on sigma receptor binding affinity and can provide an increase in half-life compared to CM156. Furthermore, we have identified a lead compound, AZ66 which displays a drugable-like pharmacokinetic profile.

Development of a novel therapeutic to treat the effects of methamphetamine has remained largely unsuccessful to date. As previous studies have demonstrated (Matsumoto et al., 2008; Kaushal et al., 2011; Seminerio et al., 2011), sigma receptors appear to represent a logical target for pharmacological intervention. Limitations, including the present metabolic issue, have inhibited the evaluation of any sigma receptor ligand against methamphetamine in later drug developmental studies. This study, aimed at developing a lead metabolically stable compound, also provides valuable insight into structure activity relationship (SAR) for sigma receptor compounds. While the effects of AZ66 against methamphetamine-induced complications will be the ultimate endpoint, it is important to recognize the functional groups modified and their impact pharmacologically.

There were four major modifications made, deemed R1, R2, X, and n. Methyl groups were added at R1 to prevent $\mathrm{N}$-dealkylation while a fluoride group (R2),previously shown to

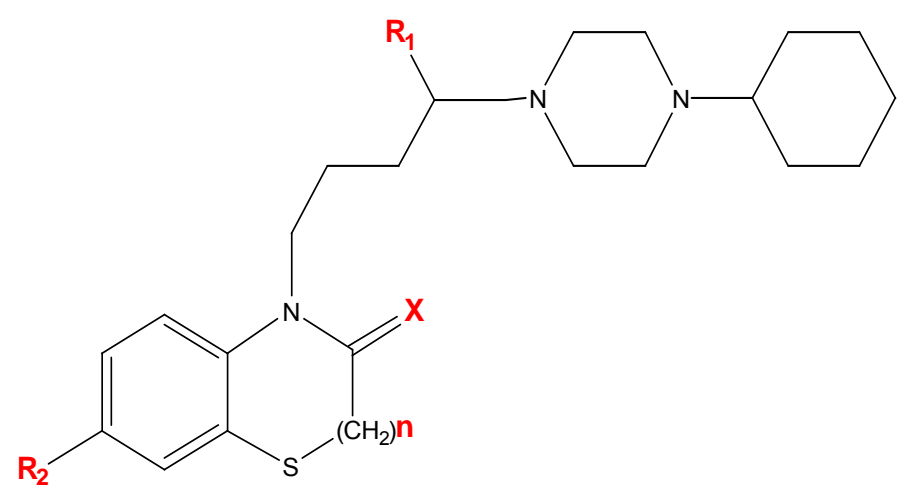
enhance sigma selectivity, was included to increase the electronegativity of the structure (the same was true for sulfur being substituted for oxygen at "X"). Increased electronegativity was highly desired because previous studies have demonstrated a strong link between the electronegativity of a structure and its biological stability (Barnette, 1984). The size of functional groups, particularly 5 and 6 member rings have significant effects on stability as well. Therefore, the size of the benzothiazole ring was adjusted from a 5 member ring to a 6 . Of the four major modifications, adjusting the ring size had the greatest effect on sigma binding affinity. AZ60 and AZ57 differ only by the size of the 
benzothiazole ring yet AZ57 has a 10 fold higher affinity for sigma-1 receptors compared to AZ60. Other analogs that incorporated minor changes along with an increased ring size displayed sigma-1 binding affinities in the micromolar range (AZ93, AZ97, AZ98, AZ99, AZ104). No significant difference in binding affinity was observed when " $X$ " had sulfur exchanged for oxygen, a more electronegative element. However, as the MES compounds demonstrated, substitution of oxygen for sulfur in the benzothiazole ring can actually reduce sigma-1 receptor binding affinity. Similar to previous studies (Berardi et al., 2004), our results demonstrate that cyclohexylpiperazine and benzo[d]thiazole are important for sigma receptor binding affinity. Furthermore, the addition of a methyl and fluoride group can provide stability and may prevent early metabolic breakdown.

AZ66 displayed the longest half-life both in vitro and in vivo when compared to three other analogs and the parent compound CM156. In addition, AZ66 maintained subnanomolar affinities at sigma-1 and sigma-2 receptors. These findings are important as modifying CM156 for metabolic stability had no effect on its binding profile yet displayed a more favorable pharmacokinetic profile when compared to CM156. The modifications made to AZ66, which included the addition of a methyl group at R1, coupled with a fluoride at R2 and the exchange of sulfur for oxygen, appear to provide the greatest likelihood of developing a novel sigma receptor ligand aimed at mitigating the effects of methamphetamine.

\subsection{Contributions}

Michael Seminerio performed all of the receptor binding experiments.

CM156 and its analogs were synthesized by Dr. Christophe Mésangeau and Ahmed Abdelazeem in Dr. Christopher R. McCurdy's lab at University of Mississippi.

National Institute of Drug Abuse (NIDA) gratuitously performed the in vitro metabolism studies.

Dr. Bonnie Avery at the University of Mississippi performed the in vivo metabolism studies. 
CHAPTER 3

\section{EVALUATION OF AZ66 AGAINST THE BEHAVIORAL EFFECTS OF METHAMPHETAMINE}




\subsection{Introduction}

Methamphetamine is currently one of the most abused illicit substances worldwide (Cadet and Krasnova, 2009; Romanelli and Smith, 2006). It is a highly addictive psychostimulant whose acute effects include hyperthermia, hypertension, severe cardiac pathologies, and potential convulsions(Cadet and Krasnova, 2009; Lan et al., 1998). Prolonged abuse of methamphetamine can result in significant neurological changes that lead to addiction, drug seeking behavior, and eventual drug dependence(Cadet and Krasnova, 2009; Lan et al., 1998; Romanelli and Smith, 2006; Volkow et al., 2001b). Currently, there is a lack of medications designed to treat either the detrimental physiologic effects of methamphetamine or the addiction liability associated with its use. There have been a substantial amount of clinical trials conducted with drug candidates aimed at treating the addictive properties of methamphetamine; however at this time there are still no FDA approved pharmacotherapies for methamphetamine dependence (Karila et al., 2010). Innovative strategies are essential for the development of pharmaceutical agents intended to treat the negative effects of methamphetamine abuse.

Sigma receptors represent a novel target for the development of new therapeutics intended to treatmethamphetamine-induced effects. There are currently two known subtypes of sigma receptors, designated sigma-1 and sigma-2. Sigma-1 receptors are 223 amino acid proteins that are distinct from any other known mammalian protein (Hanner et al., 1996). Sigma1 receptors have been cloned and have a high level of homology among differing species (Hanner et al., 1996). They can translocate between intracellular compartments where they are able to modulate signaling pathways and intracellular calcium signaling, interact with specific ion channels, and affect neurotransmitter synthesis, release, and reuptake (Aydar et al., 2002; Bergeron et al., 1993; Booth and Baldessarini, 1991; Gronier and Debonnel, 1999; Hayashi et al., 2000; Hayashi and Su, 2003, 2007). Much less is known about sigma-2 receptors, as these receptors have yet to be cloned and truly selective sigma-2 receptor ligands are currently 
lacking. Sigma-2 receptors are believed to be involved in cellular survival and modulate calcium signaling through sphingolipid products (Crawford and Bowen, 2002; Crawford et al., 2002; Vilner and Bowen, 2000; Vilner et al., 1995a).

Methamphetamine, in addition to interacting with monoamine transporters, interacts with both subtypes of sigma receptors at physiologically relevant concentrations (Nguyen et al., 2005). Repeated administrations of methamphetamine have been shown to increase binding of the sigma receptor ligand $\left[{ }^{3} \mathrm{H}\right](+)$-pentazocine in the frontal cortex, substantia nigra and cerebellum, indicative of an increase in sigma receptors in these regions of the brain(Itzhak, 1993). Notably, sigma-1 receptor protein or mRNA was upregulated in the midbrain and the hippocampus of rats trained to self-administer methamphetamine(Hayashi et al., 2010). These studies provide evidence that sigma receptors may, in part, be involved in the neuroadaptive changes that occur with repeated methamphetamine exposures.

The methamphetamine-induced changes in sigma receptor expression levels appear to have functional and behavioral consequences. Two different sigma receptor antagonists, MS377 ((R)-(+)-1-(4-chlorophenyl)-3-[4-(2-methoxyethyl)piperazin-1-yl]methyl-2-pyrrolidinone Ltartrate) and BMY 14802 ( $\alpha$-(4-flourophenyl)-4-(5-flouro-2-pyrimidinyl)-1-piperazine), have been shown to prevent augmented responses to repeated methamphetamine administrations in rodents, using a paradigm known as behavioral sensitization(Takahashi et al., 2000; Ujike et al., 1992). However, both of these compounds are unable to attenuate acute methamphetamineinduced behaviors (Takahashi et al., 2000; Ujike et al., 1992). Additionally, the selective sigma receptor antagonists BD1047([2-(3,4-dichlorophenyl)ethyl]-N-methyl-2-(diamino)ethylamine), BD1063(1-[2-(3,4-dichlorophenyl)ethyl]-4-methylpiperazine) and AC927 (1-(2phenethyl)piperidine oxalate), have been shown to attenuate many acute effects of methamphetamine, including methamphetamine-induced increases in locomotor activity and hyperthermia in rodent models (Seminerio et al., 2011a). These studies indicate that a selective sigma receptor ligand may attenuate some of the acute effects of methamphetamine 
administration in addition to preventing the neurological and behavioral changes associated with repeated methamphetamine exposures. It is yet to be determined as to whether a preferential sigma receptor ligand can actually reverse, in addition to prevent, the behavioral changes associated with methamphetamine-induced behavioral sensitization.

The purpose of the present study was to determine if the preferential sigma receptor ligand, AZ66 (3-(4-(4-cyclohexylpiperazin-1-yl)pentyl)-6-flourobenzo[d]thiazol-2(3H)-one), is able to attenuate the acute behavioral effects of methamphetamine and in addition, prevent the development and block the expression of methamphetamine-induced behavioral sensitization. AZ66 is an optimized sigma receptor ligand derived from a previously studied selective sigma receptor antagonist, CM156 (3-(4-(4-cyclohexylpiperazin-1-yl)butyl)benzo[d]thiazole-2(3H)thione) that has been reported to attenuate many cocaine-induced behaviors (Xu et al., 2010). Further drug development of CM156 was halted due to an exceedingly short half-life (Xu et al., 2010), and AZ66 was synthesized to avoid the metabolism issues associated with CM156. Herein, we report that AZ66, a novel sigma receptor preferring ligand, is capable of being administered orally, and attenuates many methamphetamine-induced behaviors, including the development and expression of behavioral sensitization.

\subsection{Materials and Methods}

3.2.1 Drugs and Reagents. Methamphetamine hydrochloride was obtained from SigmaAldrich (St. Louis, MO). Radioligands for binding studies were purchased from Perkin Elmer (Boston, MA). Other chemicals used for the radioligand binding studies were obtained from standard commercial sources (Sigma-Aldrich, St. Louis, MO).

3.2.2 Animals. Male, Swiss Webster mice (21-30 g, Harlan, Indianapolis, IN; Frederick, MD) were used in the present experiments. The mice were housed in groups of 4-6 with a 12:12-h light/dark cycle and ad libitum food and water. Each cage was made from polysulfone 
and provided $542 \mathrm{~cm}^{2}$ of floor space (Tecniplast, Philadelphia, PA), which was covered with corn cob bedding and packing material (ULINE, Waukegan, IL). The mice were acclimated for one week before being used in experiments and they were randomly assigned to their treatment groups. Two different shipments of mice were used for each experimental group, regardless of the sample size. All procedures were performed as approved by the Institutional Animal Care and Use Committees at the West Virginia University Health Sciences Center and the University of Mississippi.

3.2.3 Radioligand Binding Studies. The radioligand binding assays were preformed in rat brain homogenates using methods previously described in detail (Matsumoto et al., 1995; Matsumoto et al., 2008). Briefly, sigma-1 receptors were labeled with $5 \mathrm{nM}\left[{ }^{3} \mathrm{H}\right](+)$-pentazocine and sigma-2 receptors were labeled with $3 \mathrm{nM}\left[{ }^{3} \mathrm{H}\right]$ di-o-tolylguanidine (DTG)in the presence of $300 \mathrm{nM}(+)$-pentazocine to block sigma-1 receptors. Nonspecific binding was determined in the presence of $10 \mu \mathrm{M}$ haloperidol. All of the assays were terminated with the addition of ice-cold buffer and rapid vacuum filtration over glass fiber filters. Separate synthetic batches of AZ66 were used in this study and their $\mathrm{K}_{\mathrm{i}}$ values were averaged together to obtain a mean binding affinity.

3.2.4 Locomotor Activity. Locomotor activity was measured as an index of the stimulant effects of methamphetamine using an automated activity monitoring system (San Diego Instruments, San Diego, CA). The mice were given 30-60 min to acclimate to the testing room before being habituated to the testing chambers for an additional $30 \mathrm{~min}$. Each testing chamber consisted of a $16 \times 16$ photobeam array to detect lateral movements and a separate 16 photobeam array to detect rearing by the animals. Ambulatory, fine, and rearing movements were quantified to give an overall locomotor activity score. 
Mice $(n=24)$ were divided randomly into four treatment groups for the dose response study. They received a pretreatment of saline 15 min prior to a dose of methamphetamine (0.1$5.0 \mathrm{mg} / \mathrm{kg}$, i.p.). The mice were then returned to the testing chambers and their activity was quantified for $30 \mathrm{~min}$.

For the acute locomotor studies, mice $(n=65)$ were randomly assigned into a treatment group and pretreated with either saline or AZ66 (0-20 mg/kg, i.p), followed 15 min later by either saline or a stimulant dose of methamphetamine $(1 \mathrm{mg} / \mathrm{kg}$, i.p.). The mice were then returned to the testing chambers and their activity was quantified for the next $30 \mathrm{~min}$. The evaluation of AZ66 in combination with saline or methamphetamine allowed the determination of the effects of AZ66 alone, as well as its ability to mitigate the stimulant actions of methamphetamine.

For the oral administration studies, mice $(n=42)$ were pretreated by oral gavage (p.o.) with either distilled water $(0.1 \mathrm{ml} / 10 \mathrm{~g})$ or AZ66(20-30 $\mathrm{mg} / \mathrm{kg})$ and locomotor activity was recorded for 30 min after receiving an i.p. injection of either a stimulant dose of methamphetamine $(1 \mathrm{mg} / \mathrm{kg})$ or saline $(0.1 \mathrm{ml} / 10 \mathrm{~g})$. Pretreatment time was $120 \mathrm{~min}$, based on the pharmacokinetic parameters $\left(T_{\max }\right)$ of AZ66.

3.2.5 Behavioral Sensitization. The mice were acclimated to the treatment room for 60 min and then individually to a testing chamber for 30 min on each day. Locomotor activity was monitored on Days 1, 2, 3, 4, 5, 6, 7 and 15 for 30 min immediately after the treatments by using an automated activity monitoring device (San Diego Instruments, San Diego, CA).

For the dose response study, mice $(n=12)$ were randomly assigned to one of four treatment groups. On Days 1-7, mice received saline pretreatment followed 15 min later by either saline or methamphetamine $(0.1,0.5$, or $1 \mathrm{mg} / \mathrm{kg}$, i.p. $)$. After an 8-day drug-free period, which allowed the drugs and their metabolites to be washed out, mice were administered either saline or methamphetamine $(0.1,0.5,1 \mathrm{mg} / \mathrm{kg}$, i.p. $)$. 
For the development of sensitization studies, mice $(n=36)$ were randomly assigned to one of six treatment groups as shown in Table 1 and injected i.p. once a day for seven consecutive days. The two injections making up each treatment were separated by a 15 min pretreatment period; the dose of methamphetamine used was $1 \mathrm{mg} / \mathrm{kg}$. Treatments on Days 1 to 7 were followed by an 8-day drug-free period, and then all of the mice were challenged on Day 15 with methamphetamine (1 mg/kg i.p.).

For the expression of sensitization studies, mice $(n=42)$ were randomly assigned to one of six treatment groups as shown in Table 1and injected once a day (i.p.) for seven consecutive days with either saline or methamphetamine (1 mg/kg, i.p.). After an 8-day drug-free period, pretreatment with AZ66 (10-20 mg/kg, i.p.) or saline was administered 15 min prior to methamphetamine $(1 \mathrm{mg} / \mathrm{kg}$, i.p.).

3.2.6 Data Analyses. The data from the radioligand binding assays were analyzed using GraphPad Prism 4.0 (San Diego, CA) to calculate $I_{50}$ values. Apparent $\mathrm{K}_{\mathrm{i}}$ values were then calculated using the Cheng-Prusoff equation and $\mathrm{K}_{d}$ values determined in separate saturation assays(Cheng and Prusoff, 1973). The data from the acute locomotor activity measurements, development and expression of sensitization studies were analyzed using GraphPad Prism 4.0 (San Diego, CA) using an analysis of variance (ANOVA). Significant ANOVAs were followed by post-hocDunnett's tests for comparisons to control or Bonferroni's tests for pairwise comparisons. $p<0.05$ was considered statistically significant for all behavioral tests.

Table 3.1. Treatment schedule for sensitization experiments

A. Development of sensitization

\begin{tabular}{|c|c|c|c|}
\hline Group & Day 1-7 & Day 8-14 & Day 15 \\
\hline 1 & Sal + Sal & NT & Sal + Meth \\
\hline
\end{tabular}




\begin{tabular}{|c|c|c|c|}
\hline 2 & Sal + Meth & NT & Sal + Meth \\
\hline 3 & AZ66 $(10 \mathrm{mg} / \mathrm{kg})+$ Meth & NT & Sal + Meth \\
\hline 4 & AZ66 $(20 \mathrm{mg} / \mathrm{kg})+$ Meth & NT & Sal + Meth \\
\hline 5 & AZ66 $(10 \mathrm{mg} / \mathrm{kg})+$ Sal & NT & Sal + Meth \\
\hline 6 & AZ66 $(20 \mathrm{mg} / \mathrm{kg})+$ Sal & NT & Sal + Meth \\
\hline
\end{tabular}

B. Expression of sensitization

\begin{tabular}{|c|c|c|c|}
\hline Group & Day 1-7 & Day 8-14 & Day 15 \\
\hline 1 & Sal + Sal & NT & Sal + Meth \\
\hline 2 & Sal + Sal & NT $(10 \mathrm{mg} / \mathrm{kg})+$ Meth \\
\hline 3 & Sal + Sal & NT & AZ $(20 \mathrm{mg} / \mathrm{kg})+$ Meth \\
\hline 4 & Sal + Meth & NT & Sal + Meth \\
\hline 5 & Sal + Meth & NT & AZ $(10 \mathrm{mg} / \mathrm{kg})+$ Meth \\
\hline 6 & Sal + Meth & NT & AZ $(20 \mathrm{mg} / \mathrm{kg})+$ Meth \\
\hline
\end{tabular}

$n=6-10 /$ group. $\mathrm{NT}=$ no treatment. Meth = methamphetamine $(1 \mathrm{mg} / \mathrm{kg}) ;$ Sal = saline; AZ = AZ66.

All compounds were administered intraperitoneally.

\subsection{Results}

3.3.1 Competition Binding Assays. The average binding affinities of AZ66 for sigma-1 and sigma-2 receptors, in addition to seven other sites are listed in Table 3.2. AZ66 bound to both sigma-1 and sigma-2 receptors with nanomolar affinities (batch 1 had a sigma-1 affinity of $1.20 \pm 0.15 \mathrm{nM}$ and a sigma-2 affinity of $0.31 \pm 0.09 \mathrm{nM}$; batch 2 had a sigma-1 affinity of $3.50 \pm$ $0.13 \mathrm{nM}$ and a sigma-2 affinity of $0.66 \pm 0.15 \mathrm{nM})$. In addition, AZ66 had a $>200$ fold preference for sigma receptors compared to the other sites tested. However, AZ66 displayed a moderate to low affinity for the serotonin transporter, serotonin $\left(5-\mathrm{HT}_{2}\right)$ receptor, dopamine $\left(\mathrm{D}_{2}\right)$ receptor, and dopamine transporter. 
Table 3.2 Binding affinities of AZ66 for sigma receptors, monoamine transporters, and non-sigma sites

\begin{tabular}{|c|c|c|c|c|}
\hline \multicolumn{3}{|c|}{ Nonspecific binding } & & \\
\hline \multicolumn{5}{|c|}{ Sigma receptors: } \\
\hline$\sigma_{1}$ & $\left.5 \mathrm{nM} \mathrm{[}{ }^{3} \mathrm{H}\right](+)$-pentazocine & $10 \mu \mathrm{M}$ haloperidol & Rat brain & $2.4 \pm 0.63$ \\
\hline$\sigma_{2}$ & $3 \mathrm{nM}\left[{ }^{3} \mathrm{H}\right]$ di-o-tolylguanidine & $10 \mu \mathrm{M}$ haloperidol & Rat brain & $0.51 \pm 0.15$ \\
\hline \multicolumn{5}{|c|}{ Monoamine transporters: } \\
\hline Dopamine & $0.5 \mathrm{nM}\left[^{3} \mathrm{H}\right] \mathrm{WIN} 35,428$ & $50 \mu \mathrm{M}$ cocaine & Rat striatum & $872 \pm 122$ \\
\hline Serotonin & $0.2 \mathrm{nM}\left[{ }^{3} \mathrm{H}\right]$ paroxetine & $1.5 \mu \mathrm{M}$ imipramine & Rat brainstem & $612 \pm 44$ \\
\hline Norepinephrine & $0.5 \mathrm{nM}\left[{ }^{3} \mathrm{H}\right]$ nisoxetine & $4 \mu \mathrm{M}$ desipramine & Rat cerebral cortex & $>10,000$ \\
\hline \multicolumn{5}{|c|}{ Non-sigma sites: } \\
\hline Opioid & $1 \mathrm{nM}\left[{ }^{3} \mathrm{H}\right]$ naloxone & $1 \mu \mathrm{M}$ naloxone & Rat brain & $>10,000$ \\
\hline $5-\mathrm{HT} 2$ & $2 \mathrm{nM}\left[{ }^{3} \mathrm{H}\right]$ ketanserin & $1 \mu \mathrm{M}$ mianserin & Rat brain & $535 \pm 51$ \\
\hline Dopamine (D2) & $\left.5 \mathrm{nM} \mathrm{[}{ }^{3} \mathrm{H}\right](-)$-sulpiride & $1 \mu \mathrm{M}$ haloperidol & Rat brain & $1183 \pm 272$ \\
\hline NMDA/PCP & $\left.5 \mathrm{nM} \mathrm{[}{ }^{3} \mathrm{H}\right] \mathrm{TCP}$ & $10 \mu \mathrm{M}$ cyclazocine & Rat brain & $>10,000$ \\
\hline
\end{tabular}

Affinities $\left(\mathrm{K}_{\mathrm{i}}\right.$ in $\left.\mathrm{nM}\right)$ were determined in rat brain. The values in this table represent the mean \pm S.E.M. from replicate assays. $\mathrm{NMDA}=\mathrm{N}$-Methyl-D-aspartic acid; $\mathrm{PCP}=$ Phencyclidine; $\mathrm{TCP}=$ Tenocyclidine.

\subsubsection{Locomotor Activity. Methamphetamine produced an inverted U-shaped dose}

response for locomotor activity (Fig. 3.1A); peak locomotor stimulant effects were observed at 1 $\mathrm{mg} / \mathrm{kg}$, which was thereafter administered as the challenge dose of methamphetamine for all further studies. One way ANOVA confirmed that the differences between methamphetamine doses were statistically significant $(F(4,29)=10.92, p<0.0001)$. Post-hoc analysis using Dunnett's 
multiple comparison tests revealed that three doses of methamphetamine $(0.5,1.0,5.0 \mathrm{mg} / \mathrm{kg}$, i.p.) were significantly different from the saline control (Fig. 3.1A).

Pretreatment with AZ66 prior to a stimulant dose of methamphetamine significantly attenuated methamphetamine-induced hyperactivity (Fig. 3.1B). One way ANOVA confirmed a significant difference between treatment groups $(F(4,46)=12.81, p<0.0001)$. Post-hoc analysis using Bonferroni's multiple comparison tests revealed a significant attenuation of methamphetamine-induced hyperactivity at two doses of AZ66 (10 and $20 \mathrm{mg} / \mathrm{kg}$, i.p.). In the absence of methamphetamine, AZ66 had no significant effect on locomotor activity (Fig. 3.1B).

To further evaluate the drug-like characteristics of AZ66, oral administration studies were conducted (Fig. 3.1C). One way ANOVA confirmed that there was a significant difference between all treatment groups $(F(5,41)=19.01, p<0.0001)$. Post-hoc analysis using Bonferroni's multiple comparison tests revealed a significant attenuation of methamphetamine-induced hyperactivity at both doses of AZ66 (20 and $30 \mathrm{mg} / \mathrm{kg}$, p.o.). Similar to the i.p. studies, AZ66 displayed no significant effects in the absence of methamphetamine compared to saline-treated mice (Fig. 3.1C).
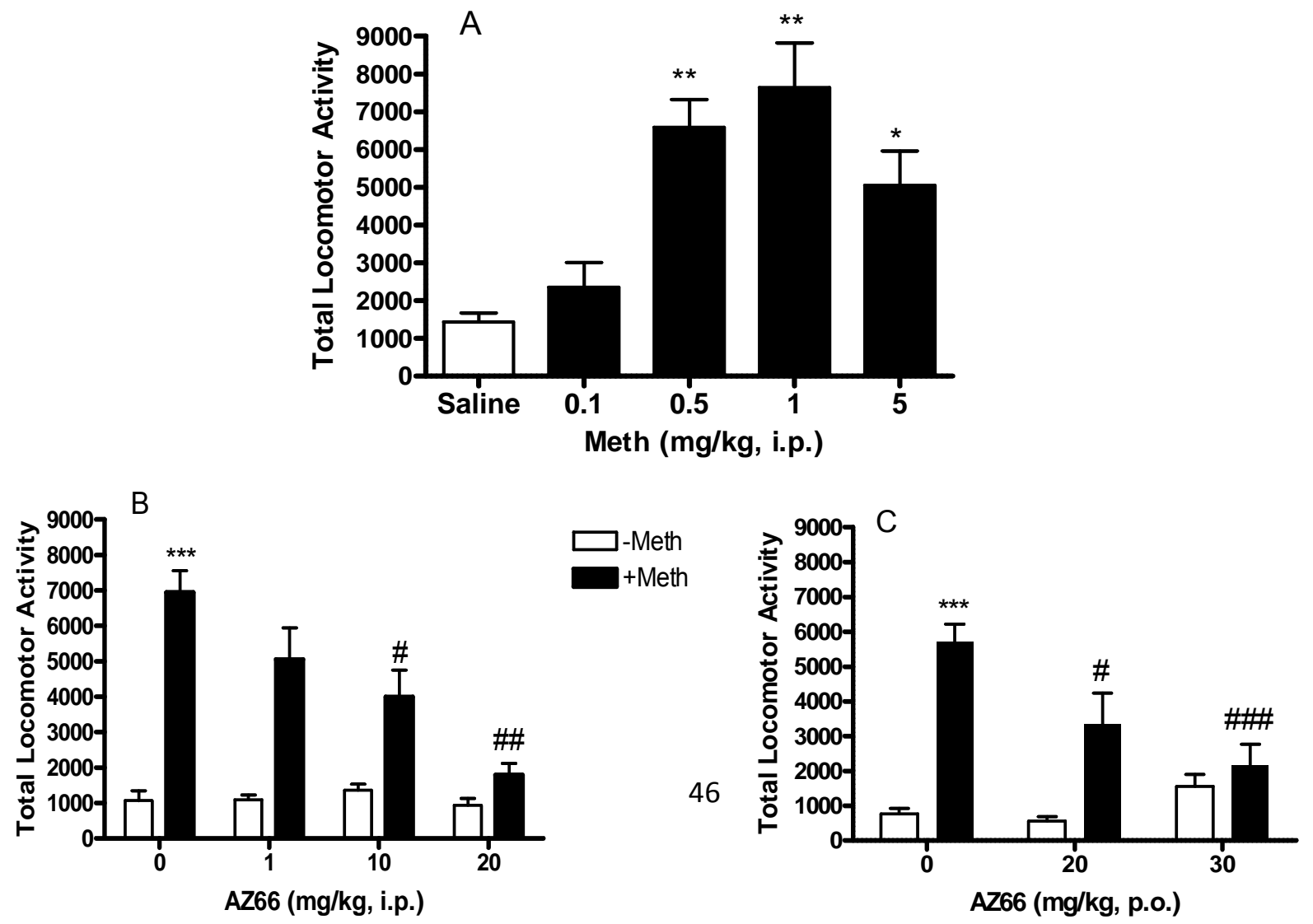
Figure3.1. The effects of methamphetamine and AZ66 on locomotor activity. (A) Dose dependent effects of methamphetamine on basal locomotor activity. Male, Swiss Webster mice ( $n=6$ per group) were injected with saline or methamphetamine (Meth, $0.1,0.5,1.0,5 \mathrm{mg} / \mathrm{kg}$, i.p.) and their activity was quantified for $30 \mathrm{~min}$.

Methamphetamine caused an inverted dose response on locomotor activity. Data are reported as mean \pm SEM. ${ }^{*} p<0.05,{ }^{* *} p<0.01$ vs. saline, post-hoc Dunnett's test. (B) Effects of AZ66 on locomotor activity following methamphetamine treatment. Male, Swiss Webster mice ( $n=6-10$ per group) were pretreated with saline or AZ66 (1, $10,20 \mathrm{mg} / \mathrm{kg}$, i.p.) $15 \mathrm{~min}$ prior to saline (white bars) or methamphetamine (1 mg/kg, i.p., black bars) administration. AZ66 significantly attenuated the locomotor stimulant effects of methamphetamine. Data are reported as mean \pm SEM. ${ }^{* * *} p<0.001$ vs. saline; $\# p<0.05$, \#\#p<0.01 vs. Meth, post-hoc Tukey's test. (C) Effects of orally administered AZ66 on methamphetamine-induced increases in locomotor activity. Mice ( $n=6-10$ per group) pretreated with oral administration of distilled water ( $0 \mathrm{mg} / \mathrm{kg} \mathrm{AZ66)}$ were challenged (i.p.) with either a stimulant dose of methamphetamine (1 mg/kg, i.p., +Meth, black bars) or saline (-Meth, white bars); all other animals pretreated with oral dosing with AZ66 (20-30 mg/kg) were challenged with methamphetamine (1 mg/kg, i.p., black bars) or saline (Meth, white bars). Animals received distilled water or AZ66 120 min prior to methamphetamine administration. Methamphetamine-induced increases in locomotor activity were significantly attenuated by pretreatment with 20 and $30 \mathrm{mg} / \mathrm{kg}$, p.o. AZ66. Data are reported as mean \pm SEM. ${ }^{* * *} p<0.001$ vs. saline; $\# p<0.05, \# \# \# p<0.001$ vs. Meth, posthoc Tukey's test.

\subsubsection{Behavioral Sensitization. When a dose response experiment was conducted to} determine the optimal dose of methamphetamine needed to produce behavioral sensitization (Fig. 3.2), methamphetamine dose-dependently increased locomotor activity on Days 1-7, and remained significantly higher on the challenge day (Day 15) when compared to Day 1. ANOVA confirmed a significant difference between the experimental groups on all of the treatment days $(F(3,31)=162, p<0.0001)$. Repeated administration of methamphetamine on Days 1-7 resulted in behavioral sensitization, which was measured as an enhanced response to methamphetamine on Day $15(0.5 \mathrm{mg} / \mathrm{kg}, q=2.94, p<0.05 ; 1.0 \mathrm{mg} / \mathrm{kg}, q=3.15, p<0.05 ;$ post hoc Dunnett's test).Based on the larger increases in total locomotor activity, $1 \mathrm{mg} / \mathrm{kg}$ of methamphetamine was used as the challenge dose in subsequent behavioral sensitization studies.

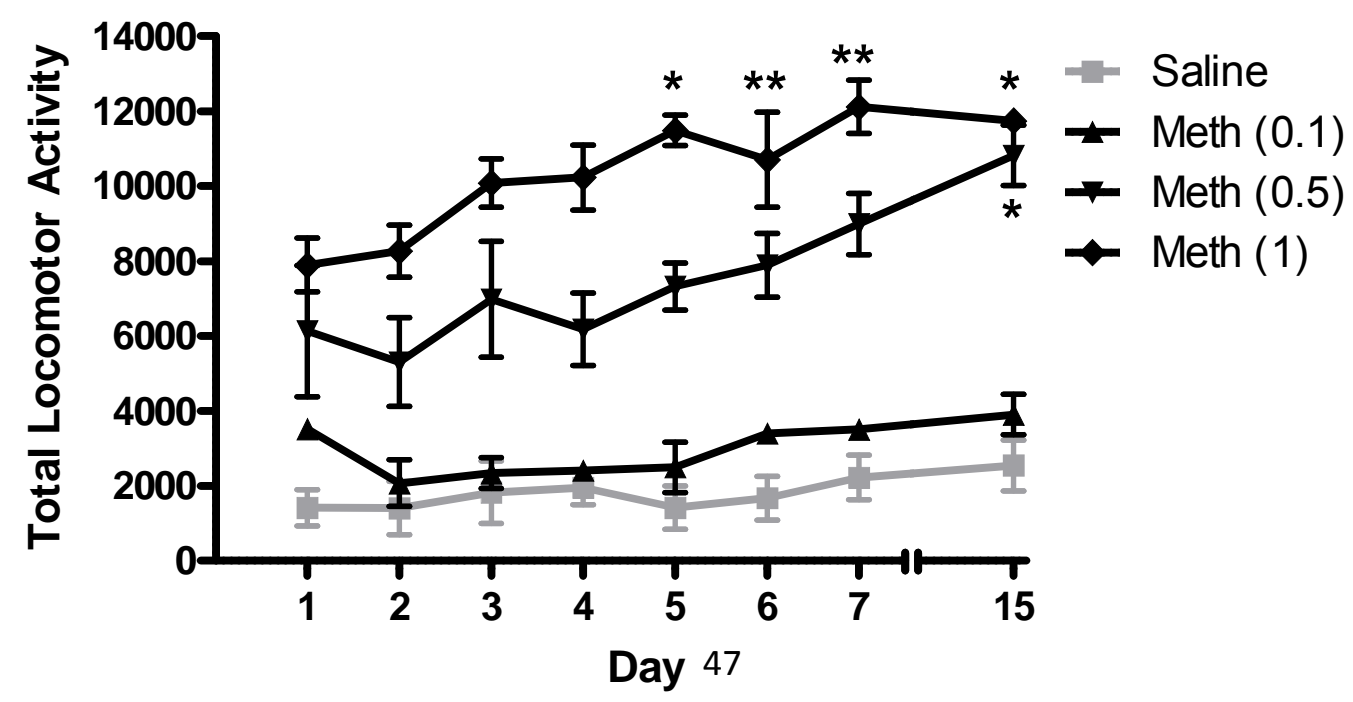


Figure 3.2. Dose dependent effects of methamphetamine on behavioral sensitization. Male, Swiss Webster mice $(n=12)$ were injected with saline or methamphetamine (Meth, $0.1,0.5,1 \mathrm{mg} / \mathrm{kg}$, i.p.) on Day 1-7. Following an 8day drug-free period, the animals were challenged with either saline or methamphetamine $(0.1,0.5,1 \mathrm{mg} / \mathrm{kg}$, i.p.) on Day 15. Repeated administration of methamphetamine $(0.5$ and $1 \mathrm{mg} / \mathrm{kg})$ on days $1-7$ resulted in behavioral sensitization on day 15. Data are reported as mean \pm SEM. ${ }^{*} p<0.05,{ }^{* *} p<0.01$ vs. Meth (Day 1 ), post-hoc Dunnett's tests.

\subsubsection{Development of Behavioral Sensitization. ANOVA demonstrated a significant} difference between the treatment groups on all treatment days: Day $1(F(5,35)=16.89$, $p<0.0001)$; Day $2(F(5,35)=43.95, p<0.0001)$; Day $3(F(5,35)=25.98, p<0.0001)$; Day 4 $(F(5,35)=27.30, p<0.0001) ;$ Day $5(F(5,35)=27.55, p<0.0001)$; Day $6(F(5,35)=25.21, p<0.0001)$; Day $7(F(5,35)=29.56, p<0.0001)$; and Day $15(F(5,35)=13.00, p<0.0001)$. Post-hoc Dunnett's test confirmed that methamphetamine-treated mice displayed a significantly higher locomotor activity in comparison to the saline-treated controls for Days 1-7. Additionally, with the exception of the methamphetamine-treated group that demonstrated an elevated locomotor response on Days 1-7, none of the other groups had significantly different locomotor activity as compared to the saline control group for any of the treatment days. Pretreatment with AZ66 (10 and 20 $\mathrm{mg} / \mathrm{kg}$, i.p.) before methamphetamine administration on Days 1-7 significantly attenuated methamphetamine-induced increases in locomotor activity compared to saline + methamphetamine treated mice. On the challenge day (Day 15), when each of the groups were administered methamphetamine, mice that received methamphetamine on Days 1-7 exhibited a significantly higher locomotor activity than mice that received saline on Days 1-7 $(t=7.22$, $p<0.001$ ), indicative of behavioral sensitization (Fig. 3.3). Mice that received AZ66 as a pretreatment to methamphetamine on Days 1-7 demonstrated a significantly lower locomotor count compared to mice who received saline prior to methamphetamine on Days 1-7: AZ66 10 $\mathrm{mg} / \mathrm{kg}(t=4.39, p<0.01)$, AZ66 $20 \mathrm{mg} / \mathrm{kg}(t=5.03, p<0.001)$ (Fig. 3.3). 


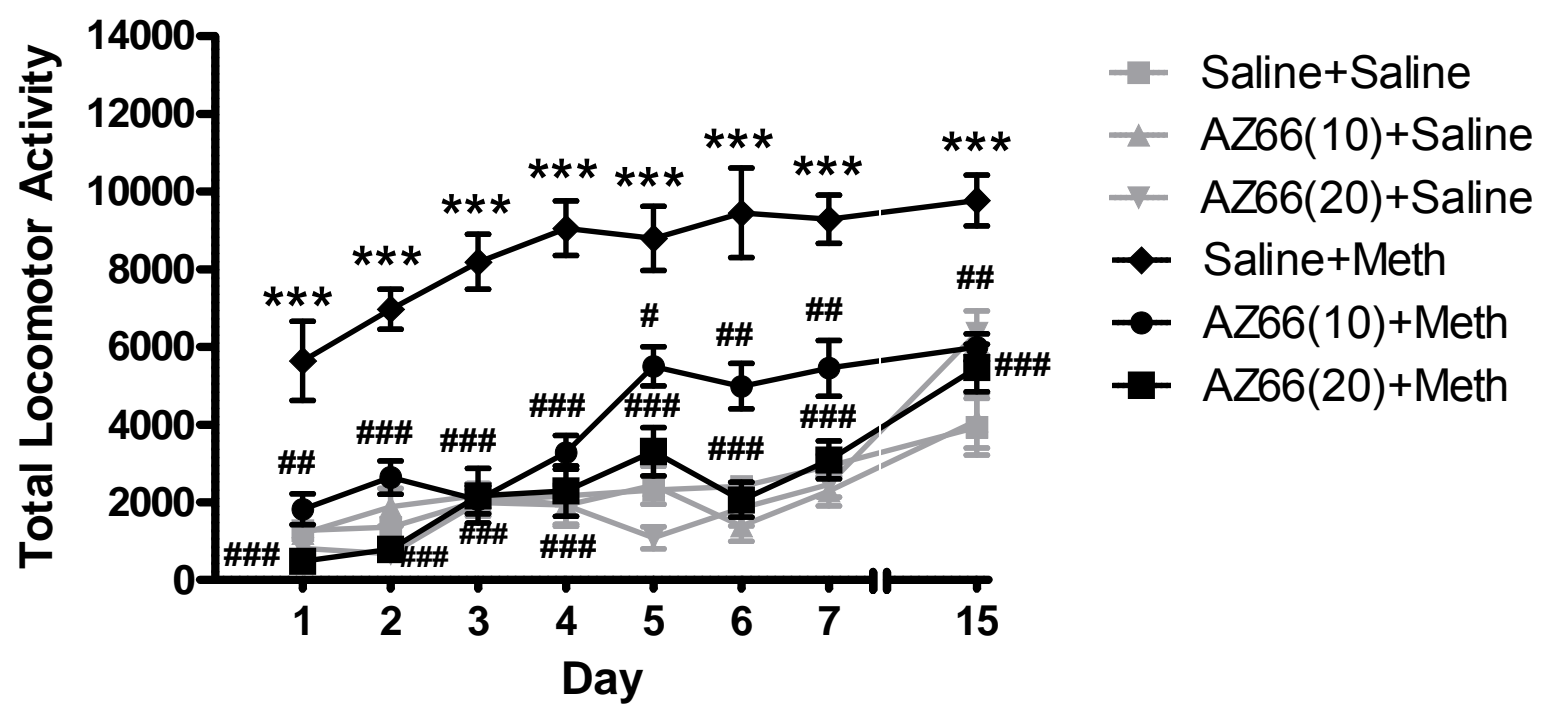

Figure3.3. Effects of AZ66 on the development of behavioral sensitization to methamphetamine. Male, Swiss Webster mice were injected (i.p.) with either saline or AZ66 (10 or $20 \mathrm{mg} / \mathrm{kg}$ ) followed $15 \mathrm{~min}$ later with either saline or methamphetamine (Meth, $1 \mathrm{mg} / \mathrm{kg}$ ) once a day for seven days. Following an 8-day drug-free period (Day 15), all of the mice were injected (i.p.) with saline, followed $15 \mathrm{~min}$ later with methamphetamine $(1 \mathrm{mg} / \mathrm{kg})$. Pretreatment with AZ66 (10 or $20 \mathrm{mg} / \mathrm{kg}$ ) on Days 1-7 significantly blocked the development of sensitization. Data are reported as

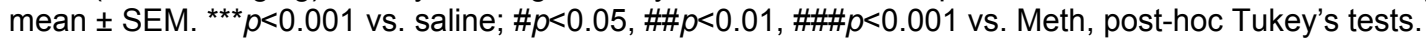

\subsubsection{Expression of Behavioral Sensitization. ANOVA confirmed a significant difference} between the methamphetamine-treated mice and saline-treated mice on Days 1-7: Day 1 $(F(5,41)=23.67, p<0.0001) ;$ Day $2(F(5,41)=43.07, p<0.0001)$; Day $3(F(5,41)=60.16, p<0.0001)$; Day $4(F(5,41)=54.48, p<0.0001)$; Day $5(F(5,41)=43.45, p<0.0001)$; Day $6(F(5,41)=36.70$, $p<0.0001)$; Day $7(F(5,41)=40.05, p<0.0001)$. On the challenge day (Day 15), there was still a significant difference between the treatment groups $(F(5,41)=25.34, p<0.0001)$, and pretreatment with AZ66 significantly attenuated hyperactivity in mice that were sensitized (methamphetamine treatments on Days 1-7). Post-hoc Bonferroni's tests confirmed that pretreatment with both doses of AZ66 prior to methamphetamine administration on Day 15 caused a significant attenuation of methamphetamine-induced hyperactivity in mice receiving saline on Days $1-7(10 \mathrm{mg} / \mathrm{kg}, t=4.03, p<0.01 ; 20 \mathrm{mg} / \mathrm{kg}, t=4.67, p<0.001)$ and mice receiving 
methamphetamine on Days $1-7(10 \mathrm{mg} / \mathrm{kg}, t=5.03, p<0.001 ; 20 \mathrm{mg} / \mathrm{kg}, t=6.75, p<0.001)$. AZ66 pretreatment also attenuated acute increases in mice only receiving methamphetamine on Day 15 (saline treatments on Days 1-7) $(10 \mathrm{mg} / \mathrm{kg}, t=6.15, p<0.001 ; 20 \mathrm{mg} / \mathrm{kg}, t=7.12, p<0.001)$. Both doses of AZ66 were shown to have no significant effects in the absence of methamphetamine compared to saline treated mice (Fig. 3.4).

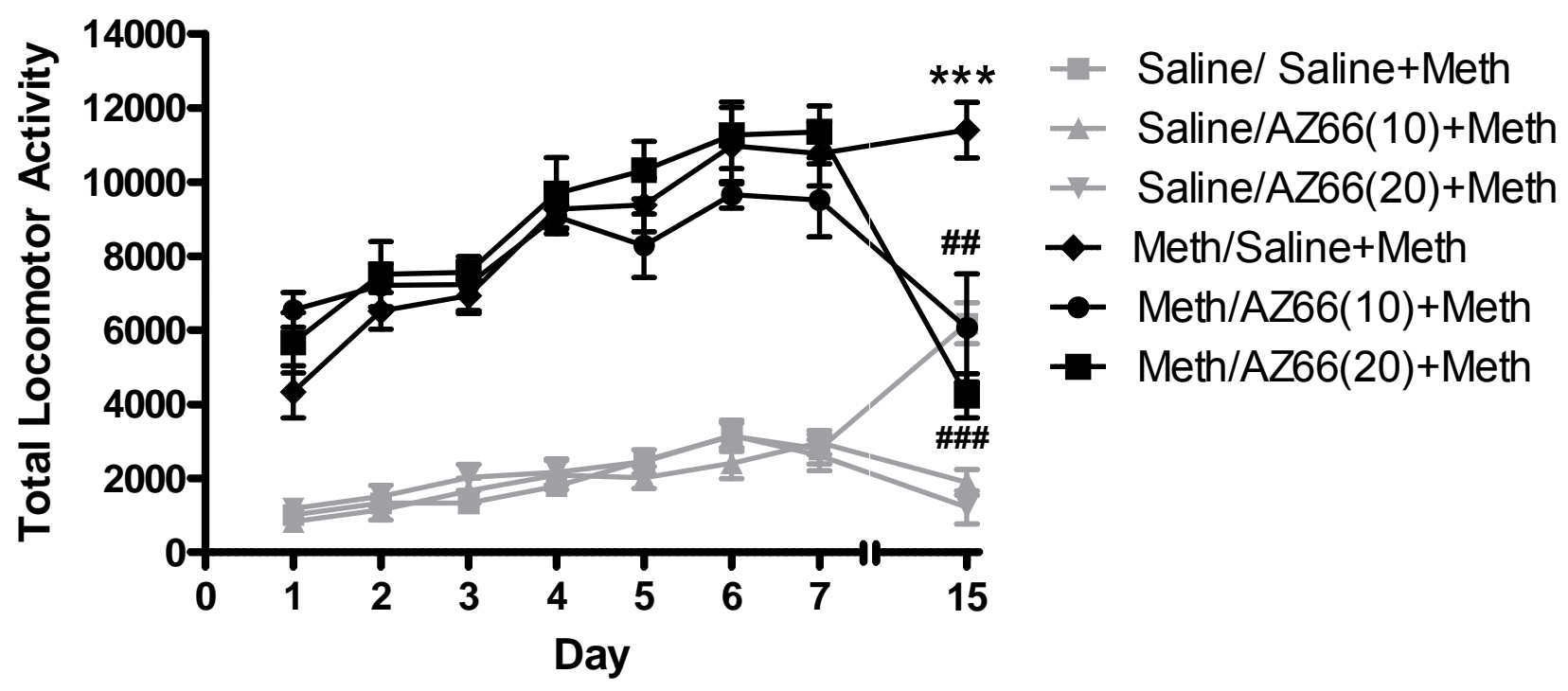

Figure3.4.Effects of AZ66 on the expression of behavioral sensitization to methamphetamine. Male, Swiss Webster mice were injected (i.p.) with saline or methamphetamine (Meth, $1 \mathrm{mg} / \mathrm{kg}$ ) once a day for seven days (Days 1-7). Following an 8-day drug-free period (Day 15), mice were injected (i.p.) with saline or AZ66 (10 or $20 \mathrm{mg} / \mathrm{kg}$ ), followed $15 \mathrm{~min}$ later with methamphetamine (1 mg/kg, Meth). Pretreatment with AZ66 (10 or $20 \mathrm{mg} / \mathrm{kg}$ ) on Day 15 significantly blocked the expression of sensitization. Data are represented as mean \pm S.E.M., ${ }^{* * *} p<0.001$ and $\# \# p<0.01$, \#\#\#p<0.001, post-hoc Tukey's tests (comparing saline + methamphetamine treatment with AZ66 + methamphetamine treatment in groups treated during days 1-7 with either saline or methamphetamine, respectively).

\subsection{Discussion}

Previously studied sigma receptor ligands attenuate many of the behavioral effects of methamphetamine administration in rodent models (Matsumoto et al., 2008; Nguyen et al., 2005; Rodvelt et al., 2011; Takahashi et al., 2000; Ujike et al., 1992). Earlier studies have focused on the acute locomotor stimulant effects of methamphetamine in addition to the prevention of methamphetamine-induced behavioral sensitization. This study is the first to our knowledge showing that an optimized, orally bioavailable sigma receptor ligand attenuates the 
expression of methamphetamine-induced behavioral sensitization, in addition to mitigating the acute locomotor stimulant effects of methamphetamine and preventing the development of methamphetamine-induced behavioral sensitization.

Radioligand binding studies demonstrated that AZ66 displays high nanomolar affinities for both sigma-1 and sigma-2 receptors and a >200 fold preference for sigma receptors compared to any other site tested. These values are significant in that AZ66 represents an orally active, metabolically optimized ligand for further drug development that retains sigma receptor affinity and selectivity.

In this study, both i.p. injection and p.o. dosing of AZ66 attenuated methamphetamineinduced increases in acute locomotor activity. Additionally, both doses of AZ66 attenuated methamphetamine-induced locomotor activity while producing no effects on their own, a characteristic that is indicative of antagonist-like properties. This is consistent with past reports of sigma receptor antagonists attenuating these behaviors (Matsumoto et al., 2008; Nguyen et al., 2005; Seminerio et al., 2011a). Data from the present study supports a role for sigma receptors in these effects and also shows that a sigma receptor preferring compound administered orally can mitigate methamphetamine-induced hyperactivity. These protective effects are likely to involve both subtypes of sigma receptors; however being that AZ66 has mixed affinity for both subtypes, the determination as to which subtype is responsible for the actions presented here cannot conclusively be made. Nevertheless, antisense oligonucleotide studies have shown that sigma-1 receptors play a role in the acute locomotor stimulant effects of methamphetamine (Nguyen et al., 2005). Knockdown of sigma-1 receptors mitigate the locomotor stimulant effects of methamphetamine and similar results are obtained through the use of sigma receptor antagonists (Nguyen et al., 2005). However, sigma-1 receptor knockout mice still respond to methamphetamine suggesting a compensatory role for sigma-2 receptors (Fontanilla et al., 2009), which is consistent with the reported ability of sigma-2 receptor agonists to produce motor activating effects (Walker et al., 1993). It is thus likely that AZ66 acts 
as a sigma receptor antagonist at both subtypes to block the acute hyperactivity induced by methamphetamine.

AZ66 also prevents the development of methamphetamine-induced behavioral sensitization. These results demonstrate the ability of AZ66 to block the neurological changes associated with repeated administration of psychostimulants such as methamphetamine. Repeated treatment with methamphetamine causes long lasting neuroadaptations within regions of the brain associated with reward (White and Kalivas, 1998). Behavioral sensitization is a quantifiable measure of these neuroadaptations and in this study, AZ66 attenuated the development of methamphetamine-induced behavioral sensitization. These results suggest that sigma receptors play a role in the establishment of sensitization and AZ66 may provide protective effects by blocking the evolution of neuroadaptations necessary for the development of behavioral sensitization. Neurons located in the ventral tegmental area (VTA) are believed to be responsible for the development of sensitization, and sigma receptors are widely distributed in the VTA (Graybiel et al., 1989). A number of other sigma receptor ligands have previously been shown to attenuate the development of sensitization to psychostimulants (Takahashi et al., 2000; Ujike et al., 1996; Ujike et al., 1992; Witkin et al., 1993; Xu et al., 2010); however the mechanism by which these events occur remain largely unknown.

Sigma receptors are involved in several aspects of neuroplasticity, including neurite outgrowth, and sigma receptor ligands modulate these processes (Hayashi and Su, 2005; Takebayashi et al., 2002, 2004). The neurologic changes associated with augmented locomotor responses to repeated administrations of methamphetamine may occur through neuroplasticity mediated in part by sigma receptors. Sigma receptors modulate dopaminergic neurotransmission in a variety of ways through protein kinase $\mathrm{C}$, calcium/calmodulin, and calcium signaling (Derbez et al., 2002; Kalivas and Stewart, 1991). Another potential mechanism by which sigma receptors may modulate neuroplasticity is through the phosphorylation of CREB (Yang et al., 2009). CREB phosphorylation has been shown to be 
altered in discrete regions of the brain following methamphetamine-induced behavioral sensitization (McDaid et al., 2006); however, the exact way in which this relates to behavioral consequences has yet to be determined. Other studies demonstrate close interactions between sigma receptors and the dopamingeric system in regions of the brain responsible for motor function, as well as sites likely responsible for the development of methamphetamine-induced behavioral sensitization (Graybiel et al., 1989; Gundlach et al., 1986; Largent et al., 1984; Takahashi et al., 2001; Tam, 1983; Ujike et al., 1992).

In addition to blocking the development of behavioral sensitization, AZ66 significantly reversed the expression of methamphetamine-induced sensitization. Expression of sensitization is a clinically relevant behavioral paradigm that measures neuroadaptations that have already occurred after repeated methamphetamine exposures(Chen et al., 2009). AZ66 blocked the expression of sensitization when administered on the challenge day (Day 15), further implicating a role for sigma receptors in sensitization. While neurons located in the VTA are important for the development of sensitization, the nucleus accumbens (NAc) is an essential region responsible for the expression of sensitization (Di Chiara et al., 2004). Sigma receptor ligands have been shown to modulate dopamine uptake in the NAc (Thompson et al., 2001) and sigma receptors may play a role in the reinforcing effects of drugs of abuse by modulating dopamine levels in the NAc (Ault and Werling, 1999). The ability of AZ66 to reverse the effects are most likely due to sigma receptor modulation of both dopamine transporters and dopamine levels in motor and limbic areas of the brain, specifically the NAc. Taken together, sigma receptors appear to have a modulatory role in both the development and expression of methamphetamine-induced sensitization.

The majority of clinical research centered on drug addiction and dependence focuses on the removal of physical dependence and withdrawal syndromes, neglecting the core symptoms of addiction and molecular etiology of the disease. Sigma receptors represent a novel strategy 
to understanding the molecular basis of drug addiction and may represent a plausible site for pharmacological intervention.

Data from radioligand binding studies and metabolism studies demonstrate AZ66 is a sigma receptor preferring ligand with a favorable pharmacological profile. Moreover, AZ66 provides protection against acute and adaptive behavioral effects of methamphetamine while having no effects on its own. Although additional studies need to be conducted in order to further characterize AZ66 as a potential medication, the data presented herein support a role for sigma receptors in the acute and subchronic behavioral effects of methamphetamine.

\subsection{Contributions}

Michael Seminerio performed the receptor binding experiments, the acute locomotor studies, the development of sensitization studies and the expression of sensitization studies.

AZ66 was synthesized by Ahmed Abdelazeem in Dr. Christopher McCurdy's lab. 


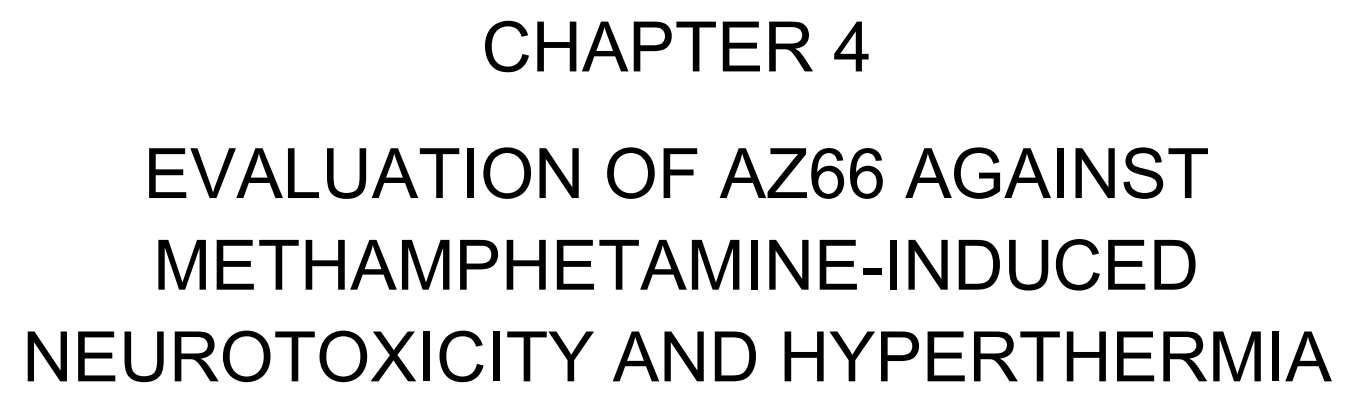




\subsection{Introduction}

Methamphetamine is an addictive psychostimulant and currently listed as the second most abused illicit substance in the world (United Nations, 2007). Methamphetamine abuse can result in several negative consequences including significant neurotoxicity at high or repeated doses (Cadet and Krasnova, 2009; Kita et al., 2003). Chronic use results in long lasting nerve terminal degeneration in specific regions of the brain (Cadet and Krasnova, 2009). Methamphetamine is believed to exert these effects through its interaction with monoamine transporters, primarily the dopamine transporter (Krasnova and Cadet, 2009; Schep et al., 2010). This results in the release of dopamine from synaptic vesicles within the nerve terminal and a resulting release of excess dopamine into the synapse by inhibition of reuptake and reversal of flow through dopamine transporters (Krasnova and Cadet, 2009; Schep et al., 2010). This is believed to lead to nerve terminal degeneration through the formation of reactive oxygen species and reactive nitrogen species (Kita et al., 2003). In addition, high doses of methamphetamine can lead to life threatening hyperthermia. Methamphetamine-induced hyperthermia, although often overlooked, has been shown to correlate directly with methamphetamine-induced lethality and neurotoxicity, suggesting the importance of understanding this effect (Bowyer et al., 1994).

In addition to affecting dopamine systems and body temperature (Fleckenstein et al., 2000), methamphetamine interacts with sigma receptors (Itzhak, 1993; Nguyen et al., 2005). Sigma receptors are unique proteins which are distinct from other known receptors and consist of at least two subtypes, sigma-1 and sigma-2 (Guitart et al., 2004; Matsumoto et al., 2003; Su and Hayashi, 2003). They are distributed in the brain and peripheral organs (Itzhak, 1994; Walker et al., 1990). Of the two subtypes, sigma-1 receptors are localized intercellularly (Hayashi et al. 2000, 2001) and have been cloned in several species (Mei and Pasternak, 2001; Prasad et al., 1998). Sigma-1 receptors have important roles in the modulation of several neurotransmitters by affecting intercellular second messenger systems, particularly calcium 
mobilization(Hayashi et al., 2000; Hayashi and Su, 2001; Hong et al., 2004; Su and Hayashi, 2001). In addition, because of the chaperone like characteristics of sigma-1 receptors, they are believed to partake in protein-protein interactions and undergo translocation between various cellular compartments (Hayashi and Su, 2007). Sigma-2 receptors, on the other hand, have not been cloned and at 18-22 kDa, are smaller than sigma-1 receptors (Hellewell et al., 1994). They are believed to regulate calcium release from stores within the endoplasmic reticulum (Vilner and Bowen, 2000) and are implicated in the regulation of cell proliferation and cell viability (Vilner and Bowen, 1993; Vilner et al., 1995). As with the sigma-1 receptor, sigma-2 receptors are widely distributed throughout the cell including the mitochondria, endoplasmic reticulum, lysosome, and plasma membrane (Zeng et al., 2007).

Recent evidence has shown that methamphetamine produces some of its physiological and behavioral effects through sigma receptors (Nguyen et al., 2005). Specifically, sigma receptors may play a role in the neurotoxic and hyperthermic effects of methamphetamine (Kaushal et al., 2012; Kaushal and Matsumoto, 2011; Kaushal et al., 2011; Matsumoto et al., 2008; Seminerio et al., 2011a). Sigma receptors are found on monoaminergic neurons (Bastianetto et al., 1995; Booth and Baldessarini, 1991; Gundlach et al., 1986) and modulate the release of neurotransmitters such as dopamine and serotontin, which has been linked to neurotoxic consequences and changes in body temperature (Salmi and Ahlenius, 1998; Schwartz et al., 1995). Previous studies have demonstrated pretreatment with sigma receptor ligands can attenuate methamphetamine-induced neurotoxicity (Kaushal et al., 2012; Kaushal and Matsumoto, 2011; Kaushal et al., 2011; Matsumoto et al., 2008; Seminerio et al., 2011a). In addition, sigma receptor ligands have been shown to modulate thermoregulation (Rawls et al., 2002).

The present study investigated whether methamphetamine-induced dopaminergic and serotonergic neurotoxicity and hyperthermia could be prevented using the optimized sigma receptor ligand AZ66 (3-(4-(4-cyclohexylpiperazin-1-yl)pentyl)-6-flourobenzo[d]thiazol-2(3H)- 
one). AZ66 has previously been shown to mitigate many of the behavioral effects of methamphetamine, including the development and expression of behavioral sensitization (Seminerio et al., 2012), suggesting its potential importance toward future drug development studies.

\subsection{Materials and Methods}

4.2.1 Animals. Male, Swiss Webster mice (21-30 g, Harlan, Indianapolis, IN; Frederick, MD) were used for all experiments. Animals were housed 1-5 per cage with a 12:12h light/dark cycle and ad libitum food and water. They were allowed one week to acclimate following their arrival before being used in an experiment. All procedures were approved by the Institutional Animal Care and Use Committee at West Virginia University.

4.2.2 Drugs and Treatment. (+)-Methamphetamine hydrochloride was purchased from Sigma-Aldrich (St. Louis, MO) and sterile saline solution was purchased from Teknova (Hollister, CA). The sigma receptor ligand, AZ66, was synthesized as previously described (Seminerio et al., 2012). All drug solutions were made with saline, and the solution volumes were administered relative to body weight $(0.1 \mathrm{ml} / 10 \mathrm{~g})$.

Mice were randomly divided into groups that were injected with saline $(0.1 \mathrm{ml} / 10 \mathrm{~g}$, i.p.) or AZ66 (10 mg/kg, i.p.) $15 \mathrm{~min}$ prior to injection with saline or methamphetamine (5 mg/kg, i.p.). The dose of AZ66 was chosen based on previous studies which demonstrated significant effects against methamphetamine while exerting no effects on its own (Seminerio et al., 2012). Similarly, previous work in our lab has shown neurotoxic dosing with methamphetamine produces a dose-dependent depletion of dopamine levels in the mouse striatum, with $5 \mathrm{mg} / \mathrm{kg}$ being the lowest dose producing statistically significant effects (Kaushal et al., 2011). Therefore, $10 \mathrm{mg} / \mathrm{kg}$ of $A Z 66$ and $5 \mathrm{mg} / \mathrm{kg}$ of methamphetamine was used. 
Each group of mice received their treatment a total of four times at $2 \mathrm{~h}$ intervals. One hour after each treatment, the body temperatures of the mice were recorded. To allow sufficient time for the methamphetamine-induced degeneration of nerve terminals to occur, the animals were sacrificed and the brains removed one week later (Cappon et al., 2000). The striata of the mice were then collected on ice and evaluated for dopamine levels and dopamine transporter (DAT) expression. The detailed procedure for each of the end points is provided below.

4.3.3 Dopamine Assays. The mice ( $n=5 / g r o u p)$ were randomly assigned to one of the following treatments: (1) Saline + Saline; (2) Saline + METH (1.25, 2.5, or 5 mg/kg); (3) CM156 (5, 10, or $20 \mathrm{mg} / \mathrm{kg})+$ Saline; (4) CM156 (5, 10, or $20 \mathrm{mg} / \mathrm{kg})+\operatorname{METH}(1.25,2.5$, or $5 \mathrm{mg} / \mathrm{kg})$. The first compound in each treatment group (Saline or CM156) was administered 15 min prior to the second injection (Saline or METH). All of the combinations of treatments were given i.p. at 2 hour intervals totaling four times.

To allow sufficient time for the METH-induced degeneration of dopamine nerve terminals to occur, the animals were sacrificed and the brains removed one week following treatment (Cappon et al., 2000). The striatum and cerebellum were dissected from each treated mice and then frozen in liquid nitrogen. The tissues were stored at $-80^{\circ} \mathrm{C}$ for later analysis of dopamine content.

Using a dopamine research enzyme immunoassay kit and protocols provided by the manufacturer (Rocky Mountain Diagnostics, Colorado Springs, CO), mouse brain striatal dopamine were quantified. Brain tissues were homogenized in $0.01 \mathrm{~N} \mathrm{HCl}$. Dopamine was extracted and then acylated to $\mathrm{N}$-acyldopamine using the buffer and reagents provided by the ELISA kit. Acylated dopamine from the tissue samples was then incubated with solid phase bound dopamine, dopamine antiserum, and antiserum buffer to compete for a fixed number of antiserum binding sites. Free antigen and free antigen-antiserum complexes were removed via wash buffer. The antibody bound to the solid phase dopamine was detected using an anti-rabbit 
IgG-peroxidase conjugate with TMB as the substrate. The amount of antibody bound to the solid phase dopamine was measured by monitoring the reaction at $450 \mathrm{~nm}$. The solid phase dopamine measured was inversely proportional to the dopamine concentration of the tissue sample and was quantified relative to a standard curve of known concentrations.

4.3.4 Serotonin Assays. For assessing the effects of AZ66 and METH on brain serotonin levels, mice ( $n=5 /$ group) were randomly assigned to one of four groups described in the previous dopamine assay section. Similar to the procedure used for the dopamine measurements, the animals were sacrificed and the brains removed one week following treatment (Cappon et al., 2000). The striatum and cerebellum were dissected from each treated mice and then frozen in liquid nitrogen. The tissues were stored at $-80^{\circ} \mathrm{C}$ for later analysis of serotonin content.

Using a serotonin research enzyme immunoassay kit and protocols provided by the manufacturer (Rocky Mountain Diagnostics, Colorado Springs, CO), mouse brain striatal serotonin was quantified. Brain tissues were homogenized in $0.2 \mathrm{M}$ perchloric acid, followed by centrifugation at $3,000 \mathrm{rpm}$ for $10 \mathrm{~min}$ at $4^{\circ} \mathrm{C}$. Supernatant was obtained and used for the serotonin measurements. Serotonin was first quantitatively derivatised into N-acyl5-HT using the acylation buffer provided with the kit. Acylated serotonin from the tissue samples were then incubated with solid phase bound serotonin and serotonin antiserum to compete for fixed number of antiserum binding sites. Free antigen and free antigen-antiserum complexes were removed by wash buffer. The antibody bound to the solid phase serotonin was detected using an anti-rabbit lgG-peroxidase conjugate with TMB as the substrate. The amount of antibody bound to the solid phase serotonin was measured by monitoring the reaction at $450 \mathrm{~nm}$. The solid phase serotonin measured was inversely proportional to the serotonin concentration of the tissue sample and was quantified relative to a standard curve of known concentrations. 


\subsubsection{Immunohistochemistry Studies. Striatal sections were assessed for DAT}

expression. The mice were randomly assigned to one of the following treatment groups: (1)

Saline + Saline; (2) Saline + METH (5 mg/kg); (3) AZ66 (10 mg/kg) + METH (5 mg/kg); (4) AZ66

$(10 \mathrm{mg} / \mathrm{kg})+$ Saline. The treatments were administered as previously described for the dopamine assays.

One week following treatment, the mice were perfused transcardially with $0.1 \mathrm{M}$ phosphate buffered saline ( $\mathrm{pH} 7.4)$, followed by $4 \%$ paraformaldehyde. The brains were further fixed overnight in $4 \%$ paraformaldehyde. Coronal sections $(50 \mu \mathrm{m})$ of the fixed tissue were made throughout the rostral-caudal extent of the striatum using a cryostat, and processed in a free-floating state in $0.1 \mathrm{M}$ Tris- $\mathrm{HCl}$ buffered saline (TBS, $\mathrm{pH}$ 7.5). The sections were treated with $0.3 \%$ in $\mathrm{H}_{2} \mathrm{O}_{2}$ in TBS for 30 min at room temperature. The sections were then treated with TBS containing $0.2 \%$ Triton $\mathrm{X}-100$ and $1.5 \%$ normal goat serum for $30 \mathrm{~min}$ at room temperature. Incubation of the sections with anti-rat DAT antibody (Chemicon International, Temecula, CA; MAB369, dilution 1:10,000) was performed for $36 \mathrm{~h}$ at $4^{\circ} \mathrm{C}$. The labeled sections were then washed twice in TBS and processed using Vectastain Elite ABC (Vector Laboratories, Burlingame, CA). Sections were then incubated with biotinylated secondary antirat antisera (diluted 1:200) in TBS-NBS for 60 min. This was then followed by incubation of the sections with avidin-biotinylated peroxidase substrate in TBS for $60 \mathrm{~min}$. The staining was then visualized by reacting 3, 3'-diaminobendine containing $0.01 \% \mathrm{H}_{2} \mathrm{O}_{2}$ for 5 min.

The stained sections were mounted onto gelatin-coated slides and dried. The sections were then dehydrated, cleared, and cover-slipped. The images were captured digitally using a Leica DMIL microscope (Leica Microsystems, Bannockburn, IL) and optical density readings were quantified in anterior regions of the striatum using Kodak ID image analysis software. To obtain the data point for a given animal, the optical density readings from at least three sections were averaged. 
4.3.5 Body Temperature. The mice $(n=5)$ were randomly assigned to treatment groups, which were the same as those described for the dopamine and serotonin assays. All of the combinations of drug treatments were given i.p. at $2 \mathrm{~h}$ intervals totaling four times. Core body temperature was measured $1 \mathrm{~h}$ following each of the four treatment injections with a Thermalert TH-S monitor (Physitemp Instruments Inc., Clifton, NJ). During the temperature measurements, mice were gently held at the base of the tail and a probe (RET-3) was inserted approximately $2.5 \mathrm{~cm}$ past the rectum into the colon for 8-10 s until a rectal temperature was maintained for 3$4 \mathrm{~s}$.

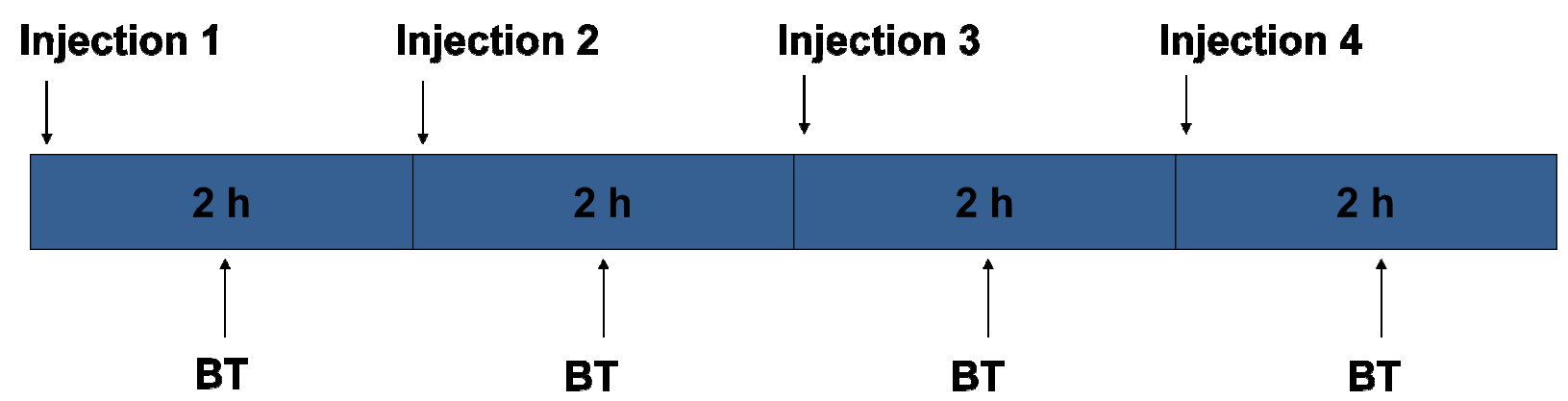

Figure 4.1.Repeated dosing paradigm of methamphetamine. Male, Swiss Webster mice were pretreated (i.p.) with saline or AZ66 (10 mg/kg) followed 15 min later with saline or METH (5 mg/kg). This schedule of treatment was repeated at 2 hour intervals, a total of four times. One hour after each of the four injections, the core body temperature (BT) of the mice were recorded. One week later, the brains were processed according to the designated study.

4.3.6 Data Analysis. The data from the dopamine and serotonin assays, immunohistochemical studies and core body temperature readings were evaluated using oneway analysis of variance (ANOVA). Post-hoc analyses were performed with Dunnett's tests or Bonferroni's tests for comparisons to controls and Tukey's tests for pairwise comparisons. For all analyses, $p<0.05$ was considered statistically significant. GraphPad Prism (San Diego, CA) was used for all data analyses. 


\subsection{Results}

\subsubsection{Neurotoxicity Evaluations}

Dopamine assays. Consistent with other investigations, one-way analysis of variance showed that METH produced a dose dependent reduction of dopamine levels in the striatum brain region (Fig.4.2; $F(3,27)=7.26, p<0.001)$. Post-hoc Dunnett's tests revealed that the striatal changes produced by the following doses of METH differed significantly from the saline control group: $2.5 \mathrm{mg} / \mathrm{kg}(q=2.55, p<0.05), 5 \mathrm{mg} / \mathrm{kg}(q=4.61, p<0.001)$

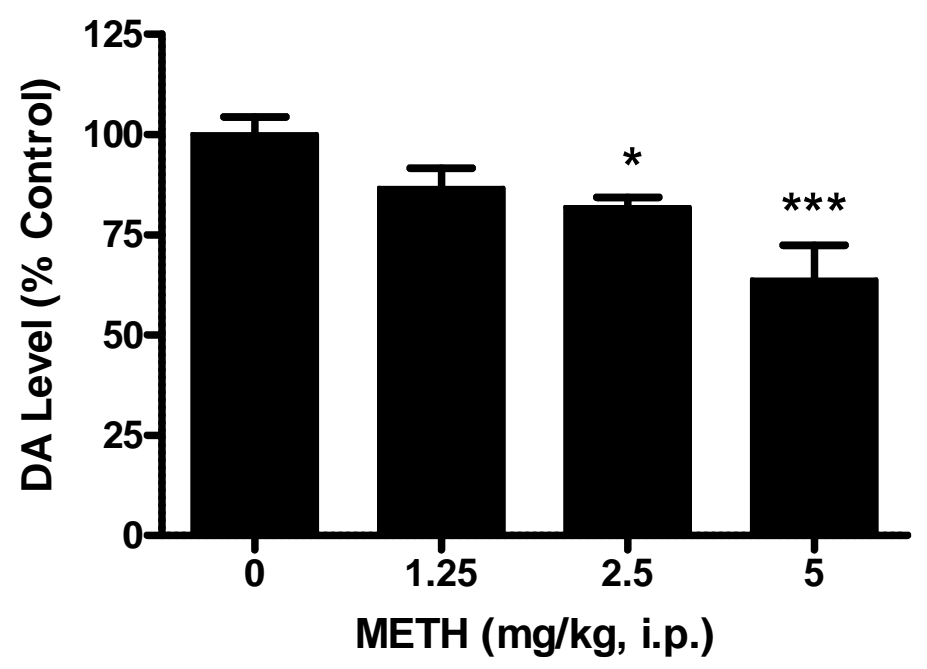

Figure 4.2. Dose response effects of METH on dopamine (DA) levels in the striatum. Male, Swiss Webster mice ( $n=7-9$ per group) were injected (i.p.) with METH (1.25- $5.0 \mathrm{mg} / \mathrm{kg}$, i.p.) or saline (0 mg/kg, i.p.) at 2 hour intervals for a total of four times. DA levels in the striatum and cerebellum tissues were measured one week later, and data was reported as mean \pm SEM. ${ }^{*} p<0.05,{ }^{* * *} p<0.01$ vs. saline.

Figure 4.3 shows the effects of the sigma receptor ligand AZ66 on methamphetamineinduced dopamine depletions in the mouse striatum. Analysis of variance confirmed significant differences between groups $(F(3,36)=13.67, p<0.001)$. Post-hoc Tukey's test confirmed that methamphetamine produced significant decreases in striatal dopamine levels compared to saline treated animals $(q=6.17, p<0.001)$ and pretreatment with AZ66 significantly attenuated methamphetamine-induced dopamine depletions $(q=8.88, p<0.001)$. When AZ66 was 
administered alone, the striatal dopamine levels were not significantly changed compared to saline-treated animals $(p>0.05)$.

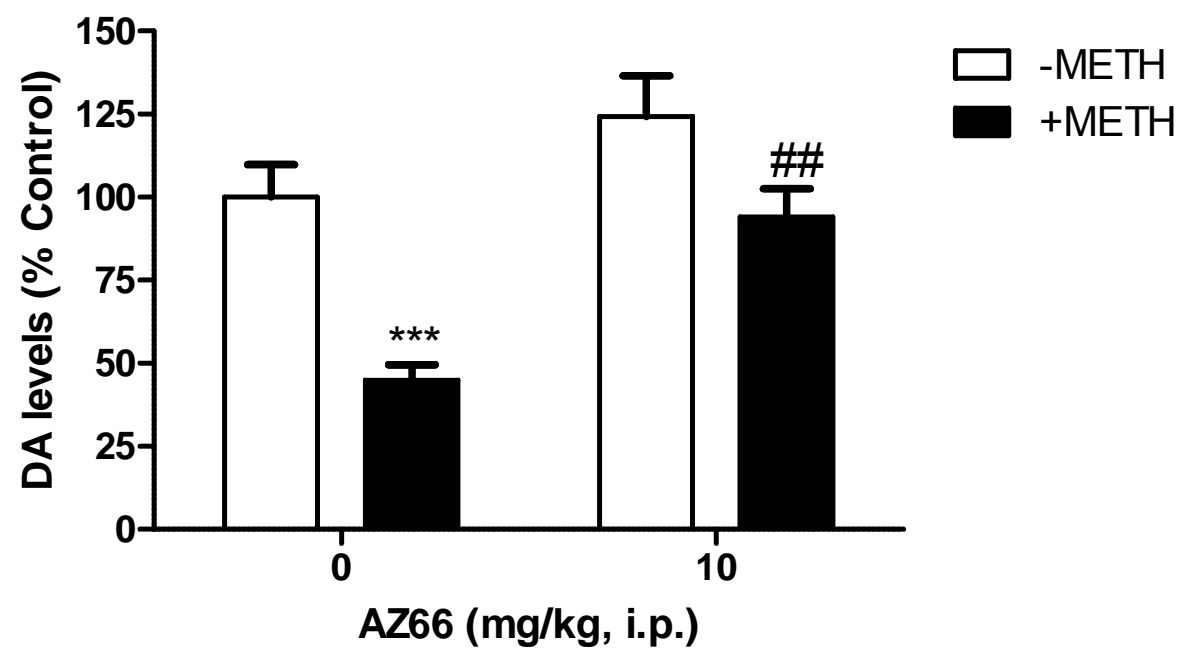

Figure 4.3. Effects of methamphetamine (METH) and AZ66 on dopamine levels in the mouse striatum. Male, Swiss Webster mice ( $n=6-8$ per group) were pretreated with saline (SAL) or AZ66 (AZ, $10 \mathrm{mg} / \mathrm{kg}, \mathrm{i} . \mathrm{p}$.). After $15 \mathrm{~min}$, the mice were then treated with saline (SAL) or METH $(5 \mathrm{mg} / \mathrm{kg}$, i.p.). This treatment schedule was repeated 4 times at $2 \mathrm{~h}$ intervals. One week later, the brain was removed and dopamine levels were measured via ELISA. Data was reported as mean \pm SEM ${ }^{* * *} p<0.001$ vs. saline, \#\#\# <0.001 vs. METH.

Serotonin Assays. Figure 4.4 shows the effects of the sigma receptor ligand AZ66 and methamphetamine on serotonin levels in the mouse striatum. ANOVA demonstrated no significant differences between groups $(q=1.12, p>0.05)$. 


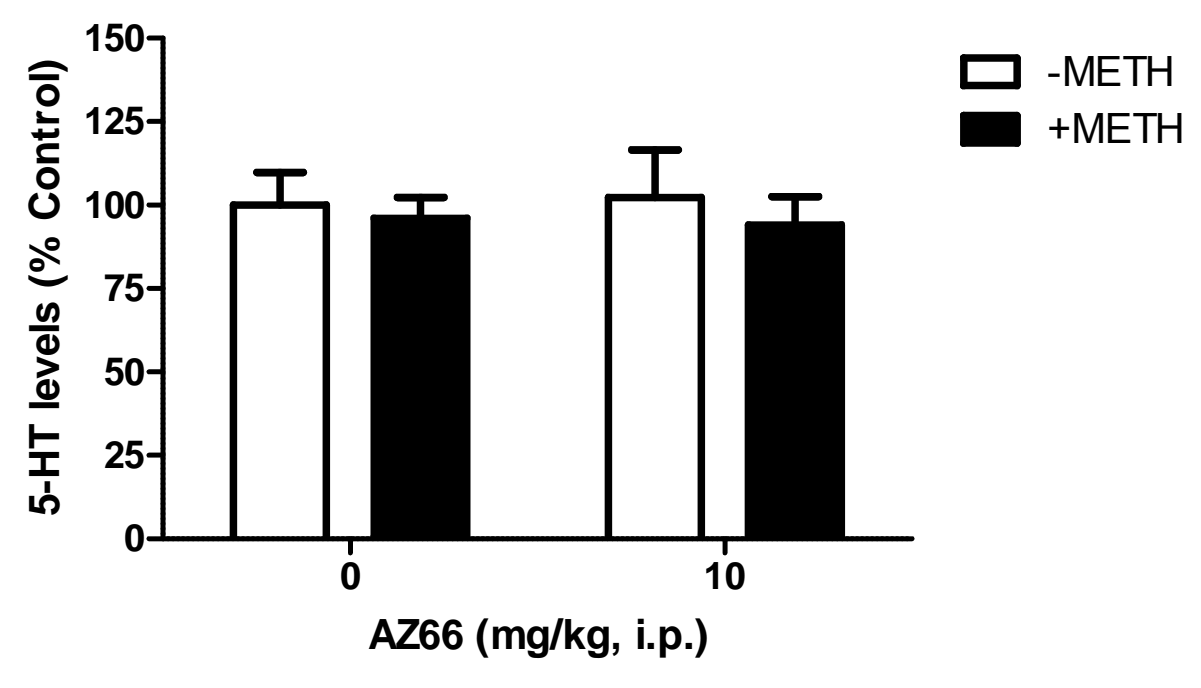

Figure 4.4. Effects of methamphetamine (METH) and AZ66 on 5-HT levels in the mouse striatum. Male, Swiss Webster mice ( $n=6-8$ per group) were pretreated with saline (SAL) or AZ66 (AZ, $10 \mathrm{mg} / \mathrm{kg}$, i.p.). After $15 \mathrm{~min}$, the mice were then treated with saline (SAL) or METH $(10 \mathrm{mg} / \mathrm{kg}$, i.p.). This treatment schedule was repeated 4 times at $2 \mathrm{~h}$ intervals. One week later, the brain was removed and 5-HT levels were measured via ELISA. Data was reported as mean \pm SEM.

4.3.2 DAT Immunohistochemistry. To test the effects of AZ66 on methamphetamine-induced DAT reductions, immunohistochemical analyses were conducted. Figure4.5 depicts the effects of methamphetamine and AZ66 on DAT immunoreactivity in the mouse striatum, with a significant difference between the treatment groups $(F(3,38)=118.70, p<0.0001)$. Post-hoc Tukey's multiple comparisons tests confirmed that methamphetamine caused a significant reduction in DAT immunoreactivity relative to treatment with saline alone $(q=25.55, p<0.001)$. Pretreatment with AZ66 significantly attenuated methamphetamine-induced neurotoxicity ( $q=20.97, p<0.001)$, whereas treatment with AZ66 alone had no significant effects on DAT expression compared to saline alone $(q=3.65, p>0.05)$. 


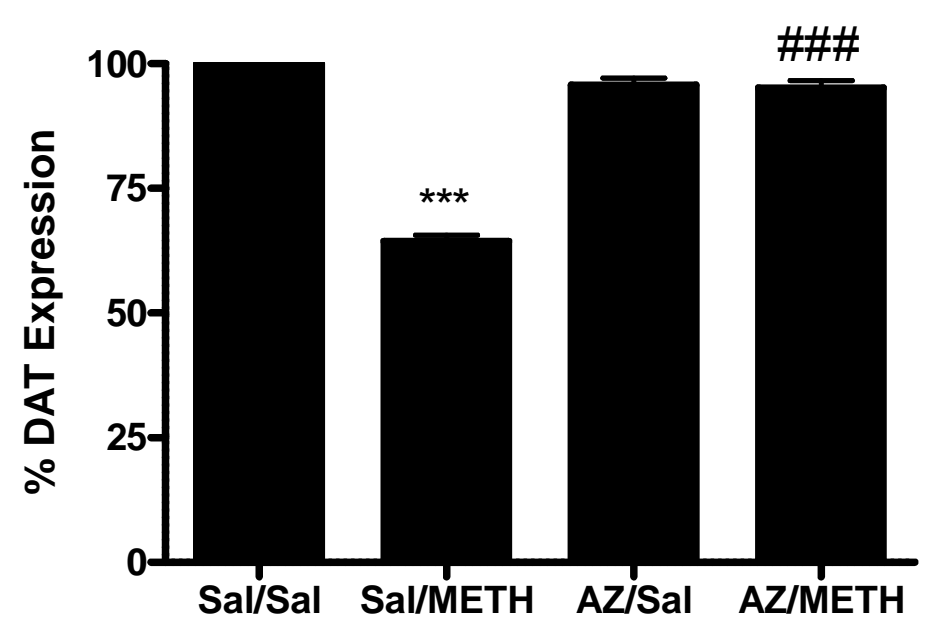

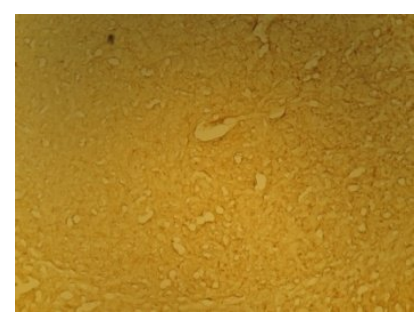

Sal/ Sal

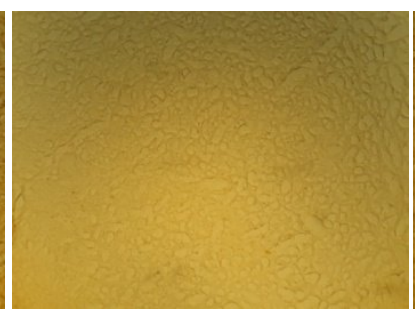

Sal/ METH

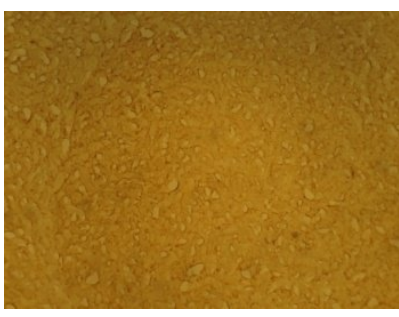

AZ/ Sal

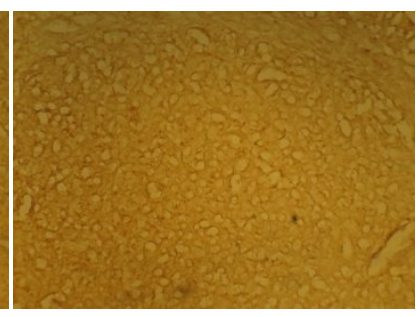

AZ/ METH

Figure 4.5. Effects of methamphetamine (METH) and AZ66 on dopamine transporter immunoreactivity in the mouse striatum. Male, Swiss Webster mice ( $n=4$ per group) were pretreated with saline (SAL) or AZ66 (AZ, 10 $\mathrm{mg} / \mathrm{kg}$, i.p.). After $15 \mathrm{~min}$, the mice were then treated with saline (SAL) or METH (5 mg/kg, i.p.). This treatment schedule was repeated 4 times at $2 \mathrm{~h}$ intervals. One week later, the brain was removed and stained for dopamine transporter immunoreactivity. A representative section from each treatment group is shown, along with average optical density readings (mean \pm SEM). ${ }^{* * *} p<0.001$ vs. saline, \#\#\# < 0001 vs. METH.

4.3.3 Hyperthermia. Methamphetamine produced a significant increase in body temperature, which was attenuated by AZ66. One-way ANOVA showed significant differences between all groups $(F(3,15)=19.08, p<0.001)$. ANOVA of body temperature measured following each treatment time point revealed significant changes in all but the first time point (BT1) (Fig. 4.6): BT1 $(F(3,39)=9.67, p>0.05)$; BT2 $(F(3,39)=13.93, p<0.01)$; BT3 $(F(3,39)=14.02, p<0.01)$; BT4 $(F(3,39)=21.14, p<0.01)$. Post-hoc Tukey's tests confirmed methamphetamine significantly increased body temperature after the second injection onwards (BT2, $q=8.09, p<0.001$; BT3, $q=7.72, p<0.001 ; \mathrm{BT} 4, q=8.36, p<0.001) . \mathrm{AZ66}$ significantly mitigated the hyperthermia effects of 
methamphetamine(BT3, $q=5.20, p<0.01$; BT4, $q=5.11, p<0.01)$. When AZ66 was administered in the absence of methamphetamine, ANOVA showed that there were no significant changes in basal body temperature compared to saline treated animals $(q=1.56, p>0.05)$.

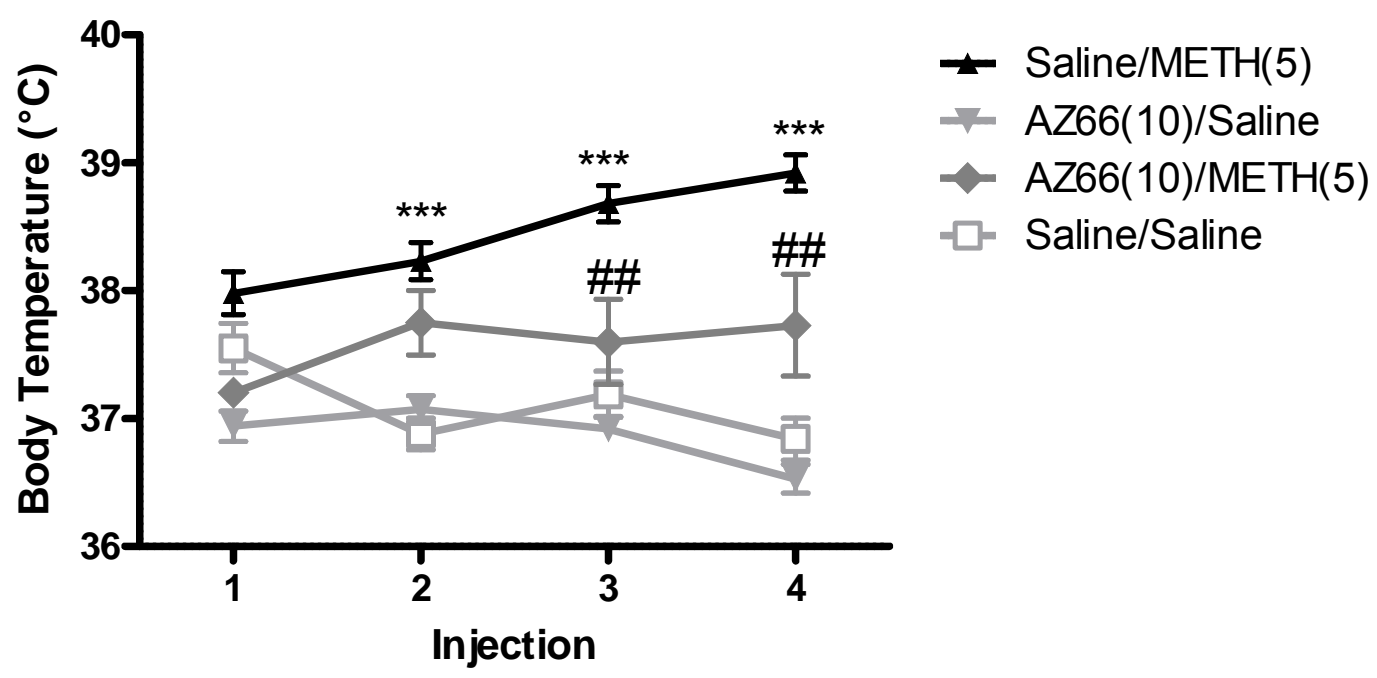

Figure 4.6. Effects of AZ66 on methamphetamine (METH)-induced hyperthermia. Male, Swiss Webster mice ( $n$ = 6-8 per group) were pretreated with saline or AZ66 (10 mg/kg, i.p.), and after $15 \mathrm{~min}$, the mice were treated with saline or METH ( $5 \mathrm{mg} / \mathrm{kg}$, i.p.). Core body temperature was measured $1 \mathrm{~h}$ after each injection combination. This regimen was repeated four times at $2 \mathrm{~h}$ intervals. Data was reported as mean $\pm \mathrm{SEM}$. ${ }^{* \star \star} \mathrm{p}<0.001$ vs. saline, \#\#p < 0.01 vs. METH.

\subsection{Discussion}

The selective sigma receptor ligand AZ66 has been optimized for metabolic stability and tested against the stimulant effects of methamphetamine in our previous study (Seminerio et al., 2012). The current study demonstrates that $A Z 66$ has protective effects against methamphetamine-induced dopaminergic neurotoxicity and hyperthermia.

Consistent with previous reports (Kaushal and Matsumoto, 2011; Nguyen et al., 2005) this work also demonstrates that targeting sigma receptors can provide neuroprotective effects against methamphetamine-induced neurotoxicity. While future studies will need to be conducted to delineate the exact mechanism of this interaction, a number of hypotheses can begin to explain the neuroprotective effects of sigma receptor ligands. Sigma receptors have been 
shown to modulate various neurotransmitter systems afflicted by methamphetamine (Bastianetto et al., 1995; Guitart et al., 2004; Mishina et al., 2005). Specifically, our results further emphasize a modulatory role of sigma receptors in the dopaminergic system and regions of the brain responsible for dopamine transmission.

Dopamine depletions following methamphetamine administration appear primarily dependent on dopamine transporter function (Cadet and Krasnova, 2009; Krasnova and Cadet, 2009; Schmidt et al., 1985). Animals lacking dopamine transporters are protected against dopamine depletions (Fumagalli et al., 1998a; Fumagalli et al., 1998b; Giros et al., 1996). In addition, striatal dopamine depletions are proportional to the degree of hyperthermia, which is linked to methamphetamine-induced lethality (Bowyer et al., 1994). The selective sigma receptor ligand, AZ66, was found to protect against methamphetamine-induced striatal dopamine and dopamine transporter reductions as well as increases in body temperature. These findings support previous studies that also demonstrate neuroprotective properties of sigma receptor ligands (Kaushal et al., 2011; Matsumoto et al., 2008; Seminerio et al., 2011).

The mechanisms responsible for methamphetamine-induced neurotoxicity are complex and involve multiple interacting and cascading processes: excessive release of monoamines like dopamine; auto-oxidation of dopamine leading to reactive oxygen species (ROS) generation; activation of endoplasmic reticulum (ER) stress pathways, mitochondrial death cascades, and glutamatergic/N-methyl-d-aspartate (NMDA)-mediated excitotoxic mechanisms (Krasnova and Cadet, 2009). Modulation of sigma receptors can alter similar processes in the other studied systems: release of neurotransmitters such as dopamine (Bastianetto et al., 1995) protective effects against ROS-related dysfunctions such as brain ischemia (Schetz et al., 2007); regulation of ER stress and mitochondrial death cascades (Tsai et al., 2009) and modulation of NMDA receptor function, including excitotoxic mechanisms (DeCoster et al., 1995; Shen and Phillips, 1998; Shimazu et al., 2000). Therefore, AZ66 most likely provides neuroprotection by 
intervening at multiple points in the neurotoxic cascade of methamphetamine through sigma receptors via a combination of competitive and non-competitive interactions.

In addition to the aforementioned mechanisms related to methamphetamine, targeting sigma receptors has been reported to effectively attenuate neurotoxicity in several other models including $\beta$-amyloid, carbon monoxide, and ischemic stroke (Marrazzo et al., 2005; Marrazzo et al., 2006; Meunier et al., 2006). Furthermore, sigma receptors appear to play a role in animal models of neuropsychiatric complications like depression, psychosis, cognitive and motor deficits (Mishinet et al., 2005; Guitart et al., 2004), which are also observed in methamphetamine users and have been associated with the neurotoxic effects of methamphetamine (Cruickshank and Dyer, 2009). Therefore, the ability of AZ66 to mitigate methamphetamine-induced neurotoxicity may have broader implications for other neurotoxic and neuropsychiatric conditions.

Taken together with previous studies utilizing AZ66, we believe AZ66 represents a viable lead compound for mitigating the effects of methamphetamine. Additional studies will need to be conducted to further evaluate AZ66 as a therapeutic and characterize the role of sigma receptors in the actions of methamphetamine.

\subsection{Contributions}

Michael Seminerio performed the dopamine and serotonin ELISA'S, the DAT immunohistochemistry studies, and the hyperthermia studies.

AZ66 was synthesized by Ahmed Abdelazeem in Dr. Christopher McCurdy's lab. 


\section{CHAPTER 5 \\ EVALUATION OF AZ66 AGAINST METHAMPHETAMINE-INDUCED COGNITIVE IMPAIRMENT}




\subsection{Introduction}

Methamphetamine is an abused drug which produces neurotoxic effects and psychiatric complications (Cadet et al., 2003; Davidson et al., 2001). In addition, methamphetamine has recently been shown to produce cognitive impairments (Hart et al., 2012). The role of methamphetamine abuse in cognitive-related decline has remained controversial, however current studies suggest while acute use of methamphetamine may actually improve memory and attention; chronic use results in a decrease of memory and reaction speed. This effect has been observed both in humans via clinical tests such as the Wisconsin card sorting test and animals studies which evaluate maze sequential learning (Chapman et al., 2001), motor performance (Walsh and Wagner, 1992), spatial impairment (Friedman et al., 1998) and object recognition (Belcher et al., 2008; Bisagno et al., 2002; Kamei et al., 2006; O'Dell et al., 2011; Reichel et al., 2012).It is hypothesized that methamphetamine use may increase an abusers risk of neurodegenerative diseases such as Parkinson's disease(Kuehn, 2011; Morrow et al., 2011). Recently, it has been shown in a 15 year prospective study that methamphetamine abuse results in a significantly higher risk of the development of Parkinson's disease(Callaghan et al., 2010). Currently there are no approved pharmacological treatments for the neurologic deficits arising from methamphetamine abuse. Recent work showing a specific connection between methamphetamine abuse and an increase risk of neurodegenerative diseases such as Parkinson's further emphasizes the need for pharmacotherapies aimed at treating these consequences of methamphetamine abuse.

Previous work has demonstrated sigma receptors may be a viable target to attenuate some of the effects of methamphetamine. Methamphetamine is known to interact with both subtypes of sigma receptors at physiologically relevant concentrations(Nguyen et al., 2005) and sigma receptors have been shown to be involved in many of the behavioral and physiological effects of methamphetamine (Kaushal et al., 2012; Kaushal and Matsumoto, 2011; Kaushal et al., 2011; 
Matsumoto et al., 2008; Seminerio et al., 2011; Seminerio et al., 2012). Pretreatment with selective sigma-1/sigma-2 receptor ligands such as AC927 ( $\mathrm{N}$-phenethylpiperdine oxalate)or CM156 (3-(4-(4-cyclohexylpiperazin-1-yl)butyl)benzo[d]thiazole-2(3H)-thione) have been shown to attenuate methamphetamine-induced hyperthermia, dopaminergic neurotoxicity, and serotonergic neurotoxicity, in addition to mitigating some of the stimulant effects of methamphetamine such as increases in locomotor activity (Kaushal et al., 2011; Matsumoto et al., 2008). Sigma receptor ligands also exhibit protective effects in various models of cognitive impairment (van Waarde et al., 2011) and sigma receptors are thought to have a functional role in Parkinson's disease (Mishina et al., 2005). The protective effects of sigma receptor ligands against methamphetamine-induced neurotoxicity and cognitive impairment further validates sigma receptors as potential targets for pharmacologic treatments against methamphetamine.

The current study utilizedAZ66 (3-(4-(4-cyclohexylpiperazin-1-yl)pentyl)-6flourobenzo[d]thiazol-2(3H)-one), a mixed sigma-1/sigma-2 ligand derived from CM156 and optimized for metabolic stability (Seminerio et al., 2011), to determine its effects as a pretreatment against methamphetamine-induced cognitive impairment. AZ66 has previously been shown to mitigate many of the behavioral effects of methamphetamine, including the development and expression of behavioral sensitization (Seminerio et al., 2012), suggesting its potential importance toward future drug development studies. This study is the first to evaluate a selective sigma receptor ligand for its ability to attenuate cognitive impairment following repeated methamphetamine administration.

\subsection{Materials and Methods}

5.2.1 Memory Measurements. Mice ( $n=10 /$ group) were randomly assigned to treatment groups, which were the same as those described for the neurotoxicity studies. All of the combinations of drug treatments were given i.p. at $2 \mathrm{~h}$ intervals a total of four times. Following 
one week, animals were evaluated for memory in the object recognition test and step-through passive avoidance test. The detailed procedure for each of the tests is provided below.

5.2.2 Object Recognition Test. The test was carried out as described previously (Li et al., 2011). Each mouse was allowed to move freely in an open-field box for 5 min as habituation. Twenty-four hours later, mice were individually placed in the center of the box containing two identical objects (Lego blocks) located in the two diagonal corners. The cumulative time spent exploring each object was recorded during a 5 min period. Exploration was defined as actively touching or facing (within $2 \mathrm{~cm}$ toward) the object. One day later (24 $\mathrm{h}$ after training), mice were tested for memory using the same procedure except that one of the familiar objects was replaced with a novel object. The time of exploration of each object [Tf and Tn for familiar (f) and novel $(n)$ objects, respectively] was recorded for determination of the recognition index $(\mathrm{RI})=$ $\mathrm{Tn} /(\mathrm{Tf}+\mathrm{Tn})$.

5.2.3 Step-through passive avoidance test. The test was performed as described previously (Zhang et al., 2005) with some modifications. The apparatus (Model E10-16SC; Coulbourn Instruments, Allentown, PA) consisted of a two-compartment chamber with an illuminated compartment connected to a darkened one by a guillotine door. The experiment consisted of single training and testing sessions.

On the first day, the animal was placed in the chamber and allowed to roam freely between the illuminated and darkened side for $5 \mathrm{~min}$. During training (24 $\mathrm{h}$ later), the mouse was placed in the illuminated compartment, facing away from the closed guillotine door, for 1 min before the door was raised. The latency to enter the darkened compartment was recorded. After the mouse entered the darkened compartment, the door was closed and an electric shock $(0.4 \mathrm{~mA}$, $5 \mathrm{~s})$ was delivered from the steel-rod floor. This was repeated until the latency for the animal to 
enter the dark compartment exceeded 60 s once the door was open. The number of shocks the animal received before meeting the $>60 \mathrm{~s}$ criterion was also recorded.

Twenty-four hours later, mice began the testing session. To begin the test, the mouse was again placed in the illuminated compartment, with the guillotine door closed for 1 min. Following $1 \mathrm{~min}$, the door was opened and the retention latency to enter the darkened compartment was recorded for up to $300 \mathrm{~s}$, at which time the test was terminated. No shocks were delivered to mice that entered the darkened compartment during the test trial.

5.2.4 Morris Water Maze. This test is used to assess spatial learning and memory following procedures described previously (El-Ghundi et al., 1999) with slight modifications. In brief mice are placed into a circular pool $(95 \mathrm{~cm}$ diameter $\times 25 \mathrm{~cm}$ high) with which a circular platform $(8.5 \mathrm{~cm}$ diameter $\times 15.5 \mathrm{~cm}$ high $)$ is placed. The pool is then filled with water $\left(21 \pm 1^{\circ} \mathrm{C}\right)$ made opaque by the addition of powdered milk. On the first day of the protocol, the visible cued platform test is performed to control for sensory/motor abilities as well as motivation. Curtains are closed around the pool to eliminate distal cues, and the water level is maintained so that the platform is $1 \mathrm{~cm}$ above the water. A small red flag is then placed onto the platform and 4 controlled cue trials are run by placing the animal at random starting locations and being allowed to escape by finding the platform which is placed at a new location for each trial. During the acquisition trials which start the next day, the platform is submerged $1 \mathrm{~cm}$ below the water's surface and several extra-maze distal cues are placed on the curtains. The mice are then trained for 15 trials over 3 days ( 6 trials on day one, 5 trials on day two, and 4 trials on day three) to locate the hidden platform from different starting points (N, S, E, W, NW, and SE). Twenty-four hours after the last training session, a probe trial is conducted where the platform is removed and the animals are allowed to swim for 60 seconds. Latency to reach platform, number of entries into the target quadrant/platform site, and time spent in the target quadrant/platform site are analyzed to assess spatial memory. 
5.2.5 Data Analysis. The data from the object recognition test, step through passive avoidance test, and Morris water maze were evaluated using one-way analysis of variance (ANOVA).Post-hoc analyses were performed with Dunnett's tests or Bonferroni's tests for comparisons to controls and Tukey's tests for pairwise comparisons. For all analyses, $p<0.05$ was considered statistically significant. GraphPad Prism (San Diego, CA) was used for all data analyses.

\subsection{Results}

5.3.1 Object Recognition. The effects of methamphetamine and AZ66 on recognition memory were evaluated in Fig. 5.1. ANOVA showed significant difference between groups in the object recognition test $(F(3,31)=9.01, p<0.001)$. Post-hoc Tukey's tests confirmed that methamphetamine produced significant impairment of recognition memory when compared to the saline control ( $q=7.04, p<0.001)$; this was reversed by pretreatment with AZ66 ( $q=5.31$, $p<0.01)$. Animals treated with AZ66 alone showed no significant difference from saline-treated animals $(q=2.50, p>0.05)$.

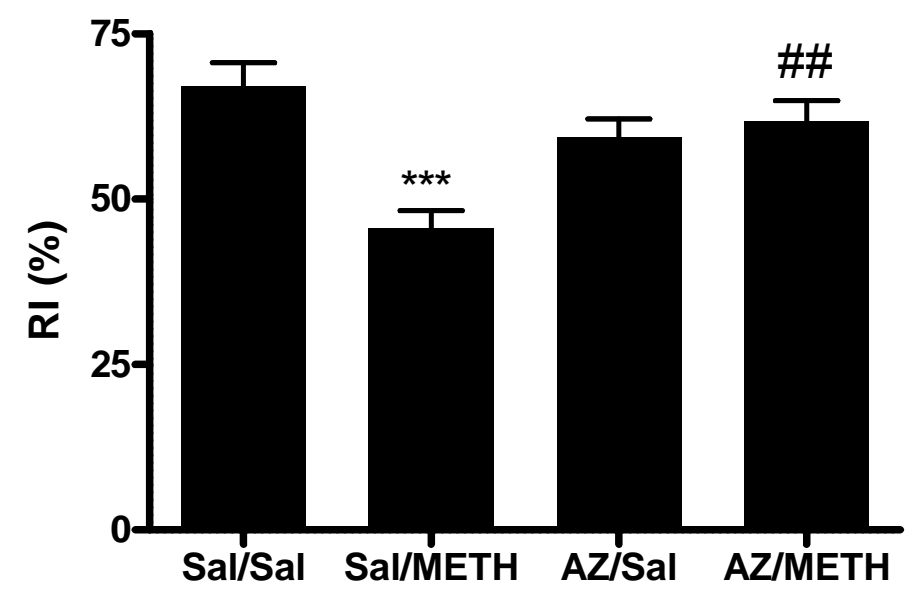

Figure 5.1. Effects of AZ66 on methamphetamine (METH)-induced memory impairment in the object recognition test. Mice were pretreated with saline (SAL) or AZ66 (AZ, $10 \mathrm{mg} / \mathrm{kg}$, i.p.). After 15 min, the mice were 
then treated with saline (SAL) or METH $(5 \mathrm{mg} / \mathrm{kg}$, i.p.). This treatment schedule was repeated 4 times at 2-h intervals. One week later, the animals underwent the object recognition test. Data are reported as mean \pm SEM; ${ }^{* * *} p$ $<0.001$ vs. saline; \#\#< 0.01 vs. METH; $n=6-8$ per group.

\subsubsection{Step-through Passive Avoidance Test. Figure 5.2depicts the effects of}

methamphetamine and AZ66 on memory using the step through passive avoidance test. No significant effects were observed on the \% entries required for acquisition of the passive avoidance task during training (Fig. 5.2A) and the 24-h latency to enter the dark compartment during testing (Fig. 5.2B) among any of the groups tested $(F(3,31)=1.03, p>0.05)$. However, while not significant, these results demonstrate a similar trend as that seen with the object recognition in which animals treated with methamphetamine alone showed increased entries into the dark compartment during the testing period and decreased latency during the testing period. These tendencies were reduced by pretreatment with AZ66.

A

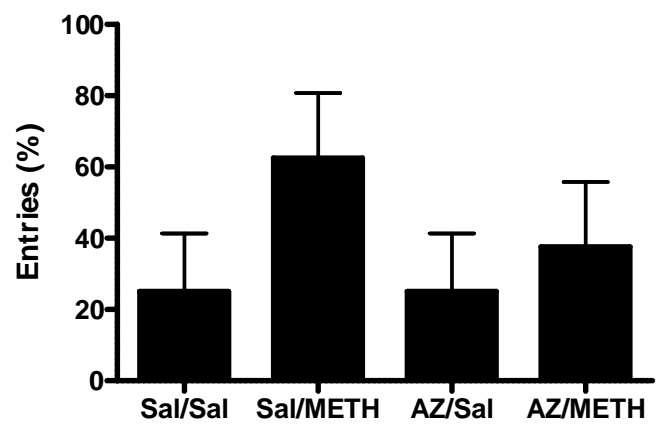

B

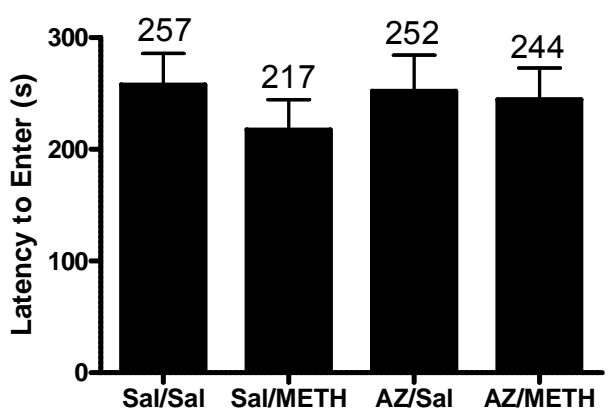

Figure 5.2. Effects of AZ66 on methamphetamine (METH)-induced cognitive impairment in the stepthrough passive avoidance test. Mice were pretreated with saline (SAL) or AZ66 (AZ, $10 \mathrm{mg} / \mathrm{kg}$, i.p.). After $15 \mathrm{~min}$, the mice were then treated with saline (SAL) or METH $(5 \mathrm{mg} / \mathrm{kg}$, i.p.). This treatment schedule was repeated 4 times at $2 \mathrm{~h}$ intervals. One week later, the animals underwent the step-through passive avoidance test. Animals were observed for (a) \% entries into the dark compartment during training and (b) latency to enter dark compartment. Data was reported as mean \pm SEM, no significant changes were observed; $n=6-8$ per group.

\subsubsection{Morris Water Maze. Figures 5.3 depicts the effects of methamphetamine and AZ66 in}

the visible platform test and figure 5.4 represents the average time to find the platform during training. No significant effect was observed in time to reach platform and the average latency to find the platform between any of the groups tested (Fig 5.3, $p=0.7026$; Fig 5.4, $p=0.0982$ ). 


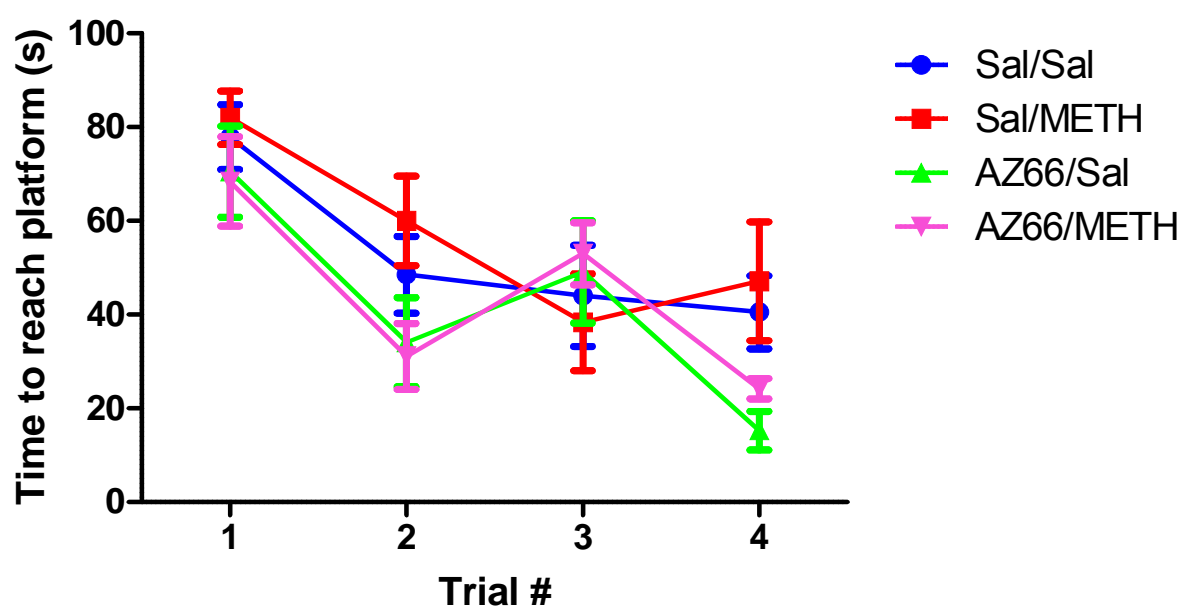

Figure 5.3. Morris water maze visible platform test. Mice were evaluated for their time to reach the visible platform following treatment with methamphetamine (METH) and AZ66.

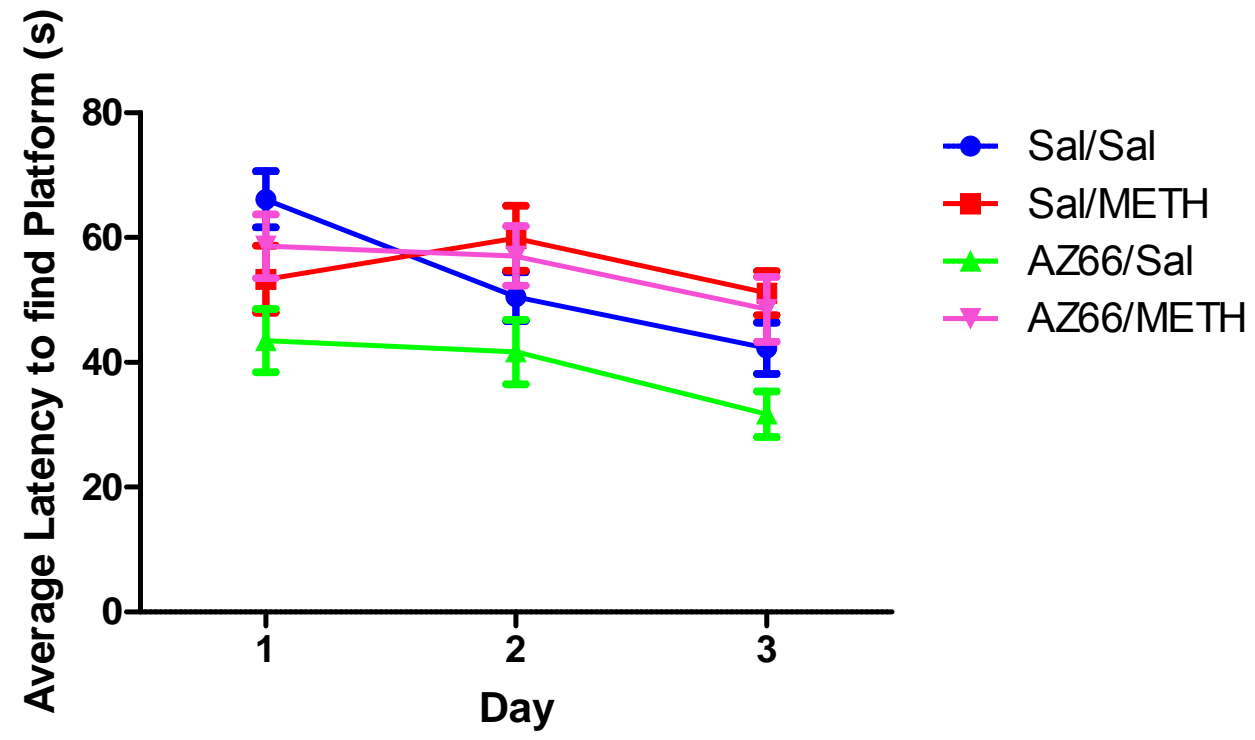

Figure 5.4. Morris water maze training. Mice were evaluated for their latency to find the platform during training on day 1 ( 6 trials), day 2 (5 trials) and day 3 (4 trials) following administration of methamphetamine (METH) and AZ66. The points represent an average for each group on each day.

Figure 5.5 depict the effects of methamphetamine and AZ66 on additional endpoints measured in the Morris water maze. Similarly to the time to reach platform, no significant effects were found in any of the other endpoints tested: velocity (Fig. 5.5A, $p=0.2115$ ), average latency 
to find platform (Fig. 5.5B, $p=0.2311$ ), \% entries in target quadrant (Fig. 5.5C, $p=0.3595$ ), and \% time in target quadrant (Fig. 5.5D, $p=0.693$ ).
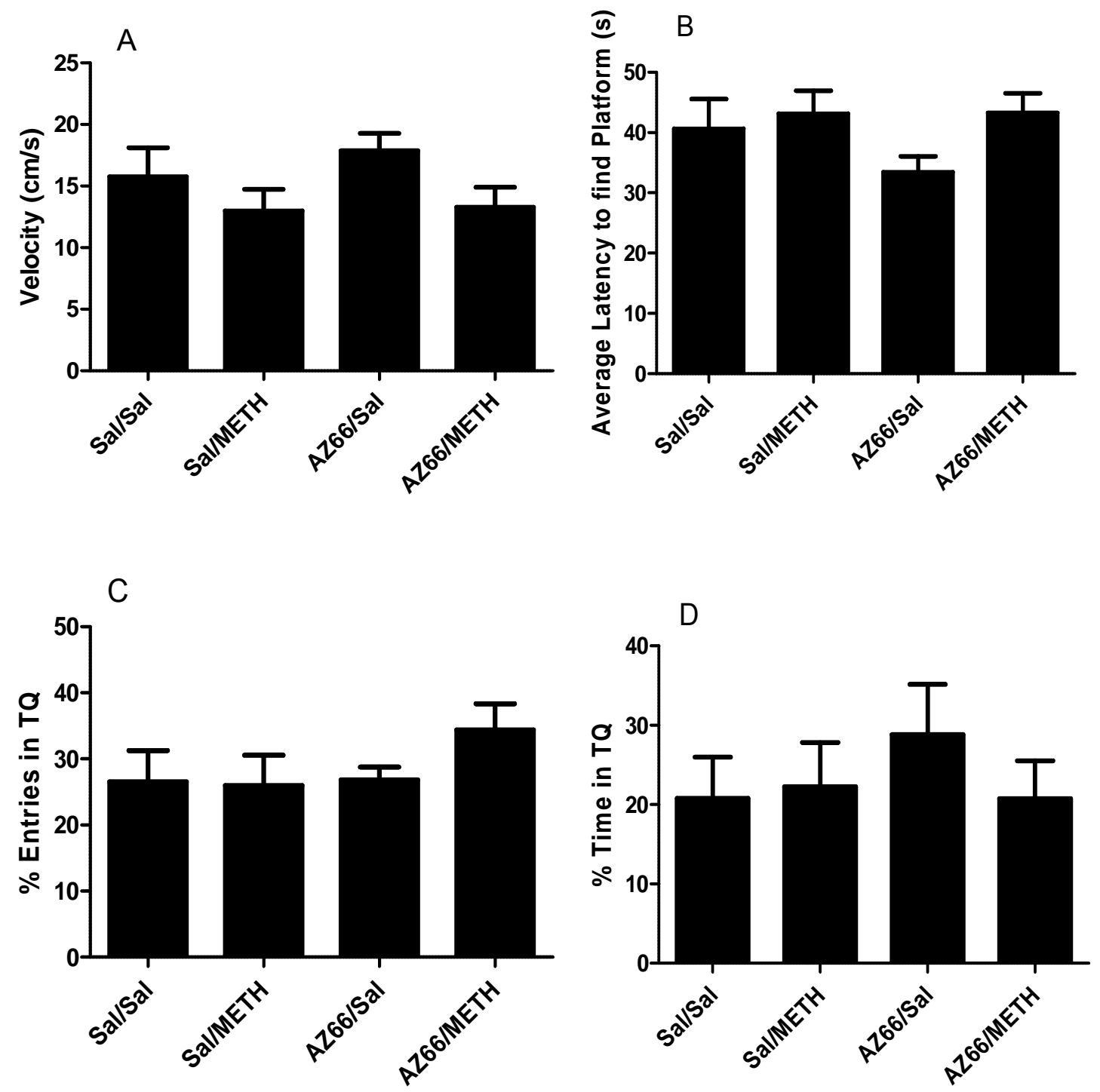

Figure 5.5. Effects of AZ66 and methamphetamine in the Morris water maze probe test.Mice were evaluated for their velocity (A), latency to platform (B), \% entries in target quadrant $(C)$ and $\%$ time in target quadrant $(D)$ following treatment with methamphetamine $(\mathrm{METH})$ or $\mathrm{AZ66}$. $\mathrm{TQ}=$ target quadrant.

\subsection{Discussion}

The current study demonstrates AZ66 has protective effects against methamphetamineinduced cognitive impairments in the object recognition test however no significant effects were 
observed in the step-through passive avoidance test or Morris water maze test. These results appear to be consistent with previous reports showing the effects of methamphetamine on cognition (Hart et al., 2012;(Herring et al., 2008). Additionally, AZ66 was previously shown to attenuate methamphetamine-induced dopaminergic neurotoxicity (unpublished data) which may suggest a mechanism for some of the protective effects of sigma receptor ligands against methamphetamine-induced cognitive impairment.

With evidence beginning to link methamphetamine exposure to the development of Parkinson's disease, dopaminergic neurotoxicity remains a central theme. A myriad of studies have shown methamphetamine produces significant depletions of dopamine levels and dopamine transporters in both human and animal models (Cadet and Krasnova, 2009; Kita et al., 2003; Morrow et al., 2011; Schmidt et al., 1985; Volkow et al., 2001a; Volkow et al., 2001c; Wilson et al., 1996). While the majority of research has been dedicated to the acute effects of methamphetamine on cognitive function (some showing an increase in cognitive function following low to moderate doses), less is known regarding the long term effects of repeated methamphetamine abuse on cognition. The following paragraphs will explore the relationship between repeated methamphetamine abuse and its effects on cognition and the dopaminergic system while illustrating the importance of sigma receptors.

A number of neurotransmitter systems are likely involved in methamphetamine-induced cognitive impairments, however methamphetamine is likely to act primarily on the dopaminergic system (Gough et al., 2002; Han and Gu, 2006; Kuczenski et al., 1995). Dopamine has been shown to modulate different cognitive functions including memory, attention, task switching and response inhibition (Cohen and Servan-Schreiber, 1993; Nordahl et al., 2003). Furthermore, dopamine deficits in regions of the striatum have been shown to reduce reaction time and simple task performance (Baunez and Robbins, 1999; Nordahl et al., 2003)while DA deficits in the prefrontal cortex also contribute to cognitive dysfunction (Baunez and Robbins, 1999; Roberts et al., 1994; Rogers et al., 1999). Methamphetamine is known to affect both the 
striatum and prefrontal cortex (Cadet and Krasnova, 2009; Kita et al., 2003) and sigma receptors are expressed in both of these regions (Guitart et al., 2004; Hayashi et al., 2010). Moreover, sigma receptors are present on dopamine neurons and can modulate their function (Bastianetto et al., 1995) suggesting a potential mechanism for the neuroprotective effects of AZ66.

The striatum plays an important though often forgotten role in cognition. It has been shown that the striatum cooperates with the hippocampus in the formation of episodic memories (Sadeh et al., 2011). Also, episodic memories are often impaired in persons with Parkinson's disease and subsequent dopaminergic-striatal deficiencies (Altgassen et al., 2007; Beste et al., 2009). Dopamine plays a strong role in the formation of episodic memories like that seen in the object recognition test (Hotte et al., 2005). Therefore, it should come as no surprise that neurotoxic doses of methamphetamine which significantly lower striatal dopamine levels impair object recognition memory (Belcher et al., 2008; Bisagno et al., 2002; Kamei et al., 2006; O'Dell et al., 2011; Reichel et al., 2012; Schroder et al., 2003). In this study, pretreatment with AZ66 significantly attenuated the effects of methamphetamine administration on object recognition memory. We believe this is through the neuroprotective properties of sigma receptors, as pretreatment with AZ66 also resulted in attenuation of methamphetamine-induced dopaminergic neurotoxicity in the striatum and sigma receptors are highly expressed in the striatal regions of the brain (Guitart et al., 2004; Hayashi et al., 2010). It is also possible that protection of these necessary striatal dopamine stores resulted in increased object recognition memory via an indirect modulatory role on glutamatergic transmission. It has previously been shown that striatal dopamine plays a role in modulating glutamatergic signaling(Marti et al., 2002; Yamamoto and Davy, 1992)and that glutamatergic signaling in the striatum plays a very important role in object recognition memory (Roullet et al., 2001; Sargolini et al., 2003). 
The pharmacology and neuroanatomy of object recognition memory is very complex, and can rely upon many brain regions and neurotransmitters, however recent research has implicated the perirhinal cortex as an important brain region responsible for object recognition memory (Reichel et al., 2012; Wan et al., 1999; Warburton and Brown, 2010). While projections between the prefrontal cortex and hippocampus are thought to contribute to cognitive memory formation(Hirai et al., 2012; Miyashita and Chang, 1988), the prefrontal cortex does not directly project to the hippocampus, but rather to the perirhinal cortex and amygdala(Burwell, 2001; Furtak et al., 2007; Hirai et al., 2012).In addition to being expressed in the prefrontal cortex, sigma receptors are also located in the amygdale (Hayashi et al., 2010) and may play a modulatory role in cognition in these areas (Wang et al., 2007). The role of the hippocampus in object recognition remains controversial; however the putative role is believed to be evoked when spatial cues or landmarks present in the room are used by animals while in the testing chamber(Morris and Frey, 1997). Since our object recognition testing chamber was enclosed within curtains, the effects of distal landmarks and the role of the hippocampus in our behavioral protocol should therefore be minimized.

Consistent with the findings in object recognition, the step through passive avoidance test also produced memory patterns in a similar trend; however the results were not significant. It has been shown that dopamine plays a strong role in different brain regions involved with the regulation of inhibitory avoidance memory. In the striatum, pharmacological blockade of dopamine receptors decreased step through passive avoidance memory (Manago et al., 2009). Dopamine infused into the amygdala post training increased passive avoidance memory, while dopamine receptor antagonists impaired retention (Lalumiere et al., 2004). In addition, the dopamine uptake inhibitor GBR 12783 injected before training was found to significantly improve passive avoidance memory in rats (Nail-Boucherie et al., 1998). We believe one reason for the lack of significant results may be due to the strength of emotional memory created by our behavioral paradigm. Emotional memory or fear memory is one of the strongest 
forms of memory, and also the easiest to learn. While normal "fear" conditioning is typically considered to be classical condition tests such as contextual fear conditioning, it is hard to deny the strong emotional fear aspect that results from the administration of a nociceptive shock seen during step through passive avoidance. In our behavioral protocol, the mice received a moderately large intensity and duration shock $(.4 \mathrm{~mA} / 5$ seconds). While this makes the training portion of the protocol easier, it can also have the confounding effect of making the memory stronger in all the treatments, resulting in a ceiling effect which may mask the promnesic effects of the experimental variable or treatment (Nail-Boucherie et al., 1998; Rossato et al., 2009). We hypothesize that training the animals with a decreased intensity and duration of a shock (.3mA/2-3 seconds) may have resulted in less "extreme" of a memory, and thus allowed more significance to be observed twenty-four hours later during our testing paradigm. Nevertheless, our results, taken with the object recognition data, suggest methamphetamine may produce some of its cognitive effects through sigma receptors.

The effects of methamphetamine and AZ66 on memory impairment using the Morris water maze, a hippocampal dependent task (Morris et al., 1982), were also evaluated. Consistent with previous reports (Herring et al., 2008), methamphetamine produced no significant impairments when compared with saline treated animals in any of the endpoints tested. In addition, AZ66 was found to have no effect on any of the endpoints tested. Given this effect, taken with other tests herein, it is possible to functionally separate effects on path integration from spatial mapping despite neural network overlap (Herring et al., 2008; Whishaw et al., 1997). Previous work has demonstrated a significant impairment following methamphetamine administration using the Cincinnati water maze, a test employed to assess path integration learning (Herring et al., 2008), however the role of sigma receptors in this effect has yet to be determined.

In conclusion, the optimized selective sigma receptor ligand AZ66 was found to significantly attenuate cognitive impairment in the object recognition test induced by repeated 
exposure to methamphetamine. This study supports a role for sigma receptors in the cognitive effects of methamphetamine while further validating AZ66 as a potential lead compound.

Future studies will need to be conducted to further characterize the role of sigma receptors in methamphetamine-induced cognitive impairment. However, our studies taken with previous literature suggests sigma receptors represent a promising target for the development of novel therapeutics aimed at alleviating a multitude of effects produced by methamphetamine.

\subsection{Contributions}

Michael Seminerio and Rolf Hansen performed the object recognition test, step through passive avoidance test, and Morris water maze test.

AZ66 was synthesized by Ahmed Abdelazeem in Dr. Christopher McCurdy's lab. 


\section{CHAPTER 7 \\ CONCLUSIONS AND FUTURE STUDIES/DIRECTIONS}




\subsection{Summary}

In summary, the studies that have been presented herein demonstrate the following:

> Structural optimizing CM156 for metabolic stability had no effect on its pharmacological profile

> AZ66 attenuates acute methamphetamine locomotor hyperactivity via two routes of administration

- Intraperitoneal

- Per os (oral)

> AZ66 significantly reduced the expression and development of behavioral sensitization evoked by subchronic exposure of methamphetamine

> AZ66 significantly attenuated methamphetamine-induced dopaminergic neurotoxicity and hyperthermia but had no effect on serotongeric neurotoxicity

> Neurotoxic dosing with methamphetamine caused significant memory impairment in the object recognition test which was attenuated when animals were pretreated with AZ66; similar trends were observed in the step-through passive avoidance test

\subsection{Future studies and directions}

8.2.1 Future studies involving the actions of sigma receptors in the actions of methamphetamine. Of the many future studies that will need to be conducted to further evaluate the role of sigma receptors in the actions of methamphetamine, self administration studies would be a priority. While previous work has demonstrated the addictive properties of methamphetamine using animal self administration models (Niwa et al., 2008; Pickens et al., 2011), the role of sigma receptor ligands in these effects remain to be elucidated. These studies would provide great insight into understanding the addictive properties of methamphetamine and the function of sigma receptors in methamphetamine related addiction.

It will also be important to delineate the role of sigma receptor subtypes in methamphetamine-induced effects. As of now, the sigma-2 receptor has yet to be cloned and 
we are currently lacking any sigma-2 selective compounds (based on $>100$ fold selectivity criteria). With the addition of a selective sigma-2 ligand, characterization of each subtype function will be easier to evaluate. The same can be said for the development of a functional assay to definitively determine whether compounds have agonist or antagonists properties at sigma receptors.

Lastly, with recent evidence beginning to link methamphetamine abuse to Parkinson's disease (Callahan et al., 2010) it will be important to study the effects of sigma receptor ligands on methamphetamine-induced cognitive impairments. While a small set of studies were performed in our lab, a number of future studies will need to address the various aspects of memory and learning (i.e. spatial and sequential) following methamphetamine exposure and the involvement of sigma receptors in these effects.

8.2.2. Future directions for methamphetamine related studies. Development of therapeutics for treating the effects of methamphetamine has been largely unsuccessful to this point in time. Research seeking improved translation of treatments from bench-to-bedside for methamphetamine abuse, whether acute or chronic, likely needs to address not only selection of the most appropriate therapeutic target but also the relevance of preclinical models. The disconnect between preclinical studies and clinical reality likely needs to be addressed going forward. Many preclinical studies employ therapeutics prior to drug administration or shortly thereafter. Clearly, this is not nearly as clinically relevant as treatment administration a number of hours after methamphetamine dosing. To truly address the effects of methamphetamine, the compound needs to be administered following the onset of symptoms of significant enough severity that they would generally lead to an individual seeking treatment, whether that be voluntarily or involuntarily. Furthermore, while the majority of neurotoxic and hyperthermia studies use a high dose binge regimen; this may not be the best paradigm to mimic real life abusers. Methamphetamine users tend to gradually increase stimulant doses of the drug rather 
than start and remain at a high dose (Segal et al., 2003). Rarely do drug abusers use the same dose multiple times a day suggesting current preclinical models should be designed more in a exponential like dosing scheme.

The role of temperature in methamphetamine-induced effects has been clearly shown in preclinical models yet pre-clinical studies continue to be conducted at standard laboratory temperatures despite the realization that exposure by abusers rarely occurs in a standardized environment (Miller and O'Callaghan, 1994, 2003). Similarly, preclinical studies often fail to address other factors leading to increased magnitude or duration of hyperthermia and associated neurotoxicity following methamphetamine abuse, such as social interaction. This is particularly relevant for therapeutic development and timing of administration based on preclinical work illustrating that while social interaction didn't result in an increased magnitude of hyperthermia, the duration of elevated body temperature persisted for a longer duration(Brown et al., 2003). While this may be difficult to incorporate into the experimental design, it is important to understand the effects of external environment may play a significant role in the effects of methamphetamine.

Nearly all pre-clinical studies using methamphetamine administer the drug independently despite the predominant use of methamphetamine in conjunction with alcohol (Kirkpatrick et al., 2012). In fact, this combination accounts for $24 \%$ of all emergency department visits related to methamphetamine use. While preclinical studies have addressed the interaction of alcohol with other stimulants, often demonstrating significant differences in physiologic parameters compared to either drug alone, little remains known concerning the interaction of methamphetamine and alcohol in commonly used animal models. Understanding this interaction may be important in future therapeutic development, particularly considering recent evidence indicating differing effects clinically when methamphetamine and alcohol are administered in combination compared to administration of either drug alone (Kirkpatrick et al., 2012). 
Differences in the way methamphetamine is abused clinically compared to the design of many preclinical studies present another parameter that can be adjusted to more appropriately represent the clinical reality. For example, preclinical studies often utilize repeated dosing over subsequent days to simulate chronic abuse. While this may be representative of one episode of use in humans, in which the drug is typically abused for a period of approximately four days before a period of abstinence, this is not entirely representative of true chronic use as patients often abuse methamphetamine over the course of months/years. (Itzhak and Achat-Mendes, 2004) It is likely that these different dosing strategies will be required to not only study both acute and chronic effects of various use patterns but the mechanisms of neurotoxicity associated with each may vary(Davidson et al., 2001).

Finally, additional work should address the interaction of the periphery with the central nervous system-mediated effects. Methamphetamine use results in systemic physiologic alterations and it is likely that combination therapies targeting multiple injurious mechanisms/pathways may be more successful in comparison to monotherapy. Modulation of inflammatory processes has proven successful in mitigating other pathologic conditions and this may be true of methamphetamine-induced hyperthermia but requires future study investigating why preclinical studies illustrate a clear disconnect between neuroinflammation and neurotoxicity in some cases but not others (Cadet et al., 2003; Itzhak and Achat-Mendes, 2004; O'Callaghan et al., 2008; Zhang et al., 2006). 


\section{References}

Ago, Y., Nakamura, S., Uda, M., Kajii, Y., Abe, M., Baba, A., Matsuda, T., 2006. Attenuation by the $5-\mathrm{HT} 1 \mathrm{~A}$ receptor agonist osemozotan of the behavioral effects of single and repeated methamphetamine in mice. Neuropharmacology 51, 914-922.

Albertson, T.E., Derlet, R.W., Van Hoozen, B.E., 1999. Methamphetamine and the expanding complications of amphetamines. West J Med 170, 214-219.

Ali, S.F., Itzhak, Y., 1998. Effects of 7-nitroindazole, an NOS inhibitor on methamphetamineinduced dopaminergic and serotonergic neurotoxicity in mice. Ann N Y Acad Sci 844, $122-130$.

Altgassen, M., Phillips, L., Kopp, U., Kliegel, M., 2007. Role of working memory components in planning performance of individuals with Parkinson's disease. Neuropsychologia 45, 2393-2397.

Asanuma, M., Tsuji, T., Miyazaki, I., Miyoshi, K., Ogawa, N., 2003. Methamphetamine-induced neurotoxicity in mouse brain is attenuated by ketoprofen, a non-steroidal antiinflammatory drug. Neurosci Lett 352, 13-16.

Ault, D.T., Werling, L.L., 1999. Phencyclidine and dizocilpine modulate dopamine release from rat nucleus accumbens via sigma receptors. Eur J Pharmacol 386, 145-153.

Aydar, E., Palmer, C.P., Klyachko, V.A., Jackson, M.B., 2002. The sigma receptor as a ligandregulated auxiliary potassium channel subunit. Neuron 34, 399-410.

Azzaro, A.J., Rutledge, C.O., 1973. Selectivity of release of norepinephrine, dopamine and 5hydroxytryptamine by amphetamine in various regions of rat brain. Biochem Pharmacol 22, 2801-2813.

Barnette, W.E., 1984. The synthesis and biology of fluorinated prostacyclins. CRC Crit Rev Biochem 15, 201-235. 
Bastianetto, S., Rouquier, L., Perrault, G., Sanger, D.J., 1995. DTG-induced circling behaviour in rats may involve the interaction between sigma sites and nigro-striatal dopaminergic pathways. Neuropharmacology 34, 281-287.

Baunez, C., Robbins, T.W., 1999. Effects of dopamine depletion of the dorsal striatum and further interaction with subthalamic nucleus lesions in an attentional task in the rat. Neuroscience 92, 1343-1356.

Belcher, A.M., Feinstein, E.M., O'Dell, S.J., Marshall, J.F., 2008. Methamphetamine influences on recognition memory: comparison of escalating and single-day dosing regimens. Neuropsychopharmacology 33, 1453-1463.

Berardi, F., Ferorelli, S., Abate, C., Colabufo, N.A., Contino, M., Perrone, R., Tortorella, V., 2004. 4-(tetralin-1-yl)- and 4-(naphthalen-1-yl)alkyl derivatives of 1-cyclohexylpiperazine as sigma receptor ligands with agonist sigma2 activity. J Med Chem 47, 2308-2317.

Bergeron, R., Debonnel, G., De Montigny, C., 1993. Modification of the N-methyl-D-aspartate response by antidepressant sigma receptor ligands. Eur J Pharmacol 240, 319-323.

Beste, C., Willemssen, R., Saft, C., Falkenstein, M., 2009. Error processing in normal aging and in basal ganglia disorders. Neuroscience 159, 143-149.

Bisagno, V., Ferguson, D., Luine, V.N., 2002. Short toxic methamphetamine schedule impairs object recognition task in male rats. Brain Res 940, 95-101.

Booth, R.G., Baldessarini, R.J., 1991. (+)-6,7-benzomorphan sigma ligands stimulate dopamine synthesis in rat corpus striatum tissue. Brain Res 557, 349-352.

Bouchard, P., Quirion, R., 1997. [3H]1,3-di(2-tolyl)guanidine and [3H](+)pentazocine binding sites in the rat brain: autoradiographic visualization of the putative sigma1 and sigma2 receptor subtypes. Neuroscience 76, 467-477.

Bowen, W.D., Bertha, C.M., Vilner, B.J., Rice, K.C., 1995. CB-64D and CB-184: ligands with high sigma 2 receptor affinity and subtype selectivity. Eur J Pharmacol 278, 257-260. 
Bowyer, J.F., Davies, D.L., Schmued, L., Broening, H.W., Newport, G.D., Slikker, W., Jr., Holson, R.R., 1994. Further studies of the role of hyperthermia in methamphetamine neurotoxicity. J Pharmacol Exp Ther 268, 1571-1580.

Brown, P.L., Wise, R.A., Kiyatkin, E.A., 2003. Brain hyperthermia is induced by methamphetamine and exacerbated by social interaction. J Neurosci 23, 3924-3929.

Burwell, R.D., 2001. Borders and cytoarchitecture of the perirhinal and postrhinal cortices in the rat. J Comp Neurol 437, 17-41.

Cadet, J.L., Jayanthi, S., Deng, X., 2003. Speed kills: cellular and molecular bases of methamphetamine-induced nerve terminal degeneration and neuronal apoptosis. FASEB J 17, 1775-1788.

Cadet, J.L., Krasnova, I.N., 2009. Molecular bases of methamphetamine-induced neurodegeneration. Int Rev Neurobiol 88, 101-119.

Cadet, J.L., Krasnova, I.N., Jayanthi, S., Lyles, J., 2007. Neurotoxicity of substituted amphetamines: molecular and cellular mechanisms. Neurotox Res 11, 183-202.

Cadet, J.L., Ordonez, S.V., Ordonez, J.V., 1997. Methamphetamine induces apoptosis in immortalized neural cells: protection by the proto-oncogene, bcl-2. Synapse 25, 176184.

Callaghan, R.C., Cunningham, J.K., Sajeev, G., Kish, S.J., 2010. Incidence of Parkinson's disease among hospital patients with methamphetamine-use disorders. Mov Disord 25, 2333-2339.

Callahan, B., Yuan, J., Stover, G., Hatzidimitriou, G., Ricaurte, G., 1998. Effects of 2-deoxy-Dglucose on methamphetamine-induced dopamine and serotonin neurotoxicity. $\mathrm{J}$ Neurochem 70, 190-197.

Cannon, B., Nedergaard, J., 2004. Brown adipose tissue: function and physiological significance. Physiol Rev 84, 277-359. 
Cendan, C.M., Pujalte, J.M., Portillo-Salido, E., Montoliu, L., Baeyens, J.M., 2005. Formalininduced pain is reduced in sigma(1) receptor knockout mice. Eur J Pharmacol 511, 7374.

Chapman, D.E., Hanson, G.R., Kesner, R.P., Keefe, K.A., 2001. Long-term changes in basal ganglia function after a neurotoxic regimen of methamphetamine. J Pharmacol Exp Ther 296, 520-527.

Chen, J.C., Chen, P.C., Chiang, Y.C., 2009. Molecular mechanisms of psychostimulant addiction. Chang Gung Med J 32, 148-154.

Cheng, Y., Prusoff, W.H., 1973. Relationship between the inhibition constant (K1) and the concentration of inhibitor which causes 50 per cent inhibition (I50) of an enzymatic reaction. Biochem Pharmacol 22, 3099-3108.

Cohen, J.D., Servan-Schreiber, D., 1993. A theory of dopamine function and its role in cognitive deficits in schizophrenia. Schizophr Bull 19, 85-104.

Crawford, K.W., Bowen, W.D., 2002. Sigma-2 receptor agonists activate a novel apoptotic pathway and potentiate antineoplastic drugs in breast tumor cell lines. Cancer Res 62, 313-322.

Crawford, K.W., Coop, A., Bowen, W.D., 2002. sigma(2) Receptors regulate changes in sphingolipid levels in breast tumor cells. Eur J Pharmacol 443, 207-209.

Crean, R.D., Davis, S.A., Taffe, M.A., 2007. Oral administration of (+/-)3,4methylenedioxymethamphetamine and (+)methamphetamine alters temperature and activity in rhesus macaques. Pharmacol Biochem Behav 87, 11-19.

Crean, R.D., Davis, S.A., Von Huben, S.N., Lay, C.C., Katner, S.N., Taffe, M.A., 2006. Effects of (+/-)3,4-methylenedioxymethamphetamine, (+/-)3,4-methylenedioxyamphetamine and methamphetamine on temperature and activity in rhesus macaques. Neuroscience 142, 515-525. 
Crime, U.N.O.o.D.a., 2011. 2011 World Drug Report. United Nations Office on Drugs and Crime, Vienna, Austria.

Cruickshank, C.C., Dyer, K.R., 2009. A review of the clinical pharmacology of methamphetamine. Addiction 104, 1085-1099.

Davidson, C., Gow, A.J., Lee, T.H., Ellinwood, E.H., 2001. Methamphetamine neurotoxicity: necrotic and apoptotic mechanisms and relevance to human abuse and treatment. Brain Res Brain Res Rev 36, 1-22.

DeCoster, M.A., Klette, K.L., Knight, E.S., Tortella, F.C., 1995. Sigma receptor-mediated neuroprotection against glutamate toxicity in primary rat neuronal cultures. Brain Res 671, 45-53.

Derbez, A.E., Mody, R.M., Werling, L.L., 2002. Sigma(2)-receptor regulation of dopamine transporter via activation of protein kinase C. J Pharmacol Exp Ther 301, 306-314.

Di Chiara, G., Bassareo, V., Fenu, S., De Luca, M.A., Spina, L., Cadoni, C., Acquas, E., Carboni, E., Valentini, V., Lecca, D., 2004. Dopamine and drug addiction: the nucleus accumbens shell connection. Neuropharmacology 47 Suppl 1, 227-241.

Dobkin, C., Nicosia, N., 2009. The War on Drugs: Methamphetamine, Public Health, and Crime. Am Econ Rev 99, 324-349.

Dougan, D.F., Duffield, P., Wade, D.N., 1987. Modulation of dopamine receptors in the Tapes clam by dextroamphetamine and phenylethanolamine. Comp Biochem Physiol C 86, 317-324.

El-Ghundi, M., Fletcher, P.J., Drago, J., Sibley, D.R., O'Dowd, B.F., George, S.R., 1999. Spatial learning deficit in dopamine $\mathrm{D}(1)$ receptor knockout mice. Eur J Pharmacol 383, 95-106.

Fleckenstein, A.E., Gibb, J.W., Hanson, G.R., 2000. Differential effects of stimulants on monoaminergic transporters: pharmacological consequences and implications for neurotoxicity. Eur J Pharmacol 406, 1-13. 
Fontanilla, D., Johannessen, M., Hajipour, A.R., Cozzi, N.V., Jackson, M.B., Ruoho, A.E., 2009. The hallucinogen N,N-dimethyltryptamine (DMT) is an endogenous sigma-1 receptor regulator. Science 323, 934-937.

Friedman, S.D., Castaneda, E., Hodge, G.K., 1998. Long-term monoamine depletion, differential recovery, and subtle behavioral impairment following methamphetamineinduced neurotoxicity. Pharmacol Biochem Behav 61, 35-44.

Fukumura, M., Cappon, G.D., Broening, H.W., Vorhees, C.V., 1998. Methamphetamineinduced dopamine and serotonin reductions in neostriatum are not gender specific in rats with comparable hyperthermic responses. Neurotoxicol Teratol 20, 441-448.

Fumagalli, F., Gainetdinov, R.R., Valenzano, K.J., Caron, M.G., 1998a. Role of dopamine transporter in methamphetamine-induced neurotoxicity: evidence from mice lacking the transporter. J Neurosci 18, 4861-4869.

Fumagalli, F., Jones, S., Bosse, R., Jaber, M., Giros, B., Missale, C., Wightman, R.M., Caron, M.G., 1998b. Inactivation of the dopamine transporter reveals essential roles of dopamine in the control of locomotion, psychostimulant response, and pituitary function. Adv Pharmacol 42, 179-182.

Furtak, S.C., Wei, S.M., Agster, K.L., Burwell, R.D., 2007. Functional neuroanatomy of the parahippocampal region in the rat: the perirhinal and postrhinal cortices. Hippocampus $17,709-722$.

Ginawi, O.T., Al-Majed, A.A., Al-Suwailem, A.K., 2005. NAN-190, a possible specific antagonist for methamphetamine. Regul Toxicol Pharmacol 41, 122-127.

Giros, B., Jaber, M., Jones, S.R., Wightman, R.M., Caron, M.G., 1996. Hyperlocomotion and indifference to cocaine and amphetamine in mice lacking the dopamine transporter. Nature 379, 606-612. 
Gough, B., Imam, S.Z., Blough, B., Slikker, W., Jr., Ali, S.F., 2002. Comparative effects of substituted amphetamines (PMA, MDMA, and METH) on monoamines in rat caudate: a microdialysis study. Ann N Y Acad Sci 965, 410-420.

Graybiel, A.M., Besson, M.J., Weber, E., 1989. Neuroleptic-sensitive binding sites in the nigrostriatal system: evidence for differential distribution of sigma sites in the substantia nigra, pars compacta of the cat. J Neurosci 9, 326-338.

Gronier, B., Debonnel, G., 1999. Involvement of sigma receptors in the modulation of the glutamatergic/NMDA neurotransmission in the dopaminergic systems. Eur J Pharmacol 368, 183-196.

Guitart, X., Codony, X., Monroy, X., 2004. Sigma receptors: biology and therapeutic potential. Psychopharmacology (Berl) 174, 301-319.

Gundlach, A.L., Largent, B.L., Snyder, S.H., 1986. Autoradiographic localization of sigma receptor binding sites in guinea pig and rat central nervous system with (+)3H-3-(3hydroxyphenyl)-N-(1-propyl)piperidine. J Neurosci 6, 1757-1770.

Han, D.D., Gu, H.H., 2006. Comparison of the monoamine transporters from human and mouse in their sensitivities to psychostimulant drugs. BMC Pharmacol 6, 6.

Hanner, M., Moebius, F.F., Flandorfer, A., Knaus, H.G., Striessnig, J., Kempner, E., Glossmann, H., 1996. Purification, molecular cloning, and expression of the mammalian sigma1-binding site. Proc Natl Acad Sci U S A 93, 8072-8077.

Hayashi, T., Justinova, Z., Hayashi, E., Cormaci, G., Mori, T., Tsai, S.Y., Barnes, C., Goldberg, S.R., Su, T.P., 2010. Regulation of sigma-1 receptors and endoplasmic reticulum chaperones in the brain of methamphetamine self-administering rats. J Pharmacol Exp Ther 332, 1054-1063.

Hayashi, T., Maurice, T., Su, T.P., 2000. Ca(2+) signaling via sigma(1)-receptors: novel regulatory mechanism affecting intracellular $\mathrm{Ca}(2+)$ concentration. J Pharmacol Exp Ther 293, 788-798. 
Hayashi, T., Su, T.P., 2001. Regulating ankyrin dynamics: Roles of sigma-1 receptors. Proc Natl Acad Sci U S A 98, 491-496.

Hayashi, T., Su, T.P., 2003. Intracellular dynamics of sigma-1 receptors (sigma(1) binding sites) in NG108-15 cells. J Pharmacol Exp Ther 306, 726-733.

Hayashi, T., Su, T.P., 2005. The potential role of sigma-1 receptors in lipid transport and lipid raft reconstitution in the brain: implication for drug abuse. Life Sci 77, 1612-1624.

Hayashi, T., Su, T.P., 2007. Sigma-1 receptor chaperones at the ER-mitochondrion interface regulate $\mathrm{Ca}(2+)$ signaling and cell survival. Cell 131, 596-610.

Hellewell, S.B., Bruce, A., Feinstein, G., Orringer, J., Williams, W., Bowen, W.D., 1994. Rat liver and kidney contain high densities of sigma 1 and sigma 2 receptors: characterization by ligand binding and photoaffinity labeling. Eur J Pharmacol 268, 9-18.

Hendrickson, R.G., Horowitz, B.Z., Norton, R.L., Notenboom, H., 2006. "Parachuting" meth: a novel delivery method for methamphetamine and delayed-onset toxicity from "body stuffing". Clin Toxicol (Phila) 44, 379-382.

Herring, N.R., Schaefer, T.L., Gudelsky, G.A., Vorhees, C.V., Williams, M.T., 2008. Effect of +methamphetamine on path integration learning, novel object recognition, and neurotoxicity in rats. Psychopharmacology (Berl) 199, 637-650.

Hirai, Y., Morishima, M., Karube, F., Kawaguchi, Y., 2012. Specialized cortical subnetworks differentially connect frontal cortex to parahippocampal areas. J Neurosci 32, 18981913.

Hoffmann, A., Kann, O., Ohlemeyer, C., Hanisch, U.K., Kettenmann, H., 2003. Elevation of basal intracellular calcium as a central element in the activation of brain macrophages (microglia): suppression of receptor-evoked calcium signaling and control of release function. J Neurosci 23, 4410-4419. 
Hong, W., Nuwayhid, S.J., Werling, L.L., 2004. Modulation of bradykinin-induced calcium changes in SH-SY5Y cells by neurosteroids and sigma receptor ligands via a shared mechanism. Synapse 54, 102-110.

Hotte, M., Naudon, L., Jay, T.M., 2005. Modulation of recognition and temporal order memory retrieval by dopamine D1 receptor in rats. Neurobiol Learn Mem 84, 85-92.

Itzhak, Y., 1993. Repeated methamphetamine-treatment alters brain sigma receptors. Eur J Pharmacol 230, 243-244.

Itzhak, Y., Achat-Mendes, C., 2004. Methamphetamine and MDMA (ecstasy) neurotoxicity: 'of mice and men'. IUBMB Life 56, 249-255.

Itzhak, Y., Ali, S.F., 1996. The neuronal nitric oxide synthase inhibitor, 7-nitroindazole, protects against methamphetamine-induced neurotoxicity in vivo. J Neurochem 67, 1770-1773.

Kahlert, S., Zundorf, G., Reiser, G., 2005. Glutamate-mediated influx of extracellular Ca2+ is coupled with reactive oxygen species generation in cultured hippocampal neurons but not in astrocytes. J Neurosci Res 79, 262-271.

Kalivas, P.W., Stewart, J., 1991. Dopamine transmission in the initiation and expression of drug- and stress-induced sensitization of motor activity. Brain Res Brain Res Rev 16, 223-244.

Kamei, H., Nagai, T., Nakano, H., Togan, Y., Takayanagi, M., Takahashi, K., Kobayashi, K., Yoshida, S., Maeda, K., Takuma, K., Nabeshima, T., Yamada, K., 2006. Repeated methamphetamine treatment impairs recognition memory through a failure of noveltyinduced ERK1/2 activation in the prefrontal cortex of mice. Biol Psychiatry 59, 75-84.

Karila, L., Weinstein, A., Aubin, H.J., Benyamina, A., Reynaud, M., Batki, S.L., 2010.

Pharmacological approaches to methamphetamine dependence: a focused review. $\mathrm{Br} \mathrm{J}$ Clin Pharmacol 69, 578-592.

Kasai, S., Ikeda, K., 2011. Pharmacogenomics of the human micro-opioid receptor. Pharmacogenomics 12, 1305-1320. 
Kashani, J., Ruha, A.M., 2004. Methamphetamine toxicity secondary to intravaginal body stuffing. J Toxicol Clin Toxicol 42, 987-989.

Kaushal, N., Elliott, M., Robson, M.J., lyer, A.K., Rojanasakul, Y., Coop, A., Matsumoto, R.R., 2012. AC927, a sigma receptor ligand, blocks methamphetamine-induced release of dopamine and generation of reactive oxygen species in NG108-15 cells. Mol Pharmacol 81, 299-308.

Kaushal, N., Matsumoto, R.R., 2011. Role of sigma receptors in methamphetamine-induced neurotoxicity. Curr Neuropharmacol 9, 54-57.

Kaushal, N., Seminerio, M.J., Shaikh, J., Medina, M.A., McCurdy, C.R., Matsumoto, R.R., 2009. CM156, A sigma receptor antagonist, mitgates stimulant and neurotoxic effects of methamphetamine in mice. FASEB J (abstract) 589.5.

Kaushal, N., Seminerio, M.J., Shaikh, J., Medina, M.A., Mesangeau, C., Wilson, L.L., McCurdy, C.R., Matsumoto, R.R., 2011. CM156, a high affinity sigma ligand, attenuates the stimulant and neurotoxic effects of methamphetamine in mice. Neuropharmacology 61 , 992-1000.

Kirkpatrick, M.G., Gunderson, E.W., Levin, F.R., Foltin, R.W., Hart, C.L., 2012. Acute and residual interactive effects of repeated administrations of oral methamphetamine and alcohol in humans. Psychopharmacology (Berl) 219, 191-204.

Kish, S.J., 2008. Pharmacologic mechanisms of crystal meth. CMAJ 178, 1679-1682.

Kita, T., Wagner, G.C., Nakashima, T., 2003. Current research on methamphetamine-induced neurotoxicity: animal models of monoamine disruption. J Pharmacol Sci 92, 178-195.

Kosaka, T., Sawada, T., Ichikawa, S., 1988. Effect of continuous illumination on secretion of pregnane compounds by the rat ovary. Experientia 44, 43-45.

Krasnova, I.N., Cadet, J.L., 2009. Methamphetamine toxicity and messengers of death. Brain Res Rev 60, 379-407. 
Kuczenski, R., Segal, D.S., Cho, A.K., Melega, W., 1995. Hippocampus norepinephrine, caudate dopamine and serotonin, and behavioral responses to the stereoisomers of amphetamine and methamphetamine. J Neurosci 15, 1308-1317.

Kuehn, B.M., 2011. Meth use linked to risk of Parkinson disease. JAMA 306, 814.

Lalumiere, R.T., Nguyen, L.T., McGaugh, J.L., 2004. Post-training intrabasolateral amygdala infusions of dopamine modulate consolidation of inhibitory avoidance memory: involvement of noradrenergic and cholinergic systems. Eur J Neurosci 20, 2804-2810.

Lan, K.C., Lin, Y.F., Yu, F.C., Lin, C.S., Chu, P., 1998. Clinical manifestations and prognostic features of acute methamphetamine intoxication. J Formos Med Assoc 97, 528-533.

Langa, F., Codony, X., Tovar, V., Lavado, A., Gimenez, E., Cozar, P., Cantero, M., Dordal, A., Hernandez, E., Perez, R., Monroy, X., Zamanillo, D., Guitart, X., Montoliu, L., 2003. Generation and phenotypic analysis of sigma receptor type I (sigma 1) knockout mice. Eur J Neurosci 18, 2188-2196.

Largent, B.L., Gundlach, A.L., Snyder, S.H., 1984. Psychotomimetic opiate receptors labeled and visualized with (+)-[3H]3-(3-hydroxyphenyl)-N-(1-propyl)piperidine. Proc Natl Acad Sci U S A 81, 4983-4987.

LaVoie, M.J., Hastings, T.G., 1999. Dopamine quinone formation and protein modification associated with the striatal neurotoxicity of methamphetamine: evidence against a role for extracellular dopamine. J Neurosci 19, 1484-1491.

Maeda, D.Y., Williams, W., Kim, W.E., Thatcher, L.N., Bowen, W.D., Coop, A., 2002. Narylalkylpiperidines as high-affinity sigma-1 and sigma-2 receptor ligands: phenylpropylamines as potential leads for selective sigma-2 agents. Bioorg Med Chem Lett 12, 497-500.

Mallick, B.N., Jha, S.K., Islam, F., 2002. Presence of alpha-1 adrenoreceptors on thermosensitive neurons in the medial preoptico-anterior hypothalamic area in rats. Neuropharmacology 42, 697-705. 
Manago, F., Castellano, C., Oliverio, A., Mele, A., De Leonibus, E., 2009. Role of dopamine receptors subtypes, D1-like and D2-like, within the nucleus accumbens subregions, core and shell, on memory consolidation in the one-trial inhibitory avoidance task. Learn Mem $16,46-52$.

Marrazzo, A., Caraci, F., Salinaro, E.T., Su, T.P., Copani, A., Ronsisvalle, G., 2005. Neuroprotective effects of sigma-1 receptor agonists against beta-amyloid-induced toxicity. Neuroreport 16, 1223-1226.

Marrazzo, A., Parenti, C., Scavo, V., Ronsisvalle, S., Scoto, G.M., Ronsisvalle, G., 2006. In vivo evaluation of (+)-MR200 as a new selective sigma ligand modulating MOP, DOP and KOP supraspinal analgesia. Life Sci 78, 2449-2453.

Marti, M., Mela, F., Bianchi, C., Beani, L., Morari, M., 2002. Striatal dopamine-NMDA receptor interactions in the modulation of glutamate release in the substantia nigra pars reticulata in vivo: opposite role for D1 and D2 receptors. J Neurochem 83, 635-644.

Matsumoto, R.R., 2009. Targeting sigma receptors: novel medication development for drug abuse and addiction. Expert Rev Clin Pharmacol 2, 351-358.

Matsumoto, R.R., Bowen, W., Su, T., 2007. Sigma Receptors: Chemistry, Cell Biology and Clinical Implications. Springer Science + Business Media, LLC.

Matsumoto, R.R., Bowen, W.D., Tom, M.A., Vo, V.N., Truong, D.D., De Costa, B.R., 1995. Characterization of two novel sigma receptor ligands: antidystonic effects in rats suggest sigma receptor antagonism. Eur J Pharmacol 280, 301-310.

Matsumoto, R.R., Liu, Y., Lerner, M., Howard, E.W., Brackett, D.J., 2003. Sigma receptors: potential medications development target for anti-cocaine agents. Eur J Pharmacol 469, $1-12$.

Matsumoto, R.R., Shaikh, J., Wilson, L.L., Vedam, S., Coop, A., 2008. Attenuation of methamphetamine-induced effects through the antagonism of sigma (sigma) receptors: Evidence from in vivo and in vitro studies. Eur Neuropsychopharmacol 18, 871-881. 
Maurer-Spurej, E., 2005. Circulating serotonin in vertebrates. Cell Mol Life Sci 62, 1881-1889.

McDaid, J., Graham, M.P., Napier, T.C., 2006. Methamphetamine-induced sensitization differentially alters pCREB and DeltaFosB throughout the limbic circuit of the mammalian brain. Mol Pharmacol 70, 2064-2074.

Mei, J., Pasternak, G.W., 2001. Molecular cloning and pharmacological characterization of the rat sigma1 receptor. Biochem Pharmacol 62, 349-355.

Mesangeau, C., Narayanan, S., Green, A.M., Shaikh, J., Kaushal, N., Viard, E., Xu, Y.T., Fishback, J.A., Poupaert, J.H., Matsumoto, R.R., McCurdy, C.R., 2008. Conversion of a highly selective sigma-1 receptor-ligand to sigma-2 receptor preferring ligands with anticocaine activity. J Med Chem 51, 1482-1486.

Meunier, J., leni, J., Maurice, T., 2006. Antiamnesic and neuroprotective effects of donepezil against learning impairments induced in mice by exposure to carbon monoxide gas. $\mathrm{J}$ Pharmacol Exp Ther 317, 1307-1319.

Miller, D.B., O'Callaghan, J.P., 1994. Environment-, drug- and stress-induced alterations in body temperature affect the neurotoxicity of substituted amphetamines in the C57BL/6J mouse. J Pharmacol Exp Ther 270, 752-760.

Miller, D.B., O'Callaghan, J.P., 2003. Elevated environmental temperature and methamphetamine neurotoxicity. Environ Res 92, 48-53.

Mishina, M., Ishiwata, K., Ishii, K., Kitamura, S., Kimura, Y., Kawamura, K., Oda, K., Sasaki, T., Sakayori, O., Hamamoto, M., Kobayashi, S., Katayama, Y., 2005. Function of sigma1 receptors in Parkinson's disease. Acta Neurol Scand 112, 103-107.

Miyashita, Y., Chang, H.S., 1988. Neuronal correlate of pictorial short-term memory in the primate temporal cortex. Nature 331, 68-70.

Morris, B.J., Cochran, S.M., Pratt, J.A., 2005. PCP: from pharmacology to modelling schizophrenia. Curr Opin Pharmacol 5, 101-106. 
Morris, R.G., Frey, U., 1997. Hippocampal synaptic plasticity: role in spatial learning or the automatic recording of attended experience? Philos Trans R Soc Lond B Biol Sci 352, 1489-1503.

Morris, R.G., Garrud, P., Rawlins, J.N., O'Keefe, J., 1982. Place navigation impaired in rats with hippocampal lesions. Nature 297, 681-683.

Morrow, B.A., Roth, R.H., Redmond, D.E., Elsworth, J.D., 2011. Impact of methamphetamine on dopamine neurons in primates is dependent on age: implications for development of Parkinson's disease. Neuroscience 189, 277-285.

Nail-Boucherie, K., Dourmap, N., Jaffard, R., Costentin, J., 1998. The specific dopamine uptake inhibitor GBR 12783 improves learning of inhibitory avoidance and increases hippocampal acetylcholine release. Brain Res Cogn Brain Res 7, 203-205.

Nash, J.F., Yamamoto, B.K., 1992. Methamphetamine neurotoxicity and striatal glutamate release: comparison to 3,4-methylenedioxymethamphetamine. Brain Res 581, 237-243.

Nguyen, E.C., McCracken, K.A., Liu, Y., Pouw, B., Matsumoto, R.R., 2005. Involvement of sigma (sigma) receptors in the acute actions of methamphetamine: receptor binding and behavioral studies. Neuropharmacology 49, 638-645.

Nicosia, N., Pacula, R., Kilmer, B., Lundberg, R., Chiesa, J., 2008. The economic cost of methamphetamine use in the United States

NIDA, 2011. Drug-Related Hospital. Emergency Room Visits, NIDA Info Facts.

Niwa, M., Yan, Y., Nabeshima, T., 2008. Genes and molecules that can potentiate or attenuate psychostimulant dependence: relevance of data from animal models to human addiction. Ann N Y Acad Sci 1141, 76-95.

Nordahl, T.E., Salo, R., Leamon, M., 2003. Neuropsychological effects of chronic methamphetamine use on neurotransmitters and cognition: a review. J Neuropsychiatry Clin Neurosci 15, 317-325. 
Numachi, Y., Ohara, A., Yamashita, M., Fukushima, S., Kobayashi, H., Hata, H., Watanabe, H., Hall, F.S., Lesch, K.P., Murphy, D.L., Uhl, G.R., Sora, I., 2007. Methamphetamineinduced hyperthermia and lethal toxicity: role of the dopamine and serotonin transporters. Eur J Pharmacol 572, 120-128.

O'Callaghan, J.P., Sriram, K., Miller, D.B., 2008. Defining "neuroinflammation". Ann N Y Acad Sci $1139,318-330$.

O'Dell, S.J., Feinberg, L.M., Marshall, J.F., 2011. A neurotoxic regimen of methamphetamine impairs novelty recognition as measured by a social odor-based task. Behav Brain Res 216, 396-401.

Otani, K., Ujike, H., Sakai, A., Okahisa, Y., Kotaka, T., Inada, T., Harano, M., Komiyama, T., Hori, T., Yamada, M., Sekine, Y., Iwata, N., Iyo, M., Sora, I., Ozaki, N., Kuroda, S., 2008. Reduced CYP2D6 activity is a negative risk factor for methamphetamine dependence. Neurosci Lett 434, 88-92.

Pickens, C.L., Airavaara, M., Theberge, F., Fanous, S., Hope, B.T., Shaham, Y., 2011. Neurobiology of the incubation of drug craving. Trends Neurosci 34, 411-420.

Prasad, P.D., Li, H.W., Fei, Y.J., Ganapathy, M.E., Fujita, T., Plumley, L.H., Yang-Feng, T.L., Leibach, F.H., Ganapathy, V., 1998. Exon-intron structure, analysis of promoter region, and chromosomal localization of the human type 1 sigma receptor gene. J Neurochem $70,443-451$.

Quinton, M.S., Yamamoto, B.K., 2006. Causes and consequences of methamphetamine and MDMA toxicity. AAPS J 8, E337-347.

Rawls, S.M., Baron, D.A., Geller, E.B., Adler, M.W., 2002. Sigma sites mediate DTG-evoked hypothermia in rats. Pharmacol Biochem Behav 73, 779-786.

Reichel, C.M., Ramsey, L.A., Schwendt, M., McGinty, J.F., See, R.E., 2012. Methamphetamine-induced changes in the object recognition memory circuit. Neuropharmacology 62, 1119-1126. 
Roberts, A.C., De Salvia, M.A., Wilkinson, L.S., Collins, P., Muir, J.L., Everitt, B.J., Robbins, T.W., 1994. 6-Hydroxydopamine lesions of the prefrontal cortex in monkeys enhance performance on an analog of the Wisconsin Card Sort Test: possible interactions with subcortical dopamine. J Neurosci 14, 2531-2544.

Robson, M.J., Noorbakhsh, B., Seminerio, M.J., Matsumoto, R.R., 2012. Sigma-1 receptors: potential targets for the treatment of substance abuse. Curr Pharm Des 18, 902-919.

Rodvelt, K.R., Oelrichs, C.E., Blount, L.R., Fan, K.H., Lever, S.Z., Lever, J.R., Miller, D.K., 2011. The sigma receptor agonist SA4503 both attenuates and enhances the effects of methamphetamine. Drug Alcohol Depend.

Roehr, B., 2005. Half a million Americans use methamphetamine every week. BMJ 331, 476.

Rogers, R.D., Everitt, B.J., Baldacchino, A., Blackshaw, A.J., Swainson, R., Wynne, K., Baker, N.B., Hunter, J., Carthy, T., Booker, E., London, M., Deakin, J.F., Sahakian, B.J., Robbins, T.W., 1999. Dissociable deficits in the decision-making cognition of chronic amphetamine abusers, opiate abusers, patients with focal damage to prefrontal cortex, and tryptophan-depleted normal volunteers: evidence for monoaminergic mechanisms. Neuropsychopharmacology 20, 322-339.

Romanelli, F., Smith, K.M., 2006. Clinical effects and management of methamphetamine abuse. Pharmacotherapy 26, 1148-1156.

Rossato, J.I., Bevilaqua, L.R., Izquierdo, I., Medina, J.H., Cammarota, M., 2009. Dopamine controls persistence of long-term memory storage. Science 325, 1017-1020.

Rothwell, N.J., 1994. CNS regulation of thermogenesis. Crit Rev Neurobiol 8, 1-10.

Roullet, P., Sargolini, F., Oliverio, A., Mele, A., 2001. NMDA and AMPA antagonist infusions into the ventral striatum impair different steps of spatial information processing in a nonassociative task in mice. J Neurosci 21, 2143-2149.

Sabino, V., Cottone, P., Parylak, S.L., Steardo, L., Zorrilla, E.P., 2009. Sigma-1 receptor knockout mice display a depressive-like phenotype. Behav Brain Res 198, 472-476. 
Sadeh, T., Shohamy, D., Levy, D.R., Reggev, N., Maril, A., 2011. Cooperation between the hippocampus and the striatum during episodic encoding. J Cogn Neurosci 23, 15971608.

Salmi, P., 1998. Independent roles of dopamine D1 and D2/3 receptors in rat thermoregulation. Brain Res 781, 188-193.

Salmi, P., Ahlenius, S., 1998. Evidence for functional interactions between 5-HT1A and 5HT2A receptors in rat thermoregulatory mechanisms. Pharmacol Toxicol 82, 122-127.

Salmi, P., Jimenez, P., Ahlenius, S., 1993. Evidence for specific involvement of dopamine D1 and D2 receptors in the regulation of body temperature in the rat. Eur J Pharmacol 236, 395-400.

Sargolini, F., Roullet, P., Oliverio, A., Mele, A., 2003. Effects of intra-accumbens focal administrations of glutamate antagonists on object recognition memory in mice. Behav Brain Res 138, 153-163.

Schep, L.J., Slaughter, R.J., Beasley, D.M., 2010. The clinical toxicology of metamfetamine. Clin Toxicol (Phila) 48, 675-694.

Schetz, J.A., Perez, E., Liu, R., Chen, S., Lee, I., Simpkins, J.W., 2007. A prototypical Sigma-1 receptor antagonist protects against brain ischemia. Brain Res 1181, 1-9.

Schmidt, C.J., Ritter, J.K., Sonsalla, P.K., Hanson, G.R., Gibb, J.W., 1985. Role of dopamine in the neurotoxic effects of methamphetamine. J Pharmacol Exp Ther 233, 539-544.

Schmidt, H.H., Hofmann, H., Schindler, U., Shutenko, Z.S., Cunningham, D.D., Feelisch, M., 1996. No .NO from NO synthase. Proc Natl Acad Sci U S A 93, 14492-14497.

Schroder, N., O'Dell, S.J., Marshall, J.F., 2003. Neurotoxic methamphetamine regimen severely impairs recognition memory in rats. Synapse 49, 89-96.

Schwartz, P.J., Wehr, T.A., Rosenthal, N.E., Bartko, J.J., Oren, D.A., Luetke, C., Murphy, D.L., 1995. Serotonin and thermoregulation. Physiologic and pharmacologic aspects of control 
revealed by intravenous m-CPP in normal human subjects. Neuropsychopharmacology $13,105-115$.

Segal, D.S., Kuczenski, R., O'Neil, M.L., Melega, W.P., Cho, A.K., 2003. Escalating dose methamphetamine pretreatment alters the behavioral and neurochemical profiles associated with exposure to a high-dose methamphetamine binge. Neuropsychopharmacology 28, 1730-1740.

Seminerio, M.J., Kaushal, N., Shaikh, J., Huber, J.D., Coop, A., Matsumoto, R.R., 2011 a. Sigma (sigma) receptor ligand, AC927 (N-phenethylpiperidine oxalate), attenuates methamphetamine-induced hyperthermia and serotonin damage in mice. Pharmacol Biochem Behav 98, 12-20.

Seminerio, M.J., Robson, M.J., Abdelazeem, A.H., Mesangeau, C., Jamalapuram, S., Avery, B.A., McCurdy, C.R., Matsumoto, R.R., 2012. Synthesis and pharmacological characterization of a novel sigma receptor ligand with improved metabolic stability and antagonistic effects against methamphetamine. AAPS J 14, 43-51.

Services, U.D.o.H.a.H., 2007. National Survey on Drug Use and Health.

Shen, E.H., Phillips, T.J., 1998. MK-801 potentiates ethanol's effects on locomotor activity in mice. Pharmacol Biochem Behav 59, 135-143.

Shimazu, S., Katsuki, H., Takenaka, C., Tomita, M., Kume, T., Kaneko, S., Akaike, A., 2000. sigma receptor ligands attenuate $\mathrm{N}$-methyl-D-aspartate cytotoxicity in dopaminergic neurons of mesencephalic slice cultures. Eur J Pharmacol 388, 139-146.

Su, T.P., Hayashi, T., 2001. Cocaine affects the dynamics of cytoskeletal proteins via sigma(1) receptors. Trends Pharmacol Sci 22, 456-458.

Su, T.P., Hayashi, T., 2003. Understanding the molecular mechanism of sigma-1 receptors: towards a hypothesis that sigma-1 receptors are intracellular amplifiers for signal transduction. Curr Med Chem 10, 2073-2080. 
Sulzer, D., Sonders, M.S., Poulsen, N.W., Galli, A., 2005. Mechanisms of neurotransmitter release by amphetamines: a review. Prog Neurobiol 75, 406-433.

Takahashi, S., Horikomi, K., Kato, T., 2001. MS-377, a novel selective sigma(1) receptor ligand, reverses phencyclidine-induced release of dopamine and serotonin in rat brain. Eur J Pharmacol 427, 211-219.

Takahashi, S., Miwa, T., Horikomi, K., 2000. Involvement of sigma 1 receptors in methamphetamine-induced behavioral sensitization in rats. Neurosci Lett 289, 21-24.

Takebayashi, M., Hayashi, T., Su, T.P., 2002. Nerve growth factor-induced neurite sprouting in PC12 cells involves sigma-1 receptors: implications for antidepressants. J Pharmacol Exp Ther 303, 1227-1237.

Takebayashi, M., Hayashi, T., Su, T.P., 2004. A perspective on the new mechanism of antidepressants: neuritogenesis through sigma-1 receptors. Pharmacopsychiatry 37 Suppl 3, S208-213.

Tam, S.W., 1983. Naloxone-inaccessible sigma receptor in rat central nervous system. Proc Natl Acad Sci U S A 80, 6703-6707.

Tata, D.A., Raudensky, J., Yamamoto, B.K., 2007. Augmentation of methamphetamineinduced toxicity in the rat striatum by unpredictable stress: contribution of enhanced hyperthermia. Eur J Neurosci 26, 739-748.

Thomas, D.M., Dowgiert, J., Geddes, T.J., Francescutti-Verbeem, D., Liu, X., Kuhn, D.M., 2004. Microglial activation is a pharmacologically specific marker for the neurotoxic amphetamines. Neurosci Lett 367, 349-354.

Thompson, T.L., Bridges, S., Miller, C., 2001. Modulation of dopamine uptake in rat nucleus accumbens: effect of specific dopamine receptor antagonists and sigma ligands. Neurosci Lett 312, 169-172.

Tsai, S.Y., Hayashi, T., Harvey, B.K., Wang, Y., Wu, W.W., Shen, R.F., Zhang, Y., Becker, K.G., Hoffer, B.J., Su, T.P., 2009. Sigma-1 receptors regulate hippocampal dendritic 
spine formation via a free radical-sensitive mechanism involving Rac1xGTP pathway.

Proc Natl Acad Sci U S A 106, 22468-22473.

Ujike, H., Kuroda, S., Otsuki, S., 1996. sigma Receptor antagonists block the development of sensitization to cocaine. Eur J Pharmacol 296, 123-128.

Ujike, H., Okumura, K., Zushi, Y., Akiyama, K., Otsuki, S., 1992. Persistent supersensitivity of sigma receptors develops during repeated methamphetamine treatment. Eur J Pharmacol 211, 323-328.

United Nations, 2007. United Nations Office on Drugs and Crime World Drug Report Analysis. Volume 1., Vienna.

van Waarde, A., Ramakrishnan, N.K., Rybczynska, A.A., Elsinga, P.H., Ishiwata, K., Nijholt, I.M., Luiten, P.G., Dierckx, R.A., 2011. The cholinergic system, sigma-1 receptors and cognition. Behav Brain Res 221, 543-554.

Vilner, B.J., Bowen, W.D., 1993. Sigma receptor-active neuroleptics are cytotoxic to C6 glioma cells in culture. Eur J Pharmacol 244, 199-201.

Vilner, B.J., Bowen, W.D., 2000. Modulation of cellular calcium by sigma-2 receptors: release from intracellular stores in human SK-N-SH neuroblastoma cells. J Pharmacol Exp Ther 292, 900-911.

Vilner, B.J., de Costa, B.R., Bowen, W.D., 1995a. Cytotoxic effects of sigma ligands: sigma receptor-mediated alterations in cellular morphology and viability. J Neurosci 15, 117134.

Vilner, B.J., John, C.S., Bowen, W.D., 1995b. Sigma-1 and sigma-2 receptors are expressed in a wide variety of human and rodent tumor cell lines. Cancer Res 55, 408-413.

Volkow, N.D., Chang, L., Wang, G.J., Fowler, J.S., Ding, Y.S., Sedler, M., Logan, J., Franceschi, D., Gatley, J., Hitzemann, R., Gifford, A., Wong, C., Pappas, N., 2001a. Low level of brain dopamine D2 receptors in methamphetamine abusers: association with metabolism in the orbitofrontal cortex. Am J Psychiatry 158, 2015-2021. 
Volkow, N.D., Chang, L., Wang, G.J., Fowler, J.S., Franceschi, D., Sedler, M., Gatley, S.J., Miller, E., Hitzemann, R., Ding, Y.S., Logan, J., 2001b. Loss of dopamine transporters in methamphetamine abusers recovers with protracted abstinence. J Neurosci 21, 94149418.

Volkow, N.D., Chang, L., Wang, G.J., Fowler, J.S., Leonido-Yee, M., Franceschi, D., Sedler, M.J., Gatley, S.J., Hitzemann, R., Ding, Y.S., Logan, J., Wong, C., Miller, E.N., 2001c. Association of dopamine transporter reduction with psychomotor impairment in methamphetamine abusers. Am J Psychiatry 158, 377-382.

Walker, J.M., Bowen, W.D., Goldstein, S.R., Roberts, A.H., Patrick, S.L., Hohmann, A.G., DeCosta, B., 1992. Autoradiographic distribution of [3H](+)-pentazocine and [3H]1,3-dio-tolylguanidine (DTG) binding sites in guinea pig brain: a comparative study. Brain Res 581, 33-38.

Walker, J.M., Bowen, W.D., Patrick, S.L., Williams, W.E., Mascarella, S.W., Bai, X., Carroll, F.I., 1993. A comparison of (-)-deoxybenzomorphans devoid of opiate activity with their dextrorotatory phenolic counterparts suggests role of sigma 2 receptors in motor function. Eur J Pharmacol 231, 61-68.

Walsh, S.L., Wagner, G.C., 1992. Motor impairments after methamphetamine-induced neurotoxicity in the rat. J Pharmacol Exp Ther 263, 617-626.

Wan, H., Aggleton, J.P., Brown, M.W., 1999. Different contributions of the hippocampus and perirhinal cortex to recognition memory. J Neurosci 19, 1142-1148.

Wang, D., Noda, Y., Tsunekawa, H., Zhou, Y., Miyazaki, M., Senzaki, K., Nitta, A., Nabeshima, T., 2007. Role of N-methyl-D-aspartate receptors in antidepressant-like effects of sigma 1 receptor agonist 1-(3,4-dimethoxyphenethyl)-4-(3-phenylpropyl)piperazine dihydrochloride (SA-4503) in olfactory bulbectomized rats. J Pharmacol Exp Ther 322, $1305-1314$. 
Warburton, E.C., Brown, M.W., 2010. Findings from animals concerning when interactions between perirhinal cortex, hippocampus and medial prefrontal cortex are necessary for recognition memory. Neuropsychologia 48, 2262-2272.

West, P.L., McKeown, N.J., Hendrickson, R.G., 2010. Methamphetamine body stuffers: an observational case series. Ann Emerg Med 55, 190-197.

Whishaw, I.Q., McKenna, J.E., Maaswinkel, H., 1997. Hippocampal lesions and path integration. Curr Opin Neurobiol 7, 228-234.

White, F.J., Kalivas, P.W., 1998. Neuroadaptations involved in amphetamine and cocaine addiction. Drug Alcohol Depend 51, 141-153.

Wilson, J.M., Kalasinsky, K.S., Levey, A.I., Bergeron, C., Reiber, G., Anthony, R.M., Schmunk, G.A., Shannak, K., Haycock, J.W., Kish, S.J., 1996. Striatal dopamine nerve terminal markers in human, chronic methamphetamine users. Nat Med 2, 699-703.

Witkin, J.M., Terry, P., Menkel, M., Hickey, P., Pontecorvo, M., Ferkany, J., Katz, J.L., 1993. Effects of the selective sigma receptor ligand, 6-[6-(4-hydroxypiperidinyl)hexyloxy]-3methylflavone (NPC 16377), on behavioral and toxic effects of cocaine. J Pharmacol Exp Ther 266, 473-482.

Xu, Y.T., Kaushal, N., Shaikh, J., Wilson, L.L., Mesangeau, C., McCurdy, C.R., Matsumoto, R.R., 2010. A novel substituted piperazine, CM156, attenuates the stimulant and toxic effects of cocaine in mice. J Pharmacol Exp Ther 333, 491-500.

Xu, Y.T., Robson, M.J., Szeszel-Fedorowicz, W., Patel, D., Rooney, R., McCurdy, C.R., Matsumoto, R.R., 2012. CM156, a sigma receptor ligand, reverses cocaine-induced place conditioning and transcriptional responses in the brain. Pharmacol Biochem Behav 101, 174-180.

Yamamoto, B.K., Davy, S., 1992. Dopaminergic modulation of glutamate release in striatum as measured by microdialysis. J Neurochem 58, 1736-1742. 
Yang, S., Alkayed, N.J., Hurn, P.D., Kirsch, J.R., 2009. Cyclic adenosine monophosphate response element-binding protein phosphorylation and neuroprotection by 4-phenyl-1-(4phenylbutyl) piperidine (PPBP). Anesth Analg 108, 964-970.

Zeng, C., Vangveravong, S., Xu, J., Chang, K.C., Hotchkiss, R.S., Wheeler, K.T., Shen, D., Zhuang, Z.P., Kung, H.F., Mach, R.H., 2007. Subcellular localization of sigma-2 receptors in breast cancer cells using two-photon and confocal microscopy. Cancer Res 67, 6708-6716.

Zhang, L., Kitaichi, K., Fujimoto, Y., Nakayama, H., Shimizu, E., Iyo, M., Hashimoto, K., 2006. Protective effects of minocycline on behavioral changes and neurotoxicity in mice after administration of methamphetamine. Prog Neuropsychopharmacol Biol Psychiatry 30, $1381-1393$.

\section{Michael J. Seminerio}

West Virginia University, 1 Medical Center Drive, Morgantown, WV 26506 Phone: (614) 361-6714, Email: mseminerio1@gmail.com

\section{EDUCATION}

2003-2007 Washington and Jefferson College, Washington, Pennsylvania B.A. in Biology/Neuroscience 
2007-Present West Virginia University, Morgantown, West Virginia

Ph.D. Candidate, Integrated Biomedical Sciences, Pharmaceutical

\&Pharmacological Sciences

\author{
EMPLOYMENT HISTORY \\ 2004 Beaver Family Dentistry- Beaver, PA \\ Intern \\ 2006 The University of Toledo, School of Medicine- Toledo, $\mathrm{OH}$ \\ Health Science Center Volunteer \\ 2006 The University of Toledo, School of Medicine- Toledo, $\mathrm{OH}$ \\ Summer Undergraduate Research Fellow \\ 2006-2007 Washington and Jefferson College- Washington, PA \\ Undergraduate Research Assistant \\ 2007-Present West Virginia University- Morgantown, WV \\ Research Assistant; Graduate Student \\ 2011 \\ University of South Florida- Tampa, FL \\ Research Intern
}

\title{
ORGANIZATIONS/ LEADERSHIP
}

2009-2011 West Virginia University School of Pharmacy

Community Outreach Student Volunteer

2009-2012 West Virginia University School of Pharmacy

Event Coordinator for Inaugural School of Pharmacy Research Day

2010-2012American Association for Pharmaceutical Scientists (AAPS)

Founder and Chair of Student Chapter at West Virginia University

2010-2012West Virginia University School of Medicine

The Van Liere Student Advisory Committee

2010-2012 West Virginia University School of Medicine

WVU Center for Neuroscience Seminar Steering Committee

2011 Search Committee: Assistant Director of Research and Graduate Education

Student representative

2011-2012 Society for Neuroscience- West Virginia Regional Chapter

Secretary

2011-2012 Selection Committee for Behavioral and Biomedical Sciences Scholarship

Co-Chair

2011-2012 West Virginia University Health SciencesGraduate Student Organization President

2011-2013 ASPET Graduate Recruitment and Education Committee

National Student Representative

2012-Present ASPET Institutional SURF Fellowship Review

Grant Reviewer

\section{PEER REVIEWED PUBLICATIONS}

1. Stavitskaya L, Seminerio MJ, Matthews-Tsourounis MM, Matsumoto RR, Coop A (2010)The effect of the pyridyl nitrogen position in pyridylpiperzine sigma ligands. Bioorg Med Chem Lett 20:2564-2565. 
2. Seminerio MJ, Kaushal N, Shaikh J, Huber J, Coop A, Matsumoto RR (2011) Sigma receptor ligand AC927 (N-phenethylpiperdine oxalate) attenuates methamphetamineinduced hyperthermia and serotonin damage in mice. Pharmacol Biochem Behav 98:1220.

3. Kaushal N, Seminerio MJ, Shaikh J, Medina M, Wilson L, Mesangeau C, McCurdy CR, Matsumoto RR (2011)A novel substituted piperazine, 3-(4-(4-cyclohexylpiperazin-1yl)butyl)benzo[d]thiazole-2(3H)-thione (CM156), attenuates the stimulant and toxic effects of methamphetamine in mice. Neuropharm 61:992-1000.

4. Robson MJ, Elliott M, Seminerio MJ, Matsumoto RR (2011) Evaluation of sigma receptors in the antidepressant-like effects of ketamine in vitro and in vivo. Eur $\mathrm{J}$ Neuropsychopharm 22:308-317.

5. Mesangeau C, Amata E, Alsharif E, Seminerio MJ, Robson MJ, Matsumoto RR, Poupaert $\mathrm{JH}$, McCurdy CR (2011) Indole-based selective sigma-2 receptor ligands: Synthesis and pharmacological evaluation. Eur J Med Chem 46:5154-5161.

6. Seminerio MJ, Mesangeau C, McCurdy CM, Matsumoto RR (2011) Pharmacological evaluation of an optimized analog of CM156; effects on methamphetamine.AAPS J 18:902919.

7. Robson MJ, Noorkbakhsh B, Seminerio MJ, Matsumoto RR (2011) Sigma-1 receptors: Potential targets for the treatment of substance abuse. Curr Pharm Des 18:902-919.

8. Turner RJ, Seminerio MJ, Naser ZJ, Matsumoto RR, Rosen CL, Huber JD (2011) Effect of age on behavioral assessment performance-implications for an aged stroke model. $J$ Neurosurg, Accepted.

9. Seminerio MJ, Robson MJ,McCurdy CR, Matsumoto RR (2012) Sigma receptor ligands attenuate acute methamphetamine-induced hyperthermia but do not modulate IL-1 $\beta$ mRNA expression in the hypothalamus. Eur J Pharm, Submitted.

10. Seminerio MJ, Turner R, Robson MJ, O'Callaghan J, Miller D, Matsumoto RR (2012) The effects of methamphetamine on body temperature: a comprehensive review. Pharmacol Ther, invited review, Submitted.

11. Seminerio MJ, Hansen R, Kaushal N, Abdelazeem AH, Mesangeau C, McCurdy CM, Matsumoto RR (2012) The evaluation of AZ66, an optimized sigma receptor ligand, against methamphetamine-induced dopaminergic neurotoxicity and cognitive impairment.Intl $\mathrm{J}$ Neuropsychopharma, Submitted.

12. Kaushal N, Seminerio MJ, Robson MJ, McCurdy CR, Matsumoto RR (2012) Pharmacological evaluation of SN79, a sigma receptor ligand against methamphetamineinduced neurotoxicity in mice. Eur $\mathrm{J}$ Neuropsychopharm, In preparation.

13. Noorbakhsh B, Seminerio MJ, Kaushal N, Xu YT, Healy JR, Mesangeau C, McCurdy CR, Matsumoto RR (2012) Pharamcolgoical characterization of sigma-2 preferring compounds: modulation of psychostimulant-induced effects. JPET, In preparation.

14. Abdelazeem AH,Mesangeau C,Jamalapuram S, Avery BA, Abbas S,Seminerio MJ, Matsumoto RR, Poupaert JH, McCurdy CM (2012) Design and synthesis of metabolically stable benzothiazolonone derivatives of CM156 with high affinity and selectivity for sigma $(\sigma)$ receptors. J Med Chem, In preparation.

15. Stavitskaya $L^{*}$, Seminerio $\mathbf{M J}^{*}$, Noorkbakhsh B, Healy J,Bowen W, Matsumoto RR, Coop A (2012) The effect of partial opioid structures on sigma receptors. J Med Chem, In preparation.

\section{ABSTRACTS/ POSTER PRESENTATIONS (SELECTED)}

1.Seminerio MJ, Bayline R (2006) Development of innervations in the tergosternal muscle of the moth Manduca sexta based on physiological activity. $28^{\text {th }}$ Annual Western Pennsylavania Biology Undergraduate Research Symposium, Pittsburgh, PA. (podium talk and poster presentation) 
2. Seminerio MJ, Kaushal N, Medina M, Shaikh J, McCurdy CR, Matsumoto RR (2008) CM156, a novel sigma receptor antagonist, attenuates the neurotoxic effects of methamphetamine in mice. $4^{\text {th }}$ Annual West Virginia COBRE/INBRE Conference, Morgantown, WV. (poster presentation)

3. Seminerio MJ, Kaushal N, Shaikh J, Medina M, McCurdy CR, Coop A, Matsumoto RR (2009) Sigma antagonists, AC927 and CM156, protect againstmethamphetamine-induced serotonergic neurotoxicity while attenuating hyperthermia. $71^{\text {st }}$ Annual College on Problems of Drug Dependence (CPDD) Meeting, Reno, NV. (poster presentation)

4. Seminerio MJ, Abdelazeem A, McCurdy CR, Matsumoto RR (2009) Characterization of potentially stable analogs of CM156, a sigma receptor antagonist. $3^{\text {rd }}$ Annual West Virginia University Center for Neuroscience Retreat, Morgantown, WV. (poster presentation)

5. Seminerio MJ, Abdelazeem A, McCurdy CM, Matsumoto RR (2010) Characterization of optimized CM156 analogs: A potential aid in the treatment of psychostimulant-induced complications. STaR Symposium, Huntington, WV. (poster presentation)

6. Seminerio MJ, Mesangeau C, Avery BA, McCurdy CM, Matsumoto RR (2011) Pharmacological evaluation of novel sigma receptor ligands against psychostimulantinduced effects. STEM: Science and Technology Research Day, Morgantown, WV. (poster presentation)

7. Seminerio MJ, Kaushal N, Shaikh J, Mesangeau C,Abdelazeem A, Narayanan S, Coop A, McCurdy CM, Matsumoto RR (2011) Sigma receptor ligands attenuate methamphetamineinduced neurotoxicity, International Drug Abuse Research Society (IDARS) Meeting, poster presentation, Istanbul, Turkey, August 2011.

8. Seminerio MJ, Abdelazeem A, Avery BA, McCurdy CR, Matsumoto RR (2011) An optimized sigma receptor ligand attenuates the behavioral effects of methamphetamine, American Association of Pharmaceutical Scientists (AAPS) Annual Meeting, Washington DC, October 2011.

9. Seminerio MJ, AbdelazeemA, AveryB, McCurdyCM, MatsumotoRR (2011)The evaluation of an optimized sigma receptor ligand on methamphetamine-induced dopaminergic neurotoxicity and hyperthermia, Society for Neuroscience (SfN) Annual Meeting, Washington DC, November 2011.

10. Seminerio MJ, Robson MJ, MesangeauC, McCurdy CR, Matsumoto RR (2012) Sigma receptor ligands attenuate methamphetamine-induced hyperthermia but do not modulate IL-1 $\beta$ mRNA expression in select brain regions, Experimental Biology Annual Meeting, San Diego, CA, April 2012.

\section{INVITED TALKS/ SEMINARS}

1. "Evaluating novel sigma receptor ligands as potential pharmacological treatments," Department of Biology, Washington and Jefferson College, Washington, PA, 2009.

2. "The role of sigma receptors in psychostimulant-induced complications" Program in Cancer Biology, West Virginia University, Morgantown, WV, 2010.

3. "Searching for the next big drug," Introduction to Research elective, School of Pharmacy, West Virginia University, Morgantown, WV, 2010.

4. "Pharmacological evaluation of novel sigma receptor ligands against psychostimulantinduced effects," Van Liere Research Day Convocation, West Virginia University, Morgantown, WV, 2011

5. "Pharmacological evaluation of an optimized analog of CM156; effects on methamphetamine," Postdoctoral recruitment event, Vanderbilt University, Nashville, TN, 2011. 
6. "An optimized selective sigma receptor ligand attenuates the behavioral effects of methamphetamine," International Drug Abuse Research Society (IDARS), invited speaker, Istanbul, Turkey, August 2011.

7. "The evaluation of AZ66, an optimized sigma receptor ligand, against the behavioral effects of methamphetamine," Center for Clinical and Translation Science (CCTS), invited oral presentation, Lexington, Kentucky, March 2012.

\section{TEACHING ASSISTANT}

- Introduction to Research

- Immunology and Biotechnology

- Clinical Pharmacokinetics

- Chemistry of Drug Action

\section{PROFESSIONAL SOCIETY MEMBERSHIPS}

- American Association for Pharmaceutical Scientists

- American Society for Pharmacology and Experimental Therapeutics

- College on Problems of Drug Dependence

- International Drug Abuse Research Society

- Society for Neuroscience

- Rho Chi - National Honor Society in Pharmacy

\section{$\underline{\text { AWARDS }}$}

- Valuable Contributions to West Virginia University School of Pharmacy, 2009, 2010, 2011

- Biomedical and Behavioral Sciences Training Scholarship, 2009-2010

- E.J. Van Liere Poster Presentation Award - First Place, 2010

- Appointment to Biomedical and Behavioral Sciences T32 Training Grant, 2010-2012

- Presenter for STaR Symposium (one of 10 graduate students selected from 560 abstract submissions), 2010

- Robert E. Stitzel Graduate Student Award - Outstanding Achievement and Professional Development Award, 2010

- E.J. Van Liere Poster Presentation Award - Second Place, 2011

- Selected participant for the Vanderbilt University Postdoctoral Recruitment event, 2011

- Outstanding Achievement Award, West Virginia University School of Pharmacy, 2011

- Drug Design and Discovery Travel Award, American Association of Pharmaceutical Scientists, 2011

- Graduate Student Travel Award, American Society for Pharmacology and Experimental Therapeutics, Experimental Biology, 2012 